University of Louisville

ThinkIR: The University of Louisville's Institutional Repository

$5-2011$

\title{
Knowledge-sharing networks of hospital-based infection preventionists in Kentucky.
}

Timothy Lee Wiemken 1979-

University of Louisville

Follow this and additional works at: https://ir.library.louisville.edu/etd

\section{Recommended Citation}

Wiemken, Timothy Lee 1979-, "Knowledge-sharing networks of hospital-based infection preventionists in Kentucky." (2011). Electronic Theses and Dissertations. Paper 1565.

https://doi.org/10.18297/etd/1565

This Doctoral Dissertation is brought to you for free and open access by ThinkIR: The University of Louisville's Institutional Repository. It has been accepted for inclusion in Electronic Theses and Dissertations by an authorized administrator of ThinkIR: The University of Louisville's Institutional Repository. This title appears here courtesy of the author, who has retained all other copyrights. For more information, please contact thinkir@louisville.edu. 


\title{
KNOWLEDGE-SHARING NETWORKS OF HOSPITAL-BASED INFECTION PREVENTIONISTS IN KENTUCKY
}

\section{By}

Timothy Lee Wiemken

A.S., Sauk Valley Community College, 2001

B.A., Southern Illinois University Carbondale, 2003

M.P.H., Saint Louis University, 2006

\author{
A Dissertation \\ Submitted to the Faculty of the \\ Graduate School of the University of Louisville \\ in Partial Fulfillment of the Requirements \\ for the Degree of
}

Doctor of Philosophy

Department of Health Promotion and Behavioral Sciences

University of Louisville

Louisville, Kentucky

May 2011 

Copyright 2011 by Timothy Lee Wiemken

All rights reserved 


\title{
KNOWLEDGE-SHARING NETWORKS OF HOSPITAL-BASED INFECTION PREVENTIONISTS IN KENTUCKY
}

\author{
By \\ Timothy Lee Wiermken \\ A.S., Sauk Valley Community College, 2001 \\ B.A., Southern Illinois University Carbondale, 2003 \\ M.P.H., Saint Louis University, 2006
}

A Dissertation Approved on

February 23, 2011

by the following Dissertation Committee:

Dissertation Director (Ruth M. Carrico)

Philip Polgreen

Julio Ramirez

Scott LaJoie 


\section{ACKNOLWEDGMENTS}

First, I would like to thank the infection prevenionists in Kentucky (including those non-responders) for their work in making healthcare safer for patients. I would also like to thank my advisor and mentor, Dr. Ruth Carrico, for her continued guidance and support through this process. I would also like to recognize the mentorship outside of the classroom of Dr. Carrico and Dr. Julio Ramirez. This mentorship has provided priceless opportunities over the past five years. I thank each of my committee members, Dr. Julio Ramirez, Dr. A. Scott LaJoie and Dr. Philip Polgreen, for their expertise in the design, conduct, analysis, and reporting of this project. A big thanks goes out to Kelly Carrico for her help in the many telephone calls to various healthcare facilities in Kentucky. Thank you to the United States Department of Homeland Security and the National Institute for Hometown Security for grant support that allowed for the survey process. Most of all, I would like to provide a special thanks to my wife, Cassie, for her understanding and support throughout this process and her understanding through all of the mistakes I have made and will continue to make. I would also like to thank Cassie for the constant and repeated editing of this document. I also thank my family and friends who have continued to be there for me over the years. 


\section{DEDICATION}

This dissertation is dedicated to my wife

Mrs. Cassandra Jane Wiemken, JD

and my parents.

Mr. Barry Lee Wiemken

And

Mrs. Patricia Ann Wiemken

who have provided invaluable support in all aspects of my life. 


\begin{abstract}
KNOWLEDGE-SHARING NETWORKS OF HOSPITAL-BASED INFECTION PREVENTIONISTS IN KENTUCKY

Timothy Lee Wiemken
\end{abstract}

February 23, 2011

Background: Infection preventionists (IPs) have a multitude of tasks aimed at the prevention and control of infections in the healthcare setting. These tasks require a great deal of knowledge that has been more challenging to gain over the past decade due to the rapidly changing healthcare environment, the IPs' increasing numbers of duties, limited staffing, and a number of other issues. Because of these challenges, other mechanisms of rapid and efficient knowledge acquisition are needed for optimal job performance. One possible mechanism is knowledge sharing through social or professional networks.

Objective: To examine the knowledge-sharing network structure of hospitalbased IPs in Kentucky.

Methods: An electronic survey instrument was e-mailed to all hospital-based IPs in Kentucky. Roster lists were used to elicit alters for knowledge sharing. Basic demographics and employment data were collected. Directed sociograms were utilized to visually examine the network. Density and component analyses were used to evaluate network cohesion. In and out-degree, betweenness, and eigenvector statistics were calculated to examine node centrality. Key player 
reach and fragmentation algorithms were used to identify key players.

Geospatial network analysis was also used to analyze the network structure.

Results: A total of 75 IPs completed the survey for a $58 \%$ response rate. Seven IPs were excluded due to their limited focus on infection prevention activities.

The network density was $1.8 \%$. Three network components were identified. The median (range) centrality measures were as follows: in-degree, 2 (0-11); outdegree, $0.5(0-5)$; betweenness, 0 (0-567); and eigenvector $0.02(0-0.45)$. One IP.had the highest centrality measures. Three key players were identified in the reach and fragmentation analyses, of which most were in the age range that would soon qualify them for retirement. Geospatial analysis of the network revealed that it spanned the entire state of Kentucky and did not fit into any particular sectioning of the state (Medical Trade Area, APIC chapter, physical barriers, etc.).

Conclusions: Very low network density and centrality statistics indicate that the knowledge-sharing network of hospital-based IPs in Kentucky is not adequate for optimal knowledge sharing. In a state such as Kentucky with predominantly small, rural facilities that may have limited access to knowledge as compared to large, university settings, an optimal knowledge-sharing network among these facilities may allow for diffusion of new information to IPs at these facilities. Future research is needed to identify interventions to increase network connections in this field. 


\section{TABLE OF CONTENTS}

SECTION

PAGE

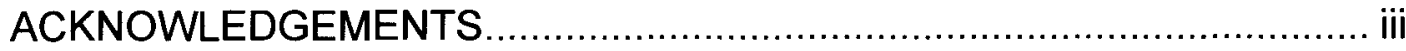

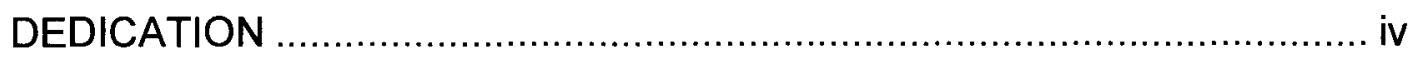

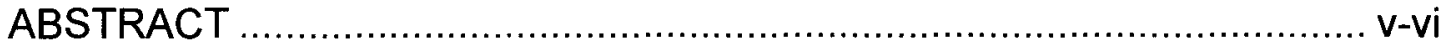

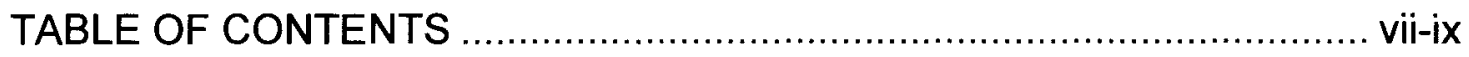

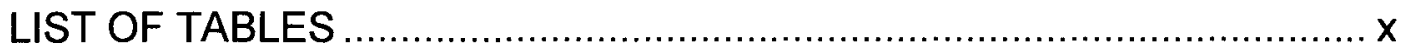

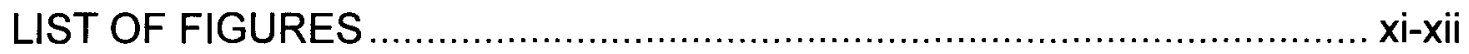

$\begin{array}{ll}\text { CHAPTER PAGE } & \text { PH }\end{array}$

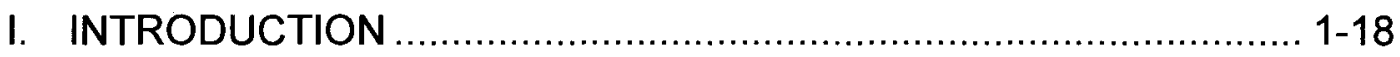

Background of the problem ................................................... 1-8

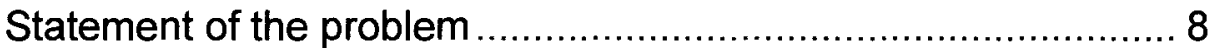

Research question \#1 …................................................. 8

Research question \#2 …................................................... 9-10

Research question \#3 ..................................................... 10-11

Research question \#4 ...................................................... 11-12

Statement of the purpose .................................................. 12-13

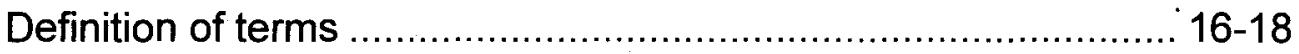

II. REVIEW OF THE LITERATURE .............................................. 19-53

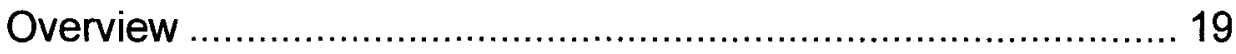


Literature review.

The roles of the infection preventionist ................................ 20-28

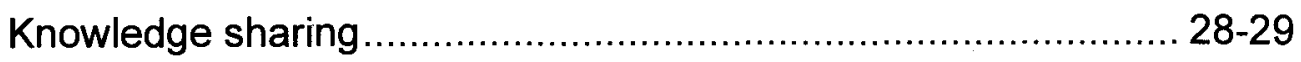

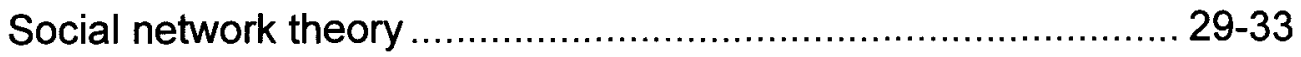

Social network analysis ..................................................... 33-43

Geographic effects on social networks ................................ 43-45

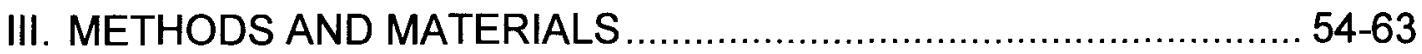

Design and population ....................................................... 54-55

Survey instrument and procedures ……............................. 55-57

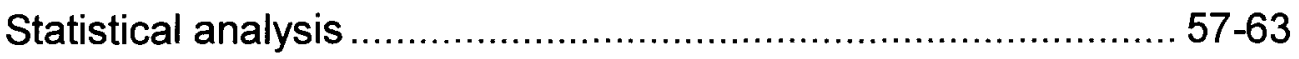

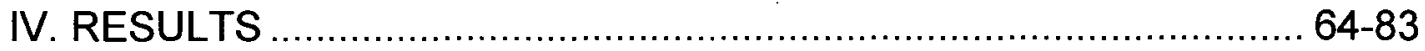

Description of the sample....................................................... $64-71$

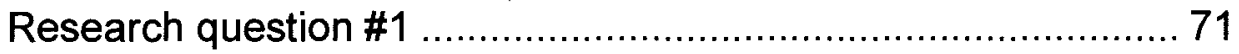

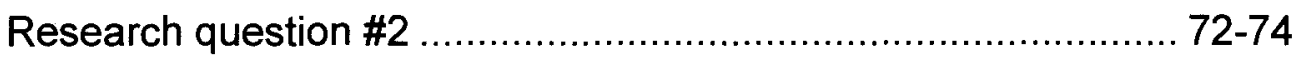

Research question \#3 …................................................ 74-77

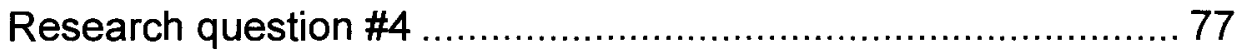

IV. SUMMARY, CONCLUSIONS, AND FUTURE RESEARCH .......... 84-108

Demographic information .................................................... 84-86

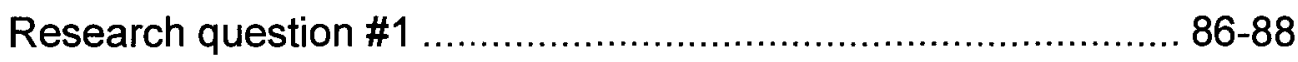

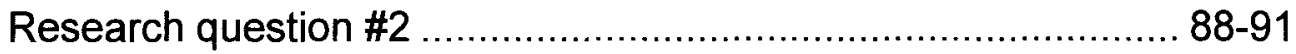

Research question \#3 ….................................................... 91-94

Research question \#4 …................................................ 94-96

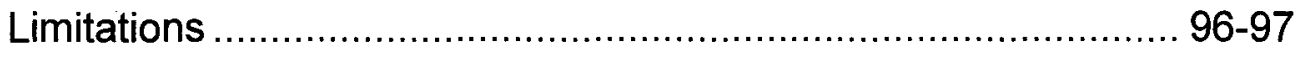


Conclusions .

$97-98$

Recommendations

$98-100$

Future Research. 100-108

REFERENCES $109-128$

APPENDIX A $129-140$ CURRICULUM VITAE 141-156 


\section{LIST OF TABLES}

TABLE

PAGE

1. Social network statistics and implications for knowledge sharing .......... 36-37

2. Demographic characteristics of survey respondents...........................65-68

3. Overall knowledge sharing/seeking behaviors of respondents ..............69

4. Knowledge sharing/seeking behaviors of respondents with non-IPs ......69-70

5. Knowledge sources of respondents ................................................. $70-71$

6. Centrality statistics of respondents ................................................ 72

7. Demographic characteristics of respondent with highest centrality.........73

8. Demographic characteristics of fragmentation key players ................... 76 


\section{LIST OF FIGURES}

FIGURE

1. Problem and solution of knowledge sharing in infection prevention ....... 14

2. Geological and physical barriers in Kentucky .................................... 14

3. Medical trade areas in Kentucky .................................................. 15

4. APIC Kentucky Chapters …....................................................... 15

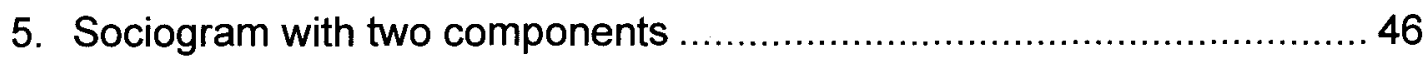

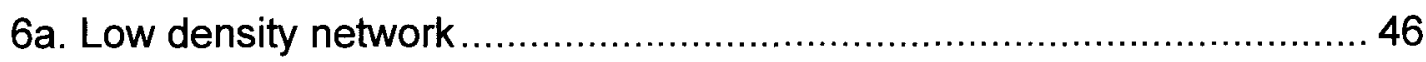

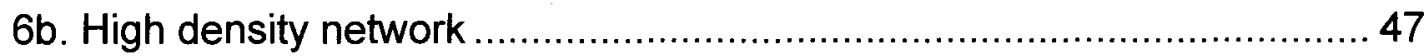

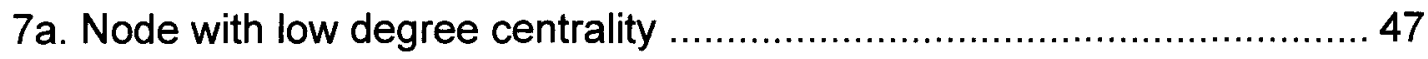

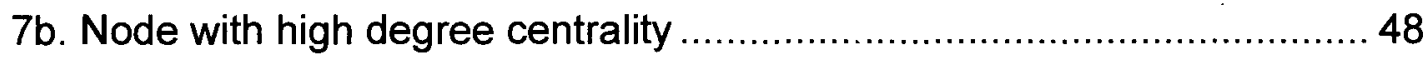

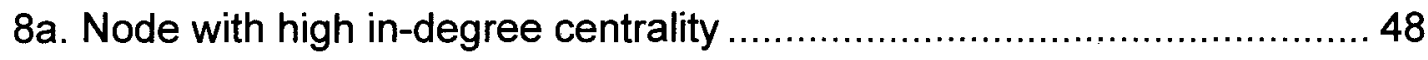

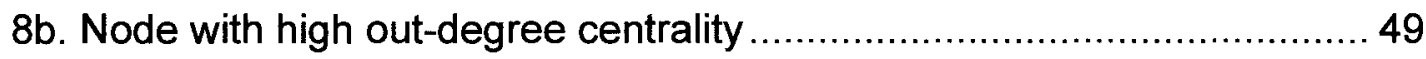

9a. Node with low betweenness centrality ............................................... 49

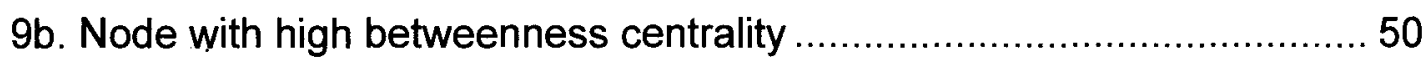

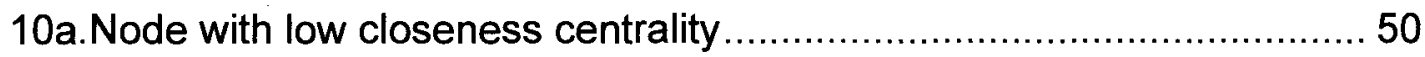

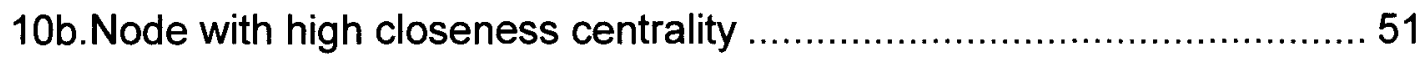

11a. Node with high in-closeness centrality ........................................... 51

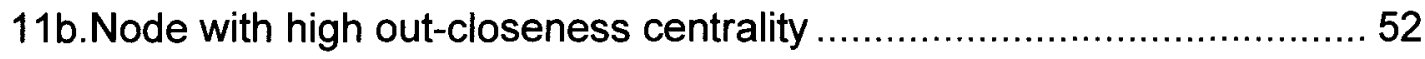

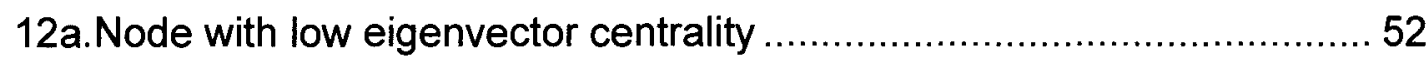

12b. Node with high eigenvector centrality ............................................. 53 
13. Geocoded location of respondents and non-respondents ................... 78

14. Sociogram of the knowledge-sharing network of respondents.............. 78

15. Component analysis sociogram of respondents ................................ 79

16. Histogram of in-degree centrality of respondents ................................ 79

17. Histogram of out-degree centrality of respondents ............................. 80

18. Histogram of betweenness centrality of respondents ........................ 80

19. Histogram of eigenvector centrality of respondents ............................. 81

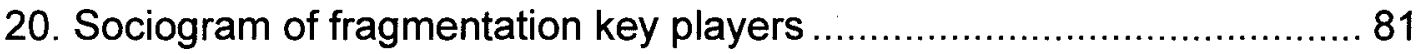

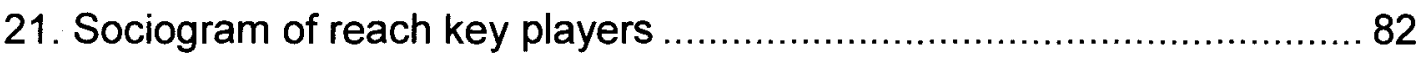

22. Sociogram with fragmentation key players removed........................... 82

23. Component analysis sociogram of APIC chapter location ................... 83

24. Sociogram of hospital bed size of respondents .................................. 83 


\section{CHAPTER ONE}

\section{Introduction}

\section{Background of the Problem}

For the more than 320 million Americans, the provision of healthcare occurs across a continuum of settings including hospitals, long term care facilities, ambulatory care settings, surgery centers, physician offices, and at home. As a consequence of care, undesired outcomes including medication errors, injuries due to patients falling, adverse drug reactions, and infection may occur. Preventing the occurrence of these undesirable and preventable outcomes is a major focus in improvement initiatives and underpins healthcare quality and healthcare finance reform. The healthcare environment, by definition of practice, houses ill persons susceptible to microorganisms that may be present in that particular environment. Thus, most if not all patients are potentially exposed to multiple infectious agents such as bacteria, fungi, and viruses (Huang \& Platt, 2003). These infectious agents may be present in or on other patients or on environmental surfaces within the healthcare setting (Huang, Datta, \& Platt, 2006; Neely, 2000). By nature of being ill, patients are also at a heightened risk for acquiring infections from one of these sources, as their immune systems may not be working at optimal capacities. Furthermore, these patients may have had a particular intervention, such as a surgical procedure, that may increase their risk for introduction of a potentially pathogenic 
microorganisms into their bodies. Infections that are associated with exposure to the healthcare environment and healthcare personnel are termed healthcareassociated infections (HAls) (Centers for Disease Control and Prevention, 2010c). These infections are not known to be present or incubating at the time of healthcare access, and many are often defined in accordance with symptom onset greater than 48 hours after healthcare access (Centers for Disease Control and Prevention, 2008). Many types of infections can be acquired in healthcare settings, including those associated with medical devices such as ventilatorassociated pneumonia (5 Million Lives Campaign, 2008b; American Thoracic Society, 2005), central-line associated bloodstream infections (5 Million Lives Campaign, 2008c; Marschall, et al., 2008), catheter-associated urinary tract infections (Lo, et al., 2008), or procedures, such as surgical site (5 Million Lives Campaign, 2008a; Owens \& Stoessel, 2008).

Overall, HAls account for more than 1.7 million infections per year in the United States and contribute to nearly 100,000 deaths (Januel, et al., 2010; Klevens, et al., 2007). HAls also account for increased healthcare costs through excess treatment, increased infection prevention and control measures, and increased length of stay and follow-up (Carbon, 1999). For example, attributable costs for one case of ventilator-associated pneumonia may be more than $\$ 40,000$ (Tablan, Anderson, Besser, Bridges, \& Hajjeh, 2004), and mortality rates for these patients have been shown to reach $50 \%$ (Ibrahim, Tracy, Hill, Fraser, \& Kollef, 2001). Although there have been some recent reports of decreases in certain HAls (Huang, Yokoe, et al., 2006; Robicsek, et al., 2008), there are newly 
emerging issues associated with them, such as increased antimicrobial resistance (Boucher, et al., 2009). Patients in healthcare facilities are likely to be exposed to antimicrobial agents; and misuse or overuse may increase the incidence of multi- or extreme-drug-resistant organisms (Boucher, et al., 2009). Furthermore, increasing antimicrobial resistance among pathogens in the healthcare setting makes treatment of infections with these pathogens more difficult, leading to increased lengths of stay, higher rates of mortality, and increased costs of care (Boucher, et al., 2009). Because of these escalating problems, prevention of these infections has become an interest of healthcare facilities, public health, news media, patients and families, and industry, as well as state and federal governments (Edmond \& Eickhoff, 2008). This interest is heightened for healthcare facilities by the recent regulation set forth by the Centers for Medicare and Medicaid Services (CMS) indicating that monetary reimbursement for treatment of HAls will no longer be provided in some circumstances (Stone, et al., 2010). This regulation is only a small part of a number of sweeping changes that will vastly transform the overall healthcare landscape. In March 2010, the one of the largest healthcare reform bills in history was signed into law. This series of changes will serve to increase healthcare coverage to the majority of Americans (Hammer, Phillips, \& Schmidt, 2010). All of these regulations continue to blur the line between public health and healthcare.

In recognizing the importance of prevention of infections, the Joint Commission, an accrediting body for hospitals and other healthcare 
organizations, requires that an infection prevention program with demonstrated improvements be in place in order for the facility to maintain accreditation and the benefits afforded by accreditation (The Joint Commission, 2010). Private insurers have also developed scorecards that use infection data as measurable outcomes. These scorecards provide data that can be weighted to influence reimbursement for services provided. These requirements compel the healthcare facility executive leaders to become interested in infection prevention or risk potential monetary losses.

In accordance with accreditation, payment and reimbursement standards, hospitals (and some other healthcare settings) are required to have a formal infection prevention and control program that is led by a qualified individual also referred to as an infection preventionist (IP). These healthcare workers are responsible for multiple activities aimed at preventing, identifying, and responding to infections within the healthcare environment. Seven major domains of the practice of infection prevention were outlined in a 2009 infection prevention practice assessment by the Certification Board on Infection Control (CBIC) (Curchoe, Fabrey, \& LeBlanc, 2008). These domains include: 1) identification of infectious disease processes, 2) surveillance and epidemiologic investigation, 3) prevention and control of HAls, 4) employee and occupational health, 5) management and communication, 6) education, and 7) research. These are discussed in context in Chapter Two. Additionally, as patients and the care they are provided move across the spectrum of healthcare, the IP must also understand systems and prevention practices across all healthcare settings 
including hospitals, outpatient clinics, ambulatory surgical centers, dialysis clinics, and treatment infusion centers. The depth of practice, competence, and the varying environments in which healthcare is provided serve to demonstrate the scope of knowledge that is necessary for the average IP. Clearly, maintaining competence in the massive and rapidly changing healthcare field is necessary for the practice of infection prevention (Murphy, Carrico, \& Warye, 2008).

Although the job of the IP has been increasing in scope and scrutiny, it has been documented that IPs also maintain responsibility for other jobs within their settings such as that of the employee health nurse, patient safety and quality manager, antimicrobial management leader, emergency preparedness coordinator, and practicing physician or nurse (Wright, et al., 2010). In order to meet the challenges of multiple job responsibilities that are required for competent performace, the IP must find ways to continually expand their knowledge. Each individual healthcare facility employs one or more IPs that focus their efforts on the unique challenges within their given facilities. Understanding that the problems occuring in healthcare facility A may have a direct effect on healthcare facility $B$ through sharing of patients and healthcare workers, developing communication and knowledge sharing capabilities within and between healthcare settings is important to patient and healthcare personnel safety, as well as to the financial well-being of the organization.

External social forces, such as social networks, can be important assets for the IP as they work to increase their knowledge (Burt, 2000; Coleman, 1988; 
Yang \& Farn, 2009). A social network is a representation of a social structure, which has been formed for a specific reason. Large social networks have been shown to increase social capital, (Burt, 2000; Coleman, 1988; Ellison, Steinfield, \& Lampe, 2007; Reagans \& Zuckerman, 2001; Yang \& Farn, 2009) increase social support, (W. Broadhead, et al., 1983; Plickert, Côté, \& Wellman, 2007; Seeman \& Berkman, 1988; Wellman \& Wortley, 1990) and improve knowledge access, (Granovetter, 1973; Haythornthwaite \& Wellman, 1998; Jack, 2005) , as well as improve the diffusion of information (Fattore, Frosini, Salvatore, \& Tozzi, 2009; Valente \& Davis, 1999; Valente \& Fosados, 2006; Valente \& Rogers, 1995). As described by Harris and Clements (2007), by understanding and harnessing these social networks, relationships can be strengthened and new connections can be formed, thereby increasing the size of the social network and the benefits afforded within a given population. Another benefit of a large social network is the ability of members to share knowledge among each other, which can increase the collective knowledge of the group and prevent the "reinvention of the wheel" phenomenon.

Although the motivation for sharing knowledge varies (Gagne, 2009), the outcomes of sharing knowledge in a professional context have been shown to be beneficial for increasing quality of professional practice (Blankenship \& Ruona, 2009). The social networks of working professionals are documented to be an important factor in knowledge sharing and information flow (Blankenship \& Ruona, 2009). Therefore, through identification of the social networks of working professionals, the flow of information (e.g. knowledge-sharing networks) can be 
assessed. This assessment is important to be able to better understand the pathways through which working professionals gain expert knowledge for maximal job performance.

Unfortunately, there is a lack of description of the social networks of IPs. From the standpoint of the IP, it is important to have a social network for many reasons. First, having a quick and reliable method of contacting content experts who may have previously encountered similar issues (health department-based epidemiologists, statisticians, other infection preventionists, policy makers, etc.) is important to prevent duplication of efforts. The principles described by experts in the field of social network theory indicate that shared knowledge and the associated expertise should be able to be readily shared among individuals. For example, Milgram (1967), through his work describing the "six degrees of separation", demonstrated that nearly everyone in the world can contact each other through very few intermediaries. Furthermore, Granovetter (1973), showed that weak connections, not necessarily close friends or colleagues, have the ability to share vast amounts of knowledge. Therefore, any person, through a social network, will be able to efficiently gain expert knowledge. With the everchanging healthcare environment and the need for rapid, practice-based knowledge and experience, access to shared knowledge is important. Social networks, supported by rapid technological communication methods, may prove to be a quick and efficient method of knowledge acquisition and dissemination. Therefore, developing an understanding of existing and potential knowledgesharing networks takes on a new significance. 
Overall, knowledge of the network structure of this group of professionals will provide evidence as to how knowledge sharing occurs within these networks, who the current perceived experts are, and what connections can be forged to provide a network structure conducive to efficient knowledge sharing. Forging these contacts may allow for better infection prevention activities and may lead to a reduction in patient mortality and healthcare costs that result from a more fully informed IP.

\section{Statement of the Problem}

Figure 1 describes the overview of the problem. To solve the issue of the lack of understanding of the knowledge-sharing networks of IPs, this study was designed to investigate four basic research questions. Due to the absence of basic research on the knowledge-sharing social networks of IPs, it is first necessary to understand their structure prior to being able to determine the functions of the people within. Hospital-based infection prevention and control programs have been in place longer than in any other healthcare setting, providing a greater opportunity for a knowledge-sharing social network to have developed. Therefore research question 1 is:

R1: What is the structure of knowledge-sharing networks among hospitalbased infection preventionists in Kentucky?

As there are local meetings of IPs in three regions of Kentucky where knowledge is shared, clearly knowledge-sharing networks exist. However, their structure is unknown. However, due to the separate locations of these meetings, 
it can be hypothesized that the network is segregated into multiple groups. Therefore, hypothesis 1 is:

H1: Knowledge-sharing networks among IPs in Kentucky hospitals consist of multiple components.

Once a brief visualization of the network is drawn, the next step is to determine the overall structure and makeup of the network through statistical analysis. It is clear that analyzing the network with social network analysis techniques will provide a rich array of information. As the knowledge-sharing networks of IPs have not been elicited or studied, it is necessary to understand them from the standpoint of the function of the personnel within. Therefore, research question 2 is:

R2: How dense are the components and what are the measures of centrality for IPs in knowledge-sharing networks in Kentucky hospitals?

As Kentucky consists of primarily rural hospitals (Rural Assistance Center, 2010) which are spread throughout a wide geographic area, it is reasonable to expect that the knowledge-sharing networks of these IPs will be fragmented into multiple components. Furthermore, this network will be of low density, as it is not expected that knowledge sharing among these healthcare workers is highly prevalent. Finally, it is expected that the IPs in this knowledge-sharing network will have low measures of network centrality, specifically: degree, betweenness, and eigenvector centrality; each indicating that the network is generally disconnected. Therefore, hypothesis 2 is: 
H2: Knowledge-sharing networks among IPs in Kentucky hospitals consist of low-density components and nodes with low centrality.

Although measures of centrality and network structure can provide a wealth of information regarding the network, in a knowledge-sharing network, it will be important to determine if any particular IPs are key players in the network. These key players in knowledge-sharing networks are relevant for two reasons: 1) to keep the network together in as few components as possible and 2) to connect a maximal number of IPs to each other (Borgotti, 2006). By identifying key players in a knowledge-sharing network of IPs, a better understanding of the most important individuals with regard to knowledge sharing will be gained. Although the theoretical foundation of key player identification has been described (Borgotti, 2006), very few studies have been published using this methodology to identify key players in a social network. Therefore, research question 3 is:

R3: Are there key players in knowledge-sharing networks among infection preventionists in Kentucky hospitals?

As the knowledge-sharing networks of IPs in Kentucky are expected to be fragmented into multiple components and are hypothesized to be decentralized and of low-density, it is reasonable to expect that there will be few meaningful key players within the network. It is reasonable to expect one key player in each of the three regional meetings of IPs in Kentucky. Therefore, hypothesis 3 is:

H3: Three meaningful key players will be present in knowledge-sharing networks among infection preventionists in Kentucky hospitals. 
Geographic separation has been documented to be negatively associated with network connections (Kadushin, 2004). This proposition is termed propinquity and has been studied by a number of authors (Liben-Nowell, Novak, Kumar, Raghavan, \& Tomkins, 2005; Rothenberg, Muth, Malone, Potterat, \& Woodhouse, 2005; Terrell, 2010; West \& Barron, 2005; Wylie, Shah, \& Jolly, 2007). The majority of these studies on geographic separation and social networks indicate that, as geographic separation increases, the likelihood that nodes are connected decreases. In Kentucky, a state in which the mostly rural hospitals (Rural Assistance Center, 2010) are separated by multiple boundaries (Netstate.com, 2009), it would be important to understand if the geography of the State plays a role in knowledge-sharing network structure. Therefore, research question 4 is:

R4: What is the role of geography in the network connections within knowledge-sharing networks of IPs in Kentucky hospitals?

Kentucky can be separated into various regions. From a geological standpoint, Kentucky can be separated into six distinct regions as seen in Figure 2 (Kentucky Secretary of State, 2010). If geography plays a role in the development of network connections in knowledge-sharing networks of hospitalbased IPs in Kentucky, it is reasonable to hypothesize that the network components may be separated into these six regions. A second method of geographic separation of the State is through medical trade areas, which indicate geographical regions where a population receives the majority of medical services (Hanchette, Biddle, Austin, \& Esterhay). The University of Louisville 
recently created a medical trade area map. This map can be found in Figure 3 and describes ten medical trade areas of the State (Hanchette, et al.). It is also possible that the knowledge-sharing networks of hospital-based IPs in Kentucky are separated into these regions, which likely share patients and services. Finally, it is possible that the geographic separation of these networks is by the three regions in which IPs have monthly meetings (Figure 4). Therefore, hypothesis 4 is:

H4: The knowledge-sharing network of hospital-based infection preventionists in Kentucky will be separated into three major components based on the three APIC regions of Kentucky.

Investigating these questions and evaluating the hypotheses will allow a clearer understanding of the knowledge-sharing networks of IPs in Kentucky. Through gaining this understanding, steps can be taken to forge new contacts to share new knowledge and bring better patient care to the hospitals in this state. Statement of the Purpose

The knowledge-sharing networks of hospital-based IPs can help us understand if and how knowledge is shared among these healthcare workers. Through careful examination of the connections between IPs for knowledge sharing purposes, connections can be identified. Differences in network-level measures with regard to demographic and geographic information will allow for a clear interpretation of who shares knowledge with whom in this professional network. If missing connections are forged, the network may allow for efficient 
and efficacious knowledge sharing, helping to prevent infections and save patient lives in the healthcare setting. 


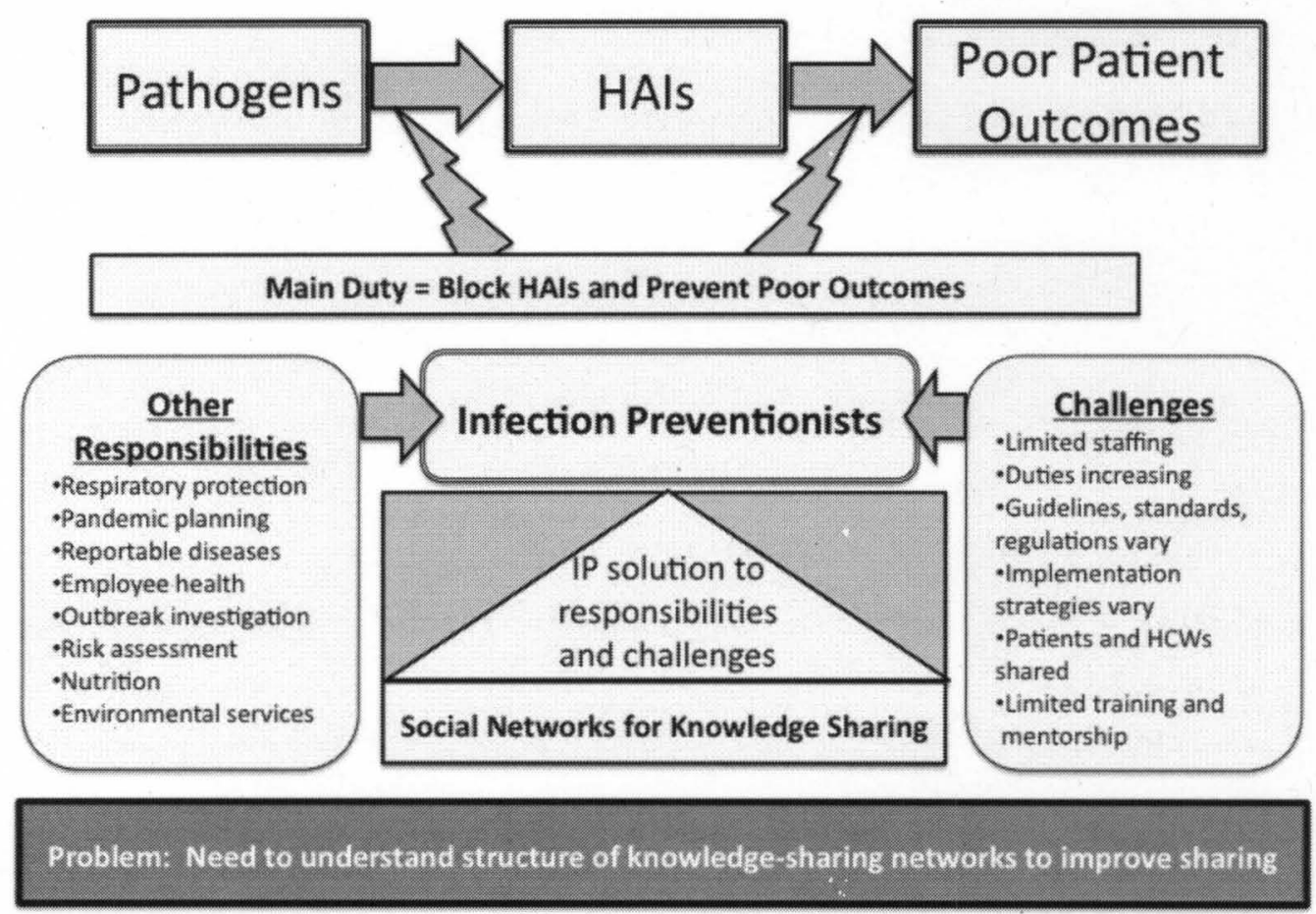

Figure 1: The problem of and solution to knowledge sharing in infection prevention

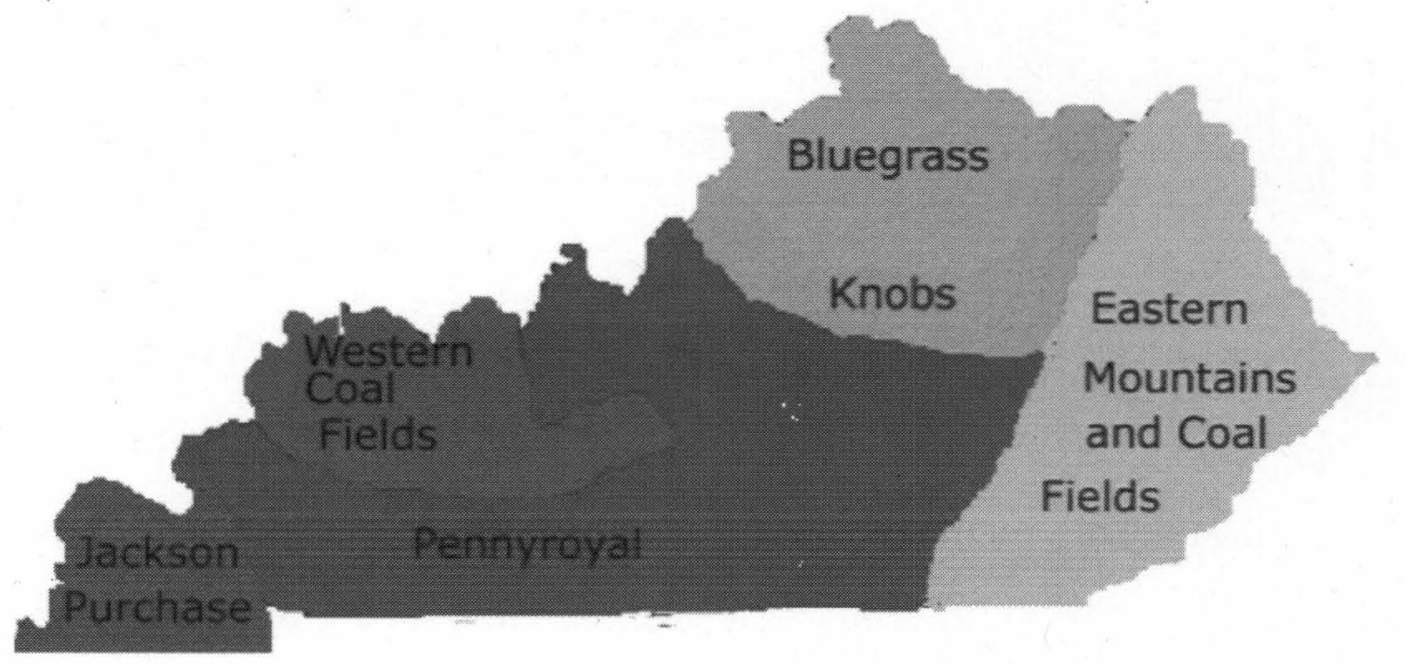

Figure 2: Geological and physical geography of Kentucky 


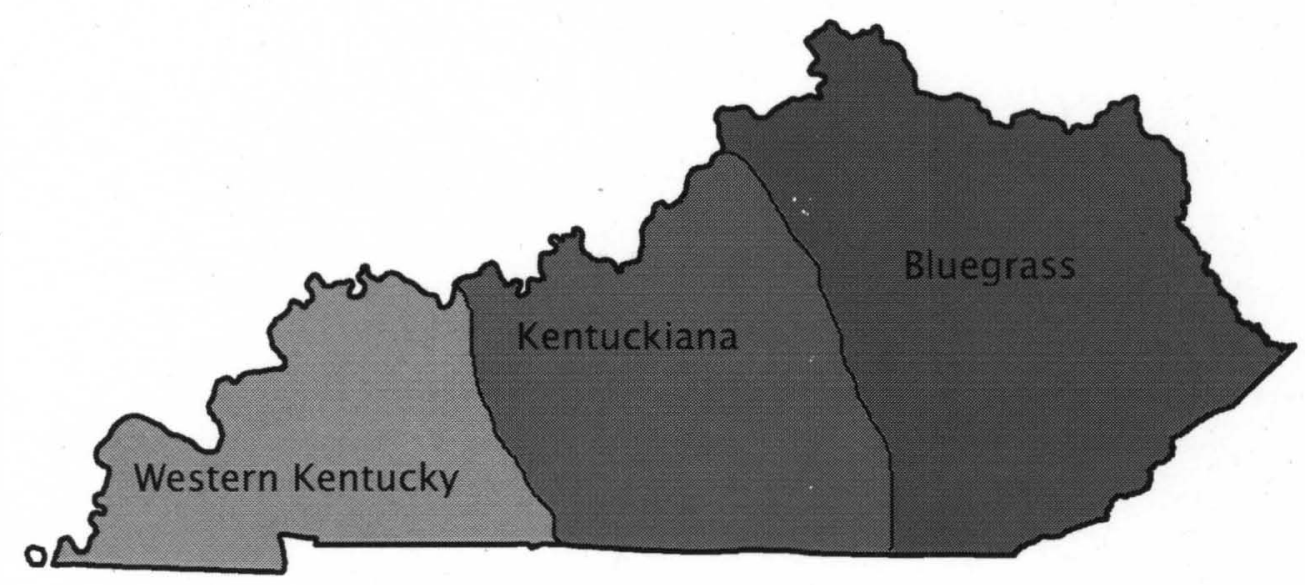

Figure 3: Medical Trade Areas (MTA) of Kentucky

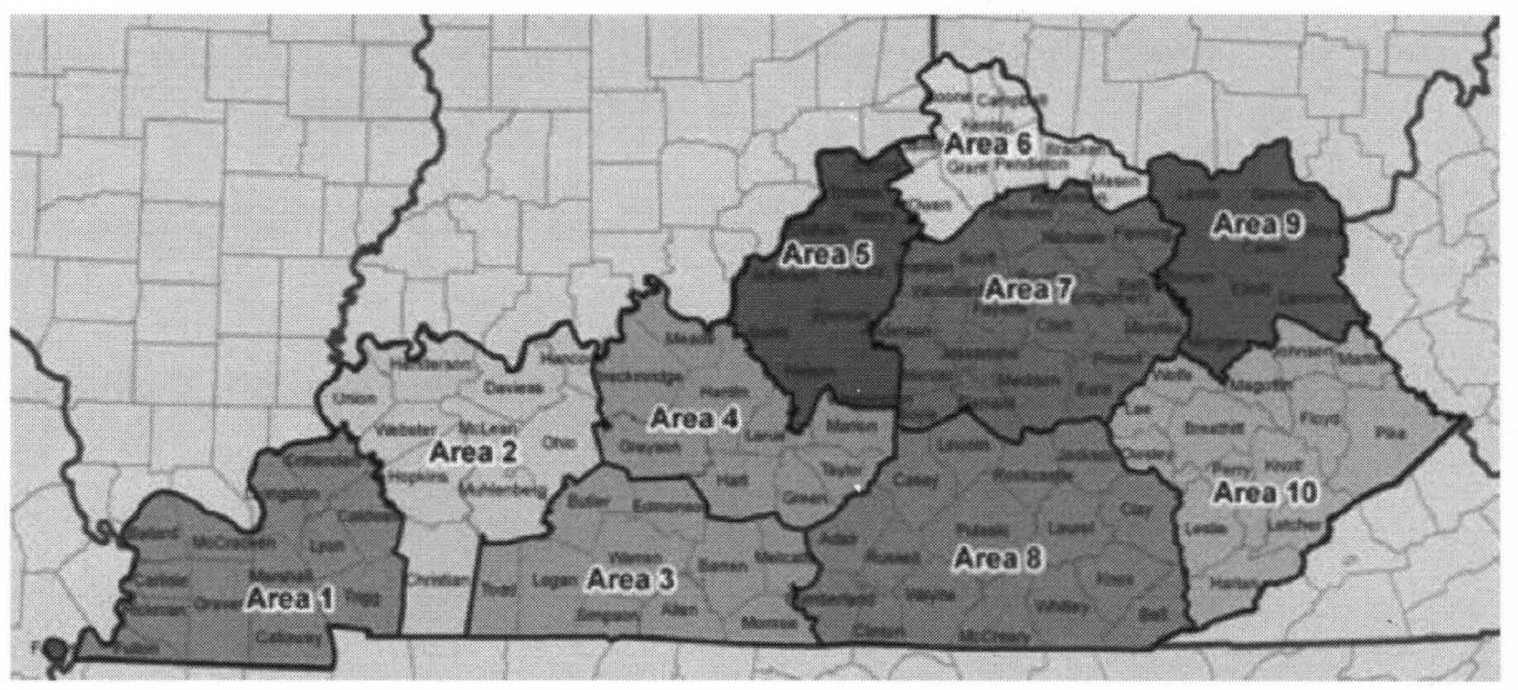

Figure 4: Kentucky chapters of the Association for Professionals in Infection Control 


\section{Definition of Terms}

Antimicrobial resistance- Antimicrobial resistance in reference to a pathogenic microorganism refers to the inability of a specific drug treatment (antimicrobial agent) to effectively kill or inhibit the growth of the microorganism (Boucher, et al., 2009).

Betweenness centrality- A network statistic that measures how many pairs of nodes a node of interest lies between.

Centrality - Network statistics that indicate the relative importance of network members.

Closeness centrality- A network statistic that measures how long it takes for a node to reach all other nodes in the network.

Connection- A connection is a tie or relationship between two nodes in a network (Granovetter, 1973). In this study, a tie is denoted as an indication of knowledge sharing from one IP to another. Also known as tie.

Degree centrality- A network statistic that measures the number of ties a node has.

Density - A measure of the number of connections divided by the number of possible connections in a network.

Eigenvector centrality- A network statistic measures the popularity of a nodes' connections. Popularity in this sense is described as having a large number of connections.

Healthcare- Healthcare refers to all of the settings in which patient care occurs. This includes not only hospitals, but also outpatient clinics, ambulatory surgical 
centers, long-term care facilities, and other environments in which patients are housed or treated.

Healthcare-associated infection (HAl)- A healthcare-associated infection is an infection that occurs in a patient during healthcare treatment for other conditions (Centers for Disease Control and Prevention, 2010c).

Infection preventionist- The infection preventionist is a healthcare worker who is employed for the task of prevention and control of healthcare-associated infections (Goldrick, 2005).

Knowledge sharing- Knowledge sharing is the exchange of information between two parties (McNeish \& Mann, 2010).

Network- A network is a representation of social structure and the associated relationships (Luke \& Harris, 2007). The structure and relationships may be formed for various reasons. In this study, the social network, or simply network, is formed through the sharing of knowledge from one IP to another. Also known as social network.

Node- A node is a member of the network. A node in a social network is also known as an actor (Luke \& Harris, 2007). In this study, nodes are defined as each infection preventionist completing the survey.

Propinquity- A proposition that indicates the closer nodes are geographically to one another, the more likely they are to be tied together (Kadushin, 2004). Relationship- A relationship is a connection or tie between two nodes in a network (Granovetter, 1973). In this study, a tie is denoted as an indication of knowledge sharing from one IP to another. Also known as tie. 
Social network- A social network is a representation of social structure and the associated relationships (Luke \& Harris, 2007). The structure and relationships may be formed for various reasons. In this study, the social network, or simply network, is formed through the sharing of knowledge from one IP to another. Sociogram- A sociogram is a social network diagram. This diagram graphically shows the nodes in a network along with their respective ties to other nodes within the network (Moreno \& Jennings, 1934).

Tie- $\mathrm{A}$ tie is a connection or relationship between two nodes in a network (Granovetter, 1973). In this study, a tie is denoted as an indication of knowledge sharing from one IP to another. 


\section{CHAPTER TWO}

Review of the Literature

Overview

Sharing knowledge in a social context is a method of increasing one's professional knowledge base. Unfortunately, little is known about the structure of these networks in healthcare, let alone among infection preventionists (IPs). This lack of information limits the ability to harness the network for interventions to increase the overall knowledge and competence of the members. In order to understand professional knowledge-sharing networks among hospital-based IPs, five major topics and their relationships are relevant. These topics include: 1) the roles of the hospital-based IP, 2) knowledge sharing, 3) social networks, 4) social network analysis, and 5) geographic effects on social networks.

\section{Literature review}

To understand the role of knowledge sharing within social networks in healthcare, specifically among hospital-based IPs, a literature review was conducted. Searches within multiple literature databases were conducted utilizing PubMed, CINAHL, ProQuest Direct, MD Consult, EBSCO, Google Scholar, JSTOR, Social Sciences Citation Index, Communication Abstracts, Sociological Abstracts, and Communication and Mass Media. Search terms were broad and included the following phrases "infection control", "infection prevention", "social network", "network", "knowledge sharing", "knowledge- 
sharing networks", "knowledge management", "social network analysis", "knowledge sharing in healthcare", "social networks in healthcare", "communication networks", and "healthcare communication". Abstracts were reviewed for content relevant to this research area. Manuscripts focusing on knowledge sharing in healthcare were given priority, as this review was not intended to be a comprehensive overview of hospitals, infection prevention, healthcare-associated infections, or social networks. Manuscripts of abstracts that warranted further examination were obtained and reviewed. Articles published after the year $\mathbf{2 0 0 0}$ were considered the most relevant as social network research is relatively new to the healthcare field. References within each article were subsequently assessed for inclusion in the literature review to ensure that seminal articles in each topic area were included.

The roles of the infection preventionist

As described in Chapter 1, the problem of healthcare-associated infections (HAls) is on the rise. Because of these issues, healthcare organizations have incorporated infection prevention into their work systems. Infection prevention in a healthcare setting is an organization-wide program that often involves some number of employees who are tasked with leading the efforts toward preventing or eliminating HAls within that healthcare setting (Goldrick, 2005). Through focused efforts on the prevention of HAls, the problems associated with them, such as poor patient outcomes and high hospital costs, can be reduced or eliminated. 
The duties of the IP and the evolution of their job responsibilities are described by the Certification Board on Infection Control and Epidemiology (CBIC) through periodic practice analyses. These practice analyses evaluate the actual practice and job responsibilities of IPs in various healthcare settings (Curchoe, et al., 2008). Seven duties have been described by the CBIC as being important for the practice of infection prevention in all healthcare settings: 1) identification of infectious disease processes, 2) surveillance and epidemiologic investigation, 3) preventing and controlling the transmission of infectious agents, 4) employee and occupational health, 5) management and communication, 6) education, and 7) research. As each of these duties encompasses a multitude of actual job tasks, it is apparent that the job of the IP is demanding and comprehensive.

The healthcare landscape encompasses a vast array of patient-care settings such as hospitals, long-term care facilities, nursing homes, home health services, hospice care, infusion centers, outpatient surgical centers, dialysis centers, and many more. The literature, as described below, has identified six themes that affect the IP and their job responsibilities: 1) limited staffing in infection prevention, 2) the number of actual duties of the IP are increasing, 3) guidelines, accreditation standards, and regulatory activities are different for each setting, 4) implementation strategies for improvement activities vary from setting to setting, 5) patients and healthcare workers move readily between settings, and 6) there is a lack of training and mentorship in infection prevention for IPs. 
The first problem affecting the IP with respect to their job duties is the lack of staffing. Despite publication of recommendations for staffing in infection prevention (Stone, et al., 2009), multiple studies have documented a continued and consistent lack of appropriate resources, both human and material, for infection prevention programs (Clements, et al., 2008; Gamage, Pugh, Litt, \& Bryce, 2009; Gamage, Varia, Litt, Pugh, \& Bryce, 2008; Goldrick, 2006; Herwaldt, Appelgate, Kuntz, Chen, \& Pottinger, 2007; Oh, Chung, Kim, \& Cho, 2006; Sarma \& Ahmed, 2010; Scheckler \& Peterson, 1986; Sekimoto, et al., 2009; Stricof, Schabses, \& Tserenpuntsag, 2008). The lack of appropriate staffing has been shown to have a detrimental effect on the development of HAls and their complications (Clements, et al., 2008).

The second issue affecting the job performance of the IP is the increasing scope and the magnitude of responsibilities (Wright, et al., 2010). Given the description of the $\mathrm{CBIC}$ practice analyses, it is clear that the job responsibilities require an inordinate amount of study and continuing education. The majority of IPs have a basic education in nursing (Haley, et al., 1985). However, the job responsibilities described in the $\mathrm{CBIC}$ practice analyses require expertise in a number of areas that may not often be included in a nursing curriculum.

The third issue that the IP faces due to the expansive healthcare landscape is the multitude of guidelines, accreditation standards, and regulatory activities that are often specific to each setting. The number of practice guidelines in healthcare that are specific to infection prevention are ever increasing and changing on a regular basis. Examples include guidelines 
developed by the Centers for Disease Control and Prevention's (CDC) Healthcare Infection Control Practices Advisory Committee (HICPAC). This chartered committee consists of a 14-member panel of experts responsible for the development of research-based practice guidelines that address areas of infection prevention practice that have been identified as important to patient safety and problematic for the healthcare system (Centers for Disease Control and Prevention, 2010b). Another important CDC committee is the Advisory Committee on Immunization Practices (ACIP), a panel of 15 experts providing guidance on various vaccine-related diseases and immunization practices (Centers for Disease Control and Prevention, 2010a). This committee is responsible for development of national guidelines regarding immunization that provide the basis for immunization practices worldwide. The Association for Professionals in Infection Control (APIC) and the Society of Healthcare Epidemiology of America (SHEA), two professional organizations, provide regular guidance on infection prevention through position papers, publications and educational offerings. The American Thoracic Society (ATS) and the Infectious Diseases Society of America (IDSA) also provide practice-based guidelines that directly impact infection prevention practice.

In addition to these guidelines, the IP must also monitor how the development of HAls impacts patient care and patient safety. These outcomes are directly reflected in accreditation standards for a variety of healthcare settings including hospitals, long-term care, home health services, ambulatory care, and behavioral health. Each of these healthcare settings has its own accreditation 
standards that are specific to infection prevention but reflect the unique aspects of care relevant to that particular setting. Accreditation for the healthcare organization is important as it is linked to reimbursement for services rendered. Three major accrediting agencies include The Joint Commission (TJC), the Centers for Medicare and Medicaid Services (CMS), and state validation surveys. The importance of knowing these standards and developing a programmatic response is evidenced by the 2008 regulation limiting Medicare/Medicaid reimbursement to healthcare facilities when certain HAls occur (Stone, et al., 2010). Lack of reimbursement for care rendered to some of those patients who develop HAls has the potential to dramatically impact the financial position and well being of the healthcare facility. The tension between the need of the IP to be knowledgeable about guidelines, able to translate that knowledge into the elements of performance to meet standards, and do that without adequate staffing and other resources, demonstrates the day-to-day challenges faced by this workgroup.

The IP is also tasked with maintaining current knowledge regarding local, state, and federal regulatory standards and requirements. Multiple state and federal statutes are present that regulate healthcare activities pertinent to the prevention of infections. For example, the Occupational Health and Safety Administration (OSHA) maintains the Bloodborne Pathogens Standard, (United States Department of Labor, 2010) which promulgates regulations for the prevention of bloodborne infectious diseases such as the human immunodeficiency virus (HIV) and the hepatitis $B$ and $C$ viruses. The 
Environmental Protection Agency (EPA) regulates the use of sterilants, tuberculocides, and disinfectants in healthcare settings (United States Environmental Protection Agency, 2009). Public health agencies and state regulatory agencies in the United States have lists of reportable diseases and conditions, and there is a growing trend toward mandating public reporting of HAls. This increasingly demanding job responsibility has been assigned to the $I P$, and what was once a rapid communication involving laboratory findings is now a labor-intensive activity that oftentimes dominates a major portion of the IP's time (McKibben, et al., 2005). Other agencies also play a role in regulatory aspects of healthcare infection prevention, and all of these organizations regularly update their rules in accordance with recent legal activities.

The fourth issue that the IP faces due to the vast healthcare landscape includes implementation strategies for improvement activities that vary from setting to setting. Each setting provides different types of care that can lead to the transmission of infection. For example, a dialysis center will have a large number of patients with catheters used for dialysis. These catheters are potential sources of infection if not inserted, used, and cared for properly (5 Million Lives Campaign, 2008c). This may be very different from the patient population in a private outpatient medical imaging center who will not be utilizing these types of catheters. In the imaging center, it may be environmental contamination issues that are the major factor in the transmission of infectious diseases (Roszak \& Colwell, 1987). These nuances demonstrate the difficulties that the IP has in implementing evidence-based guidance, ensuring regulatory compliance, and 
minimizing the negative financial impact that adverse events such as HAls pose to the organization.

Fifth, patients seek care in multiple settings and are therefore subjected to the differing $\mathrm{HAl}$ risks and prevention activities. In addition, a workforce that readily moves from facility to facility may not recognize and implement the needed practice changes that serve to preverit HAls within a given healthcare facility. Therefore, this movement of both patients and healthcare staff increases the challenges involved in standardization and application of infection prevention initiatives. Diversity of issues related to HAl transmission, even within one setting, can be challenging to the IP. For exarnple, there are over 4,500 hospitals in the United States, each with a different number of beds, a different patient population, different management structures, etc., leading to a massive net knowledge need for the IP to adequately perform their jobs.

Finally, there is a lack of training and mentorship for IPs. From a training standpoint, IPs have few options. Four major methods for self-training of the IP include advanced university education, reading of the scientific literature, training courses, and mentorship. The educational backgrounds of the IP have been documented in the landmark study on infection prevention entitled the "Study on the Efficacy of Nosocomial Infection Control" (SENIC). This study indicated that most IPs are nurses with little to no training in epidemiology, statistics, microbiology, or other fields that are both relevant and necessary to perform their job requirements (Haley, et al., 1985). It is noteworthy that the deficiencies in the 
baseline knowledge for competent infection prevention practice were recognized more than 25 years ago.

The scientific literature can be difficult for many IPs to read and apply to their settings as they may have minimal background in how to read and evaluate the literature. It has been documented that the majority of IPs do not read the literature and therefore miss the ability to recognize the value of scientific research and application of findings (Olmsted, Kowalski, Krein, \& Saint, 2006).

Few formal training courses in infection prevention are offered in the United States even though these opportunities have been identified as essential for healthcare innovation and learning (Ahmad \& Daghfous, 2010). The premier courses are available at least annually through the Association for Professionals in Infection Control (APIC) in in-class didactic formats, ranging from two to four days. The costs for attendance range from $\$ 500$ to $\$ 1,000$ excluding travel and hotel fees (Association for Professionals in Infection Control, 2010). As the field of infection prevention has already been described as overworked and understaffed with few resources available, it is clear that many of these IPs may not have the ability to take leave from work to attend these courses, even if they pay for it themselves. In the event that resources are made available so that attendance at such a course is possible, it is difficult to provide a course that will enable the IP to actively apply knowledge within the unique environments in which they work. Therefore, applicability of training is an important consideration. 
Mentorship is also a necessary but lacking component in the field of infection prevention (Bialachowski, 2009). According to a 2010 unpublished survey of IPs in Kentucky, the current average age of respondents was 53 years, leading to concerns about mass retirement and loss of current collective knowledge. This loss of collective knowledge must be overcome to ensure that

IPs are 1) not re-creating knowledge that is already available and 2) have access to mentors who can provide them with the knowledge that has been gathered over years of experience.

The setting-specific issues regarding HAl transmission, the increasing numbers of guidelines, accreditation standards, and rules, decreasing available time for training and information sharing, as well as the movement of patients and healthcare workers across healthcare settings underscores the need for knowledge sharing among IPs within and between each environment.

Unfortunately, little is known about how knowiedge is shared in healthcare settings, let alone within infection prevention.

Knowledge Sharing

Knowledge itself has been defined as "a state of knowing that constitutes facts, concepts, principles, laws, causal relationships, insights, judgments, intuition and feelings" (Ahmad \& Daghfous, 2010, p. 154). Sharing of knowledge is one way of passing on one's own knowledge and therefore increasing the needed knowledge base for professionals to adequately complete their job tasks.

The little that is known about knowledge sharing can be easily summarized. Knowledge sharing has only been referenced in one article in the 
scientific literature with regard to infection prevention (Rangachari, 2010). This topic has been studied in other areas however, including a small amount of focus within healthcare settings (Coleman, Katz, Menzel, \& Columbia University Bureau of Applied Social Research, 1966; Fattore, et al., 2009; Sales, Estabrooks, \& Valente, 2010; Zheng, Padman, Krackhardt, Johnson, \& Diamond, 2010).

Knowledge sharing focuses directly on the exchange of information between two parties (McNeish \& Mann, 2010). It has been documented that there is a paucity of data regarding knowledge sharing and therefore more work in this area is needed (McNeish \& Mann, 2010). As McNeish and Mann (2010) describe, knowledge sharing is important for many reasons including increasing focus and fostering a collaborative environment. Recognizing this, it is clear that understanding how knowledge sharing occurs between IPs can provide insight into the mechanisms of information flow in this field. Perhaps a novel or informal method of information sharing already exists that IPs have developed on their own as a mechanism of job survival. This informal process may involve some type of social network that has yet to be identified and described.

Social Network Theory

Social network theory postulates that humans are inherently social creatures and the interactions and relationships between them are meaningful (Sales, et al., 2010) and can be mathematically studied. Furthermore, much can be predicted about members of a network based on the type of network and their position within that network (Kadushin, 2004). A network is defined most simply 
as a set of relationships or ties (Kadushin, 2004). The smallest network may be a tie between two things, most commonly individuals. Clearly, the network may become much larger as other ties and individuals or nodes are added to the network.

The origins of network theory are disputed though many agree that Paul Erdos and Alfred Renyi were the pioneers in the formalization of the field through their work on random networks (Barabasi \& Bonabeau, 2003). This theory postulated that as the size of the network grew, a smaller number of ties were needed to be able to link everyone in the network together. This work was furthered by Stanley Milgram in his work on the six degrees of separation indicating that everyone can be connected through less than six intermediaries a concept Milgram coined as the small world problem (Milgram, 1967). This may be particularly relevant to the study of networks in infection prevention as the ties, nodes, and degrees of separation may demonstrate different methods that are in place, or can be influenced, for the purposes of knowledge sharing and practice improvement.

Understanding networks and the relationships that exist may best occur by use of a visual tool. This is similar to using a chart to describe data within a table. The psychologist Jacob Moreno is credited with the development of the network drawing - the sociogram (Moreno \& Jennings, 1934). This diagram places each node on a graph along with the ties connecting each of the nodes. These diagrams allow for visual representation of the network (nodes and ties) and can help identify the location of each node, which can then be used to 
predict various attributes of the node (Luke \& Harris, 2007). The applicability in understanding the existing networks within infection prevention can be demonstrated by identifying IPs (nodes) and their links to other IPs (ties) and how these relationships can be visualized through a sociogram that focuses on infection prevention knowledge sharing-networks.

The entire body of literature describing social networks is expansive. Network theory has been utilized by a number of fields such as agriculture (Ryan \& Gross, 1943), "sociology, psychology, political science, anthropology, communication, business, mathematics, statistics, computer science, and physics" (Luke \& Harris, 2007, p. 72). Little of this work has been in the fields of healthcare and public health, with the majority of that focusing on HIVIAIDS, sexually transmitted infections, and tobacco use (Ancel Meyers, Newman, Martin, \& Schrag, 2003; Andre, et al., 2007; Auerbach, Darrow, Jaffe, \& Curran, 1984; R. Broadhead, et al., 1998; W. Broadhead, et al., 1983; Choi \& Gregorich, 2009; Curran \& Abidi, 2007; Curtis \& Edwards, 1995; Drewe, 2009; Dube, Ribble, Kelton, \& McNab, 2009; Eames \& Keeling, 2002; Ennett \& Bauman, 1993; Friedman \& Aral, 2001; Friedman, Jose, Deren, Des Jarlais, \& Neaigus, 1995; Friedman, et al., 1997; Harris, 2008; Harris \& Clements, 2007; Jolly, Muth, Wylie, \& Potterat, 2001; Ladin, Hanto, O'Malley, \& Marsden, 2009; Luke \& Harris, 2007; Montoya, 1998; Morris, 1997; Morris \& Kretzschmar, 1997; Morris, Kurth, Hamilton, Moody, \& Wakefield, 2009; Morris, Zavisca, \& Dean, 1995; Potterat, Muth, et al., 2002; Potterat, Phillips-Plummer, et al., 2002; Reo, Morbius, \& Rosenblat, 2007; Rothenberg, Baldwin, Trotter, \& Muth, 2001; Rothenberg, et al., 
1998; Valente, Unger, \& Johnson, 2005; Valente \& Vlahov, 2001; Williams, et al., 1995; Wohlfeiler, 2000). All of these studies found social networks to be important factors in predicting disease transmission and health behavior. In the healthcare setting, Coleman, Katz and Menzel (1966) found that social networks influenced physician-prescribing behavior. This work formed the basis for many other similarly themed projects throughout the 1970 s and 1980s (Luke \& Harris, 2007). Little focus has been on the structure of the knowledge-sharing network of working professionals in public health and healthcare (Harris \& Clements, 2007). Rangachari (2010) presented the first discussion regarding knowledge sharing and organizational learning that influences the development and prevention of healthcare-associated infections. This work focused on the network within a specific hospital or healthcare setting, including the management and staff, and not the networks that expand beyond that institution's walls. Rangachari (Rangachari, 2009, 2010) demonstrated that knowledge acquisition and sharing must flow in a manner such that individuals are able to utilize that information for activities such as practice change. This diffusion of information becomes a crucial element in effective knowledge sharing.

Some research has examined the utility of social network theory with respect to information flow and diffusion (Ahmad \& Daghfous, 2010; Chan \& Liebowitz, 2006; Haythornthwaite, 1996; Valente \& Davis, 1999; Valente \& Foreman, 1998; Valente \& Fosados, 2006; Valente \& Rogers, 1995). The results of these studies indicate three important concepts: 1) communication is 
important for adoption of new behaviors (Valente \& Davis, 1999), 2) networks are important in the creation and sharing of knowledge (communication) (Ahmad \& Daghfous, 2010), and 3) people go to peers for information, not necessarily experts (Rice, 1993). Furthermore, as Valente and Fosados (2006) indicate, behavior change is related to interpersonal communication as opposed to communication with other sources. If networks are important for communication, knowledge creation, and sharing; people go to peers for information; and this information is important for the adoption of new behaviors; it is clear that the peer (social) networks of IPs are important for the creation and sharing of knowledge regarding infection prevention for the maximal benefit of the practice of infection prevention. What is unknown is whether these networks exist and how to evaluate them.

Social Network Analysis

A novel option for studying knowledge sharing is to examine the social networks of individuals in order to visualize and statistically analyze who is sharing knowledge with whom. Social network analysis is one technique that has been cited as being useful in following how information flows and how knowledge is shared (Haythornthwaite, 1996; Sales, et al., 2010; Valente \& Rogers, 1995). Social network analysis merges graph theory and social network theory, postulating that humans are inherently social creatures and the interactions and relationships between them are meaningful (Sales, et al., 2010) and can be mathematically defined and studied. Statistical measures in social network analysis are very different from the common statistical measures in public health 
and medicine as they focus more on the structure and relationships between items, rather than attribute analysis such as characteristics of individuals (Durland \& Fredericks, 2005). For these reasons, it is important to provide an overview of network study designs, network descriptions, and network statistics. Network Study Designs

Network study designs are often observational and can focus on two types of networks: ego networks or whole networks (O'Malley \& Marsden, 2009). Ego networks begin with one node and examine the other nodes connected to this node. Whole network analysis begins with a specifically bound population and examines all of the relationships within (Knoke \& Yang, 2008; O'Malley \& Marsden, 2009). A whole network analysis would be needed to examine the knowledge-sharing networks among IPs, as the interest is the whole group and all of the ties between them.

Network Descriptions

In examining the whole network, relationships can be either undirected or directed. Undirected networks ignore the possibility of non-reciprocal relationships between nodes (O'Malley \& Marsden, 2009). For example, if IP1 asks IP2 for information, they are defined as related or tied together. Undirected networks would consider only that they are tied together and ignore the fact that IP2 did not ask IP1 for information. In a directed network, the measurement takes into account the fact that knowledge was shared in only one direction. The directionality of the tie often depends on the research question. This demonstrates the importance of directed examinations of networks (O'Malley \& 
Marsden, 2009). The ability to recognize these attributes and structure information about the network in a way that can be analyzed strengthens the importance of the visual picture or sociogram.

As described previously, sociograms are common visual representations of social networks that provide insight into the location of each node with reference to all other nodes. Examination of the sociogram can allow for identification of various components of a network - those clusters of nodes that are completely connected to one another (Costenbader \& Valente, 2003; O'Malley \& Marsden, 2009). Figure 5 depicts a sociogram with two components. Building a sociogram that will allow a complex analysis requires the use of artificial intelligence - specific computer software that allows for the entry of specific data elements such as the nodes, the ties between nodes, the strength of the ties and the direction of the relationship. Visual examination of a sociogram is somewhat subjective, as node placement is done for the sake of visualization, rather than statistically. That is, a node that is placed centrally in the sociogram may not actually be central to the analysis or important to the network. There are, however systems methods for determining node placement. Node placement on sociograms is often done via spring embedding algorithms (Goldbeck \& Mutton, 2006). One of the more common spring embedding algorithms is that developed by Fruchterman and Reingold (1991). These spring embedding algorithms place nodes on a sociogram with opposing forces (measured as distances between nodes) in relation to other nodes, much like similar poles of a magnet or similarly charged particles repel each other. Ties act 
as springs that pull nodes together. Through use of this algorithm, a balance of forces is achieved and a final sociogram is constructed (Goldbeck \& Mutton, 2006). Once the sociogram has been constructed, visual analysis helps generate hypotheses, which can be evaluated through use of objective statistical methods.

\section{Network Statistics}

A number of descriptive statistics exist that can be calculated to perform a more objective examination of networks. The most common descriptive network statistics include network density and measures of network centrality including degree (in-degree and out-degree), betweenness, closeness (in-closeness and out-closeness), and eigenvector. These statistics and their implications for network analysis of knowledge-sharing networks are shown in Table 1.

Table 1: Social network analysis statistics and the implications of each

\begin{tabular}{|l|l|}
\hline \multicolumn{1}{|c|}{$\begin{array}{c}\text { Social Network } \\
\text { Statistic }\end{array}$} & \multicolumn{1}{c|}{ Implication } \\
\hline 1. Density & $\begin{array}{l}\text { A dense network may suggest that many ties are } \\
\text { present compared to those that are possible, and } \\
\text { knowledge is shared readily. It is unclear whether a } \\
\text { dense or a non-dense network is more beneficial } \\
\text { with regard to knowledge sharing (Rangachari, } \\
2010) .\end{array}$ \\
\hline $\begin{array}{l}\text { 2. Degree centrality } \\
\text { a. In-degree } \\
\text { b. Out Degree }\end{array}$ & $\begin{array}{l}\text { A high degree statistic in an undirected network } \\
\text { would suggest that members of the network share } \\
\text { knowledge with many other members of the network. } \\
\text { In a directed network, a high in-degree statistic } \\
\text { would suggest that the IP is highly prominent, as } \\
\text { many other IPs ask them for information. A high out- } \\
\text { degree statistic would indicate that the IP asks many } \\
\text { other IPs for information. }\end{array}$ \\
\hline
\end{tabular}




\begin{tabular}{|l|l|}
\hline \multicolumn{1}{|c|}{$\begin{array}{c}\text { Social Network } \\
\text { Statistic }\end{array}$} & \multicolumn{1}{c|}{ Implication } \\
\hline $\begin{array}{l}\text { 3. Betweenness } \\
\text { centrality }\end{array}$ & $\begin{array}{l}\text { A high betweenness statistic would suggest that the } \\
\text { IP acts as a broker of information between many } \\
\text { other IPs and therefore acts as a gateway for } \\
\text { knowledge sharing within the network. }\end{array}$ \\
\hline $\begin{array}{l}\text { 4. Closeness } \\
\text { centrality } \\
\text { a. In-closeness } \\
\text { b. Out-closeness }\end{array}$ & $\begin{array}{l}\text { A high closeness statistic in an undirected network } \\
\text { would suggest that the IP is able to contact all other } \\
\text { IPs quickly and directly, rather than through multiple } \\
\text { intermediaries. } \\
\text { In a directed network, a high out-closeness would } \\
\text { suggest that the IP is capable of contacting all other } \\
\text { IPs quickly and directly. A high in-closeness would } \\
\text { suggest that many other members of the network } \\
\text { contact the IP quickly and directly. }\end{array}$ \\
\hline 5. Eigenvector \\
centrality & $\begin{array}{l}\text { A high eigenvector centrality would suggest that the } \\
\text { IPs that an IP is connected to ask for knowledge } \\
\text { from many other IPs and therefore have access to } \\
\text { multiple sources of knowledge. }\end{array}$ \\
\hline
\end{tabular}

Network density is a measure of the ratio of the number of connections in a network versus the number of possible connections. Density ranges from 0-1, with 1 meaning that all nodes in the network are connected to each other, and 0 meaning that there are no connections between any nodes (isolates) (Costenbader \& Valente, 2003; O'Malley \& Marsden, 2009). Figures 6a and 6b depict low and high-density networks, respectively. The interpretation of network density is debated. Some investigators postulate that a dense network (e.g. where all or most nodes are connected to one another) is more relevant to a discussion of knowledge sharing since social capital (all resources within a social system) is increased as density is increased. Therefore, this results in more resources, such as human, material, and emotional, being brought to the network (Coleman, 1988). Burt (2000) argues the opposite. He postulates, as 
Granovetter's (1973) work supports, that social capital and new knowledge infiltrates a network through the "weak ties" or acquaintances. This theory argues that all members of dense networks already have the same information and they need members from outside the network to bring in new knowledge (Burt, 2000). This theory is called the Structural Holes Theory. Recognizing these two divergent theories, it is unclear how density should be used in any particular analysis. However, it is clear that density is a measure of how well connected the members are in the network. In a knowledge-sharing network, density may indicate that knowledge is being shared regularly. That is, if a tie represents a knowledge-sharing episode, and everyone is connected, then multiple knowledge-sharing episodes are occurring and there is the mechanism for knowledge to be shared regularly. The Structural Holes Theory states that if multiple components of dense networks are present, a tie linking them together may result in an effective knowledge network. There is more, however, to a network than simply its density.

Key to the analysis is the characteristics of each node. Network centrality measures are statistics that can help to identify these node characteristics. There are many measures of network centrality. The most common are degree, closeness, betweenness, and eigenvector. The use of some of these statistics is determined based on whether the network examination is undirected or directed. Degree measures the node's involvement in the network by measuring its numbers of ties (Costenbader \& Valente, 2003; O'Malley \& Marsden, 2009). For directed networks, the degree is separated into in-degree and out-degree. In- 
degree measures the number of incoming ties and the out-degree measures the number of outgoing ties (Costenbader \& Valente, 2003; O'Malley \& Marsden, 2009). A high degree statistics indicates the presence of a higher number of ties (overall or incoming and outgoing). Figures $7 \mathrm{a}$ and $7 \mathrm{~b}$ depict nodes with low and high degrees, respectively. The white node in each Figure indicates the node for which the degree is calculated. Degree has been used in public health to measure popularity via the number of times students are selected as popular by their peers (Valente, et al., 2005), and infectious disease transmission in humans (Andre, et al., 2007) and animals (Drewe, 2009). It has also been used to examine employee turnover (Feeley, Hwang, \& Barnett, 2008) and communication networks (Harris \& Clements, 2007). Few studies have used this statistic to examine knowledge sharing, however. A high degree statistic in an undirected network would suggest that members of the network share knowledge with many other members of the network. In a directed network, a high in-degree statistic (Figure 8a) would suggest that the IP is highly prominent, as many other IPs ask them for information. A high out-degree statistic (Figure 8b) would indicate that the IP asks many other IPs for information.

Betweenness is a measure of the frequency with which a node lies as an intermediary between two other nodes. A high betweenness indicates that the node lies between all other nodes and is the sole way of connecting all nodes in the network (Costenbader \& Valente, 2003; Freeman, 1979; O'Malley \& Marsden, 2009). Figures $9 a$ and $9 \mathrm{~b}$ depict nodes with low and high betweenness, respectively. These nodes are brokers and have the power of 
allowing or preventing flow of resources or information to other nodes (Costenbader \& Valente, 2003; Freeman, 1979). It is clear that these nodes with high betweenness statistics may play a role in the Structural Holes Theory as described above by brokering information into the network from other network components or from other networks. West (2005) demonstrated this by showing that managers in healthcare broker information between nurses and doctors; two groups of healthcare professionals that may not regularly share professionspecific information with each other. There are no differences in betweenness statistics for undirected and directed networks. Betweenness statistics are important from a knowledge-sharing point of view as they indicate how much control nodes have over other nodes with regard to information flow. A high betweenness statistic would suggest that the IP acts as a broker of information between many other IPs and therefore acts as a gateway for knowledge sharing within the network.

Closeness is another measure of network centrality, which measures the ability of a node to reach all other nodes with the fewest number of intermediaries. A high closeness indicates that the node can reach all of the other nodes directly with no intermediaries (Costenbader \& Valente, 2003; Freeman, 1979; Sabidussi, 1966). Closeness can also be measured for directed networks and the resultant statistics are in-closeness and out-closeness (Costenbader \& Valente, 2003). A high closeness statistic indicates that a node can contact every other node in the network very quickly with few intermediaries and therefore may be productive in knowledge sharing (Chan \& Liebowitz, 2006). 
Figures $10 \mathrm{a}$ and $10 \mathrm{~b}$ depict nodes with low and high closeness values, respectively. A high closeness statistic in an undirected network would suggest that the IP is able to contact all other IPs quickly and directly, rather than through multiple intermediaries, thereby avoiding the control of knowledge flow by other IPs (Freeman, 1979). In a directed network, a high in-closeness (Figure 11a) would suggest that the IP is capable of contacting all other IPs quickly and directly. A high out-closeness (Figure 11b) would suggest that many other members of the network contact the IP quickly and directly. Although closeness has been described in the literature relevant to other types of networks, its applicability has yet to be described in the literature on knowledge-sharing networks.

Eigenvector centrality is a measure of the number of connections a specific node's connections have, or more simply a measure of how "popular" a node's connections are (Bonacich, 1987; Costenbader \& Valente, 2003; Freeman, 1979; O'Malley \& Marsden, 2009). This is important, as there are obvious differences in the information a node can retrieve if it has one tie to another node that has one tie, versus a node with one tie to another node that has 80 ties. The node with a tie to another node with 80 ties has the ability to gain much more information as compared to the node with one tie to a node that only has one tie (Costenbader \& Valente, 2003; Freeman, 1979; O'Malley \& Marsden, 2009). Figures $12 \mathrm{a}$ and $12 \mathrm{~b}$ depict nodes with low and high eigenvector centrality, respectively. Use of eigenvector centrality in knowledgesharing networks is important as it can identify the nodes that are connected to 
nodes with the potential for many other contacts, thereby increasing the connected nodes' pool of knowledge. A high eigenvector centrality would suggest that an IP (Node B in Figure 12b) that shares information with many other IPs (Nodes C in Figure 12b) is able to provide another IP (Node A in Figure 12b) with a large body of knowledge. The use of eigenvector centrality in the study of knowledge-sharing networks provides a unique opportunity to evaluate the relative importance of any connection.

Other measures have also been developed to help describe various network attributes. Of importance for information flow in social networks is the key player algorithm developed by Borgotti (2006). The identification of sets of key players is important for two reasons, 1) rapid disruption of the connections within the network (e.g. intervening during infectious disease transmission) and 2) harnessing nodes for rapid dissemination of information through a network (e.g. knowledge sharing). Although the centrality statistics described earlier may be sufficient to identify singular nodes in a network that are key players, Borgotti describes two issues when using them to identify sets of key players: 1) deleting the nodes with the highest centrality statistics does not necessarily fragment the network (e.g. break into multiple components) and 2) when looking for more than one node as a key player, it is also necessary to take into account the other nodes selected as key players. The key player algorithm accounts for both the structure and statistical functions of the network and addresses both of these issues. Furthermore, key players may be present even when nodes are decentralized. Consequently, the KeyPlayer ${ }^{\mathrm{TM}}$ program (Analytic Technologies, 
2010 ) is useful for answering the question of which network members are able to reach the most number of nodes, thereby identifying members of a knowledgesharing network that have the ability to share knowledge with the greatest number of network members. The key player algorithm remains relatively unstudied, and therefore its utility remains largely theoretical.

Geographic Effects on Social Networks

Social network theory indicates that those who are geographically close to one another are more likely to be directly tied, a proposition known as propinquity (Kadushin, 2004). Direct ties are also clearly important for knowledge sharing as without a tie, contact cannot be made and knowledge cannot be shared. A bypass for this is to have nodes with high betweenness, as described above, who can broker information between two nodes that may be geographically separated without a direct tie. It can be argued that knowledge is best transmitted directly, without a broker who may potentially convey incorrect information. It has been documented that geographic separation negatively affects social network ties (Rothenberg, et al., 2005; Terrell, 2010; Wylie, et al., 2007), even within the healthcare environment (West \& Barron, 2005). Geographic separation can be measured in a number of ways. For example, from a physical barrier standpoint, Kentucky has been separated into six geographic regions (Netstate.com, 2009). These multiple physical barriers such as mountains and rivers may limit direct person-to-person communication. Another important method of geographic separation is through the medical trade area. Medical trade areas are areas where the population receives most of its 
medical care and takes into account care seeking and physician referral patterns (Hanchette, et al.). Using multiple health services databases, Kentucky has been separated into ten distinct medical trade areas (Hanchette, et al.). These regions may be relevant to networking as the facilities providing care to the same population with similar referral patterns may have similar infection prevention issues and may be more willing or able to share information with each other. A third geographic separation method within Kentucky is by the three Kentucky Chapters of the Association for Professionals in Infection Control (APIC). Local meetings of IPs are broken into the Western Region, Kentuckiana Region, and the Bluegrass Region (Association for Professionals in Infection Control Kentucky Chapter, 2010). These regions limit regular face-to-face communication across meeting boundaries. Although the recent advances in online social network structures may have decreased some relevance of geographic separation, there is evidence that geographic distance between nodes, even in an online network, remains a major factor in the likelihood of communication (Cantoni, Bello, \& Frigerio, 2001; Liben-Nowell, et al., 2005). Video conferencing, whereby the users can interact in a virtual face-to-face format may provide a mechanism for limiting the impact of geographic separation. Kentucky maintains an active Telehealth Network that provides this service to many of the hospitals in the state (The Kentucky Telehealth Network, 2010).

Although there are multiple methods that can be used to divide a state into various regions, it is unclear as to the relevance of geography in knowledge 
sharing. However, as the majority of data suggests that networks are fragmented by geography, it is conceivable that some form of geographic separation of Kentucky may play a role in preventing or enhancing knowledge sharing between these healthcare professionals.

This comprehensive review of 1) the roles of the hospital-based IP, 2) knowledge sharing, 3) social networks, 4) social network analysis, and 5) geographic effects on social networks, provides insight into the complex issues involved in characterizing, understanding, and analyzing the existing knowledgesharing networks of IPs. Existing knowledge-sharing practices within this group of healthcare professionals remains unexplored and therefore provides an opportunity for study. Examining the structures of this knowledge-sharing network requires a suitable analytical process, which involves the use of social network analysis. An understanding of the existing knowledge-sharing practices of IPs may then provide an opportunity for improving or enhancing the network for optimization of the knowledge sharing within. 


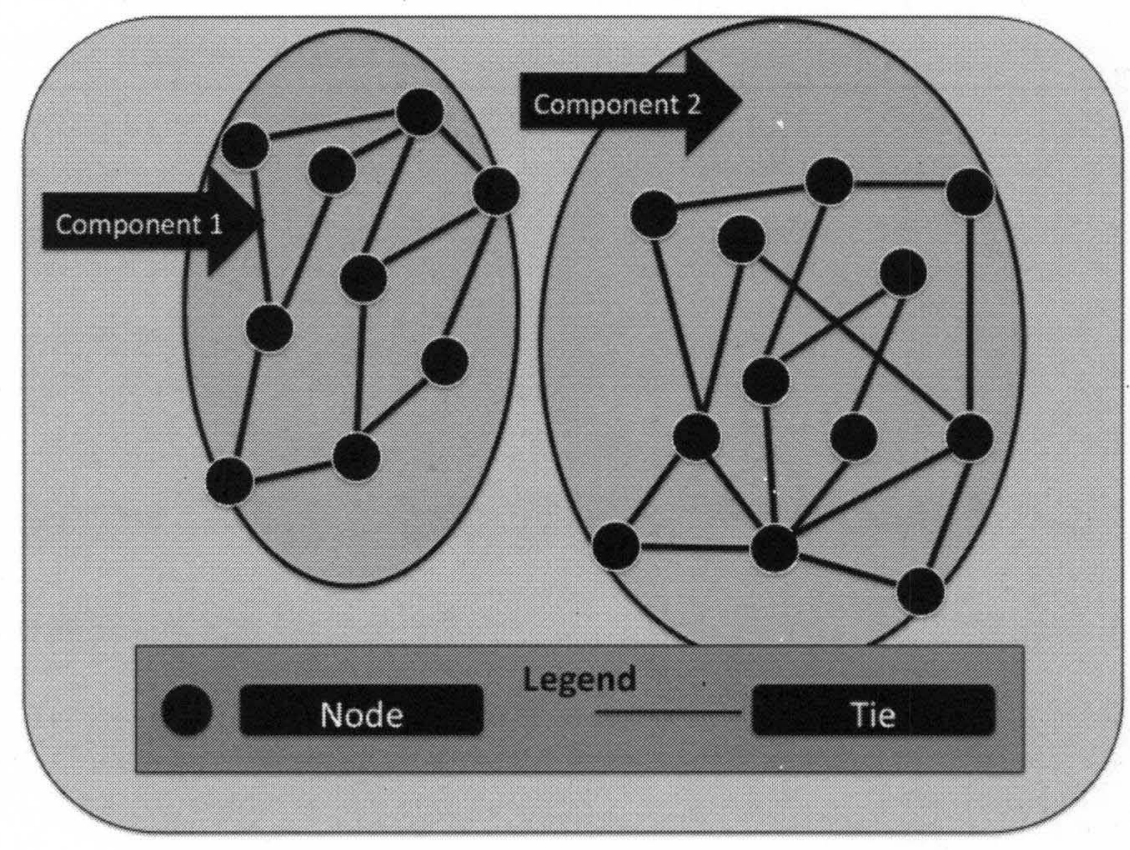

Figure 5: Sociogram with two components

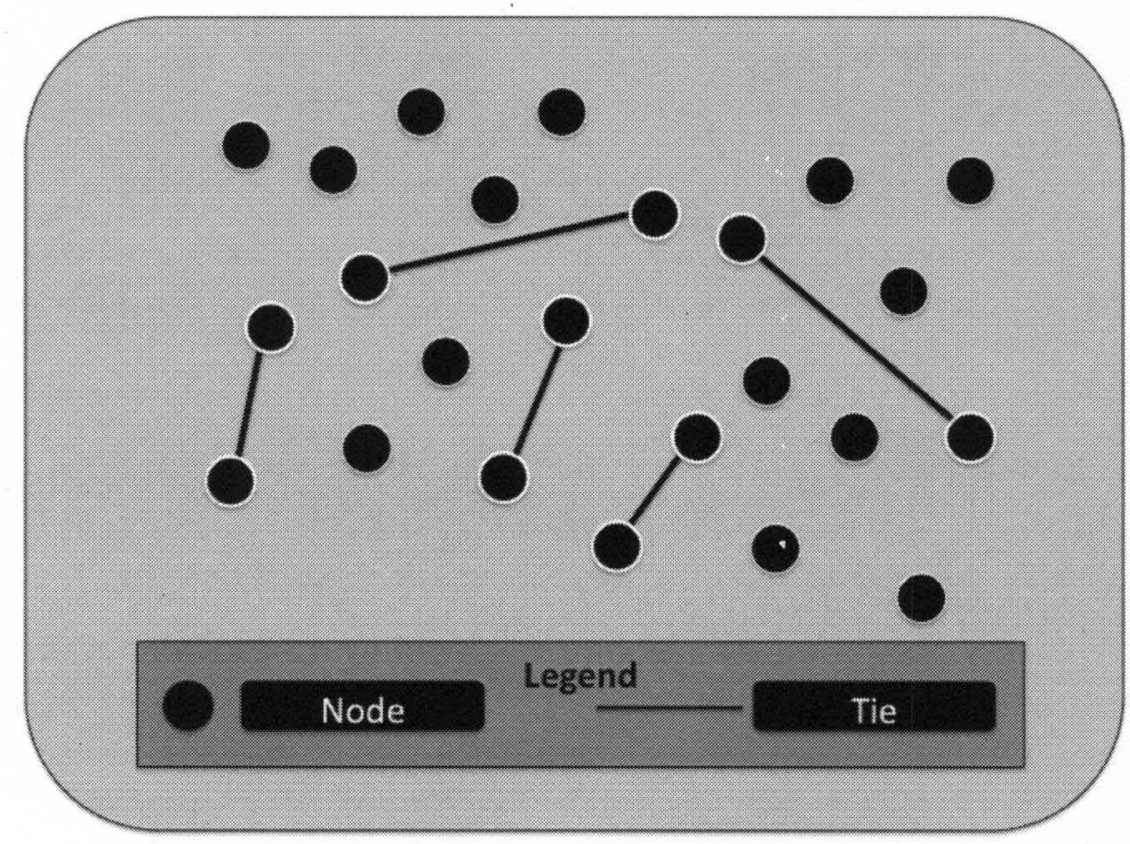

Figure 6a: Low density network 


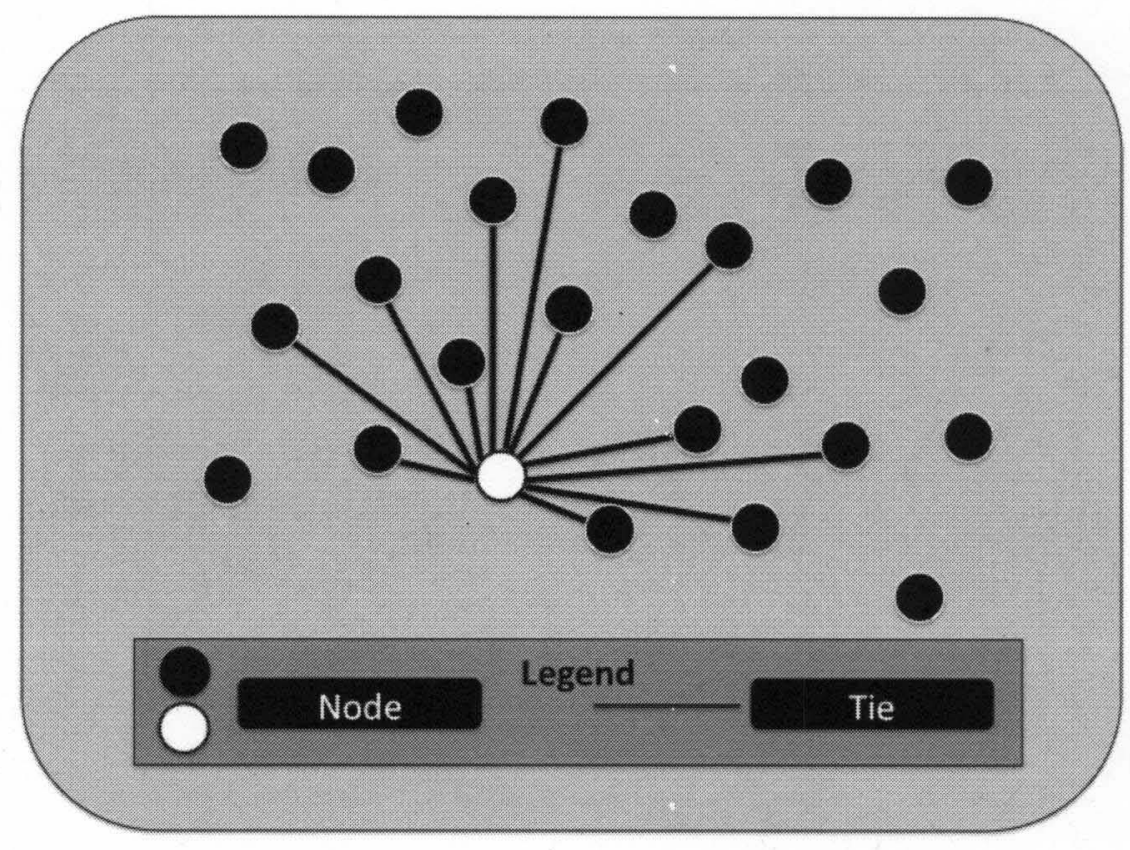

Figure 6b: High density network

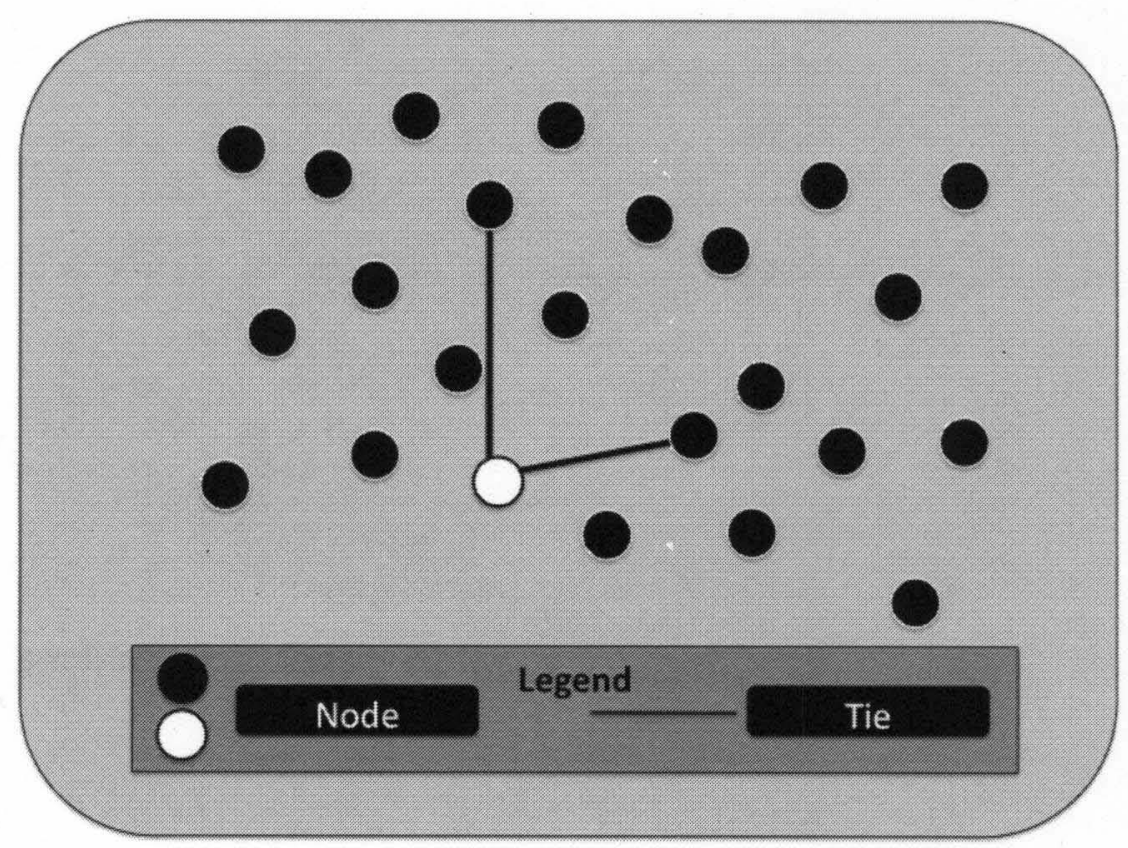

Figure 7a: Node with low degree centrality 


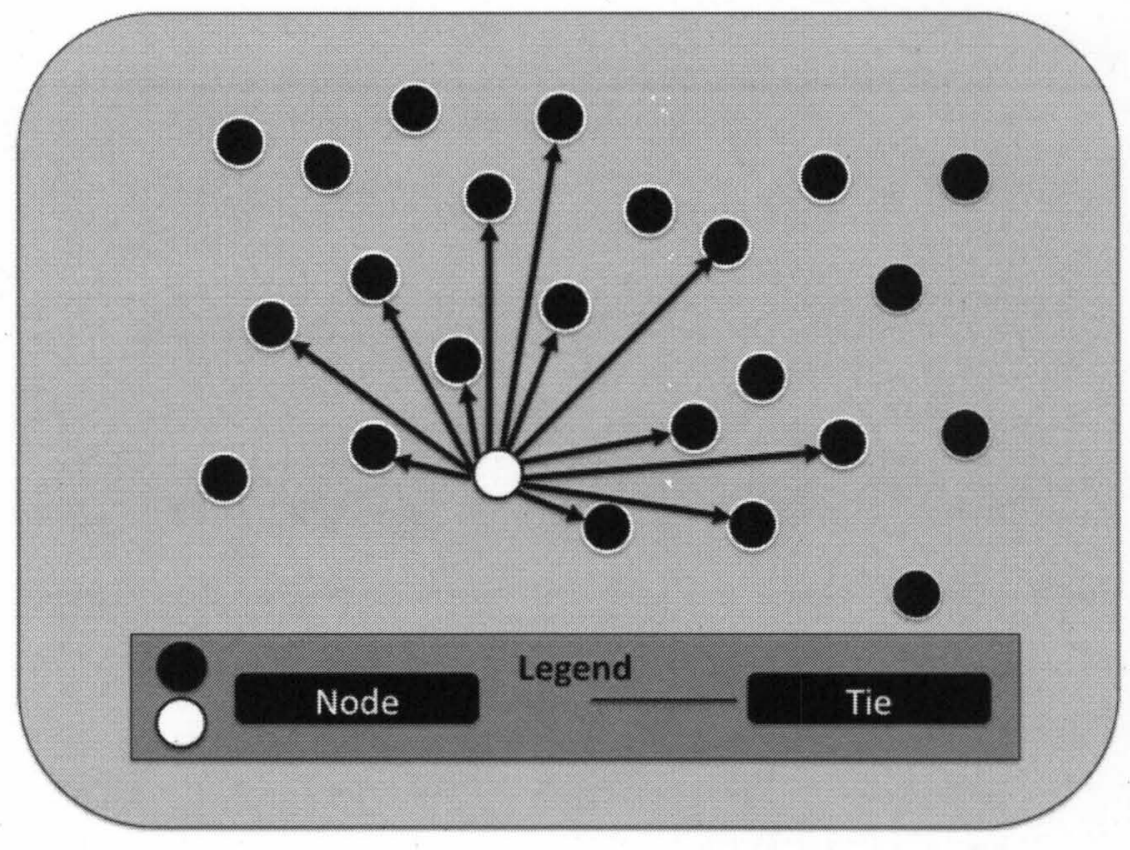

Figure $7 \mathrm{~b}$ : Node with high degree centrality

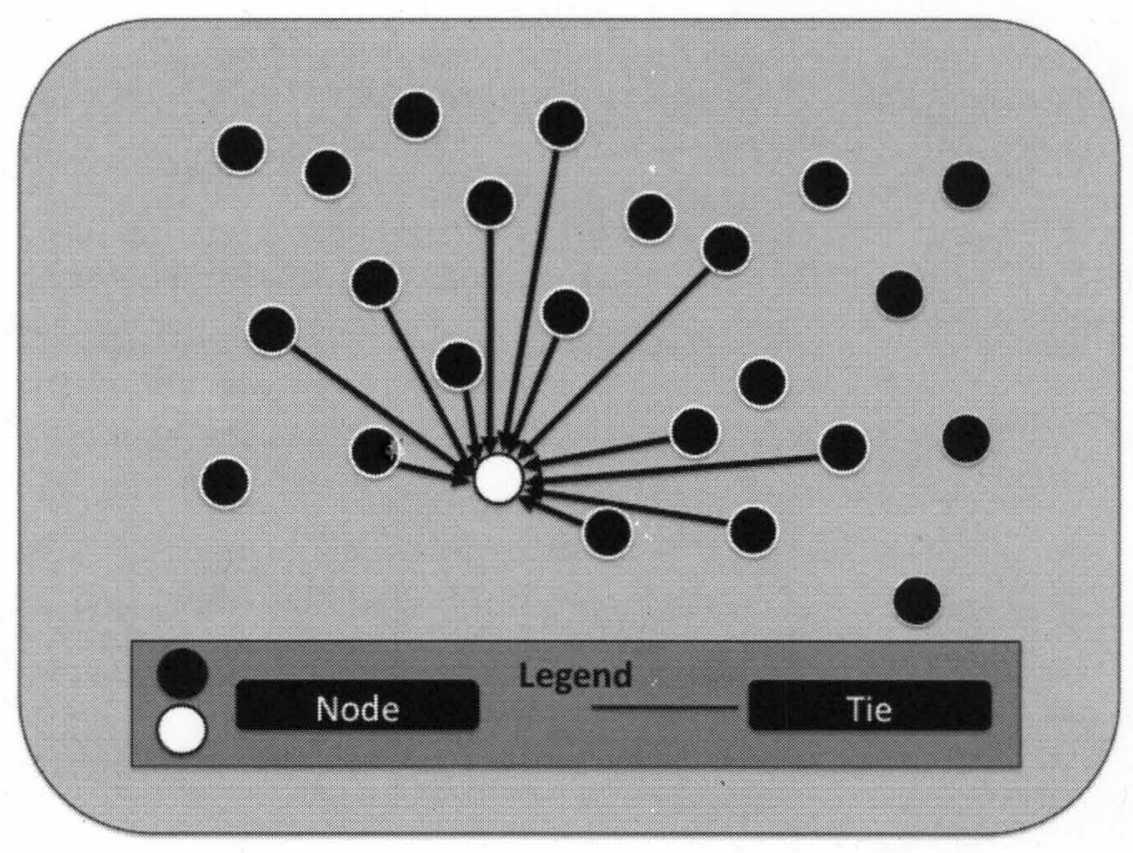

Figure 8a: Node with high in-degree centrality 


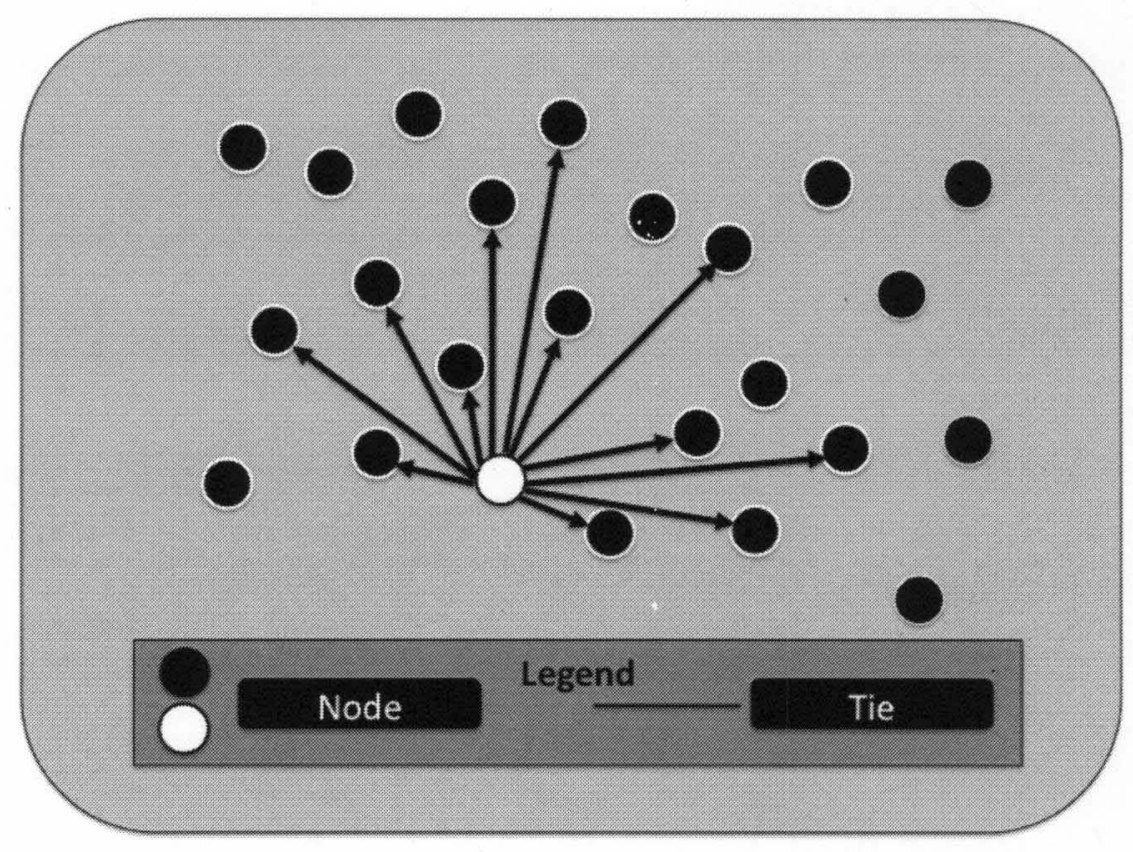

Figure 8b: Node with high out-degree centrality

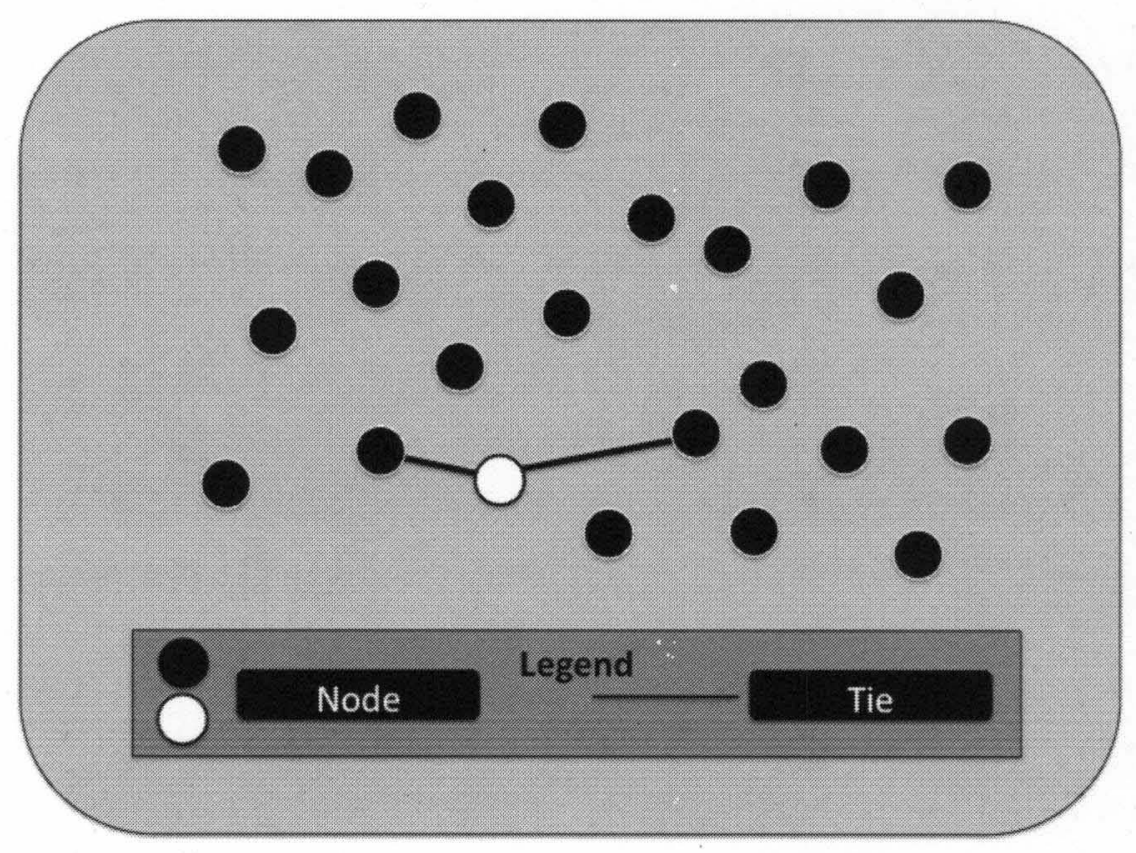

Figure 9a: Node with low betweenness centrality 


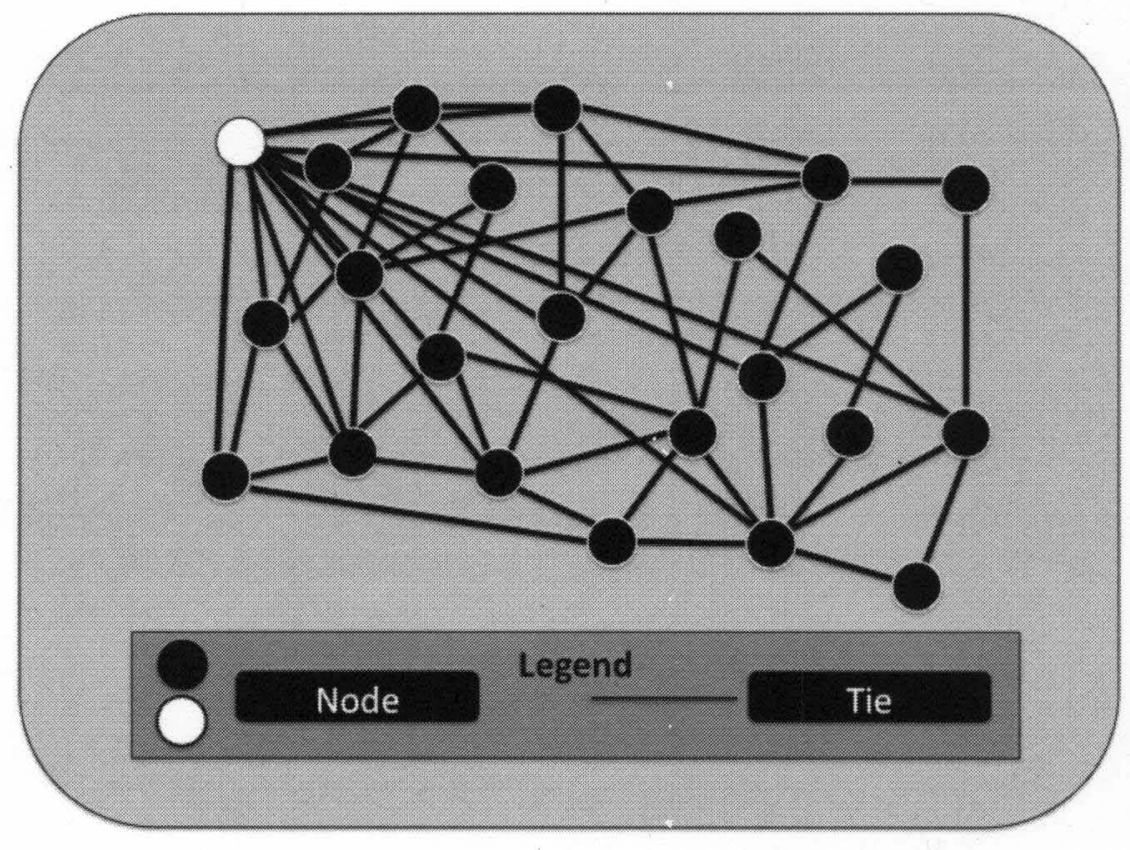

Figure 9b: Node with high betweenness centrality

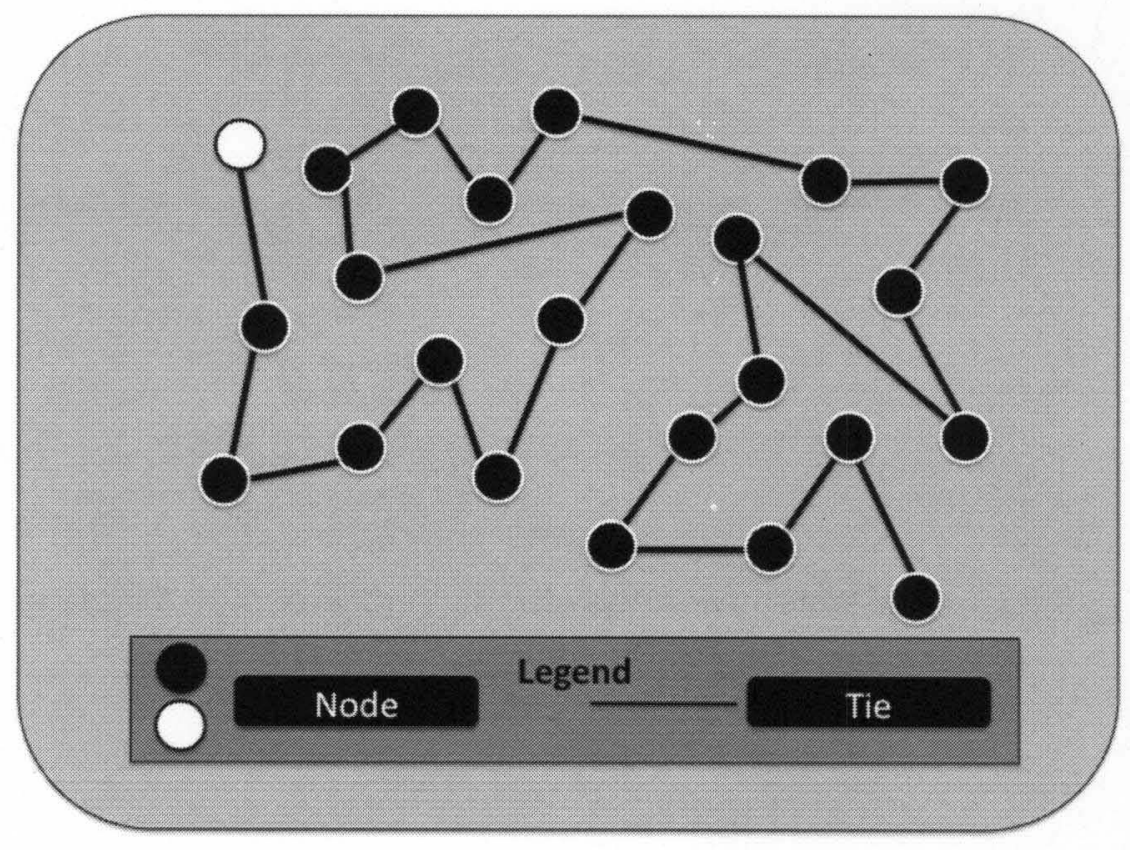

Figure 10a: Node with low closeness centrality 


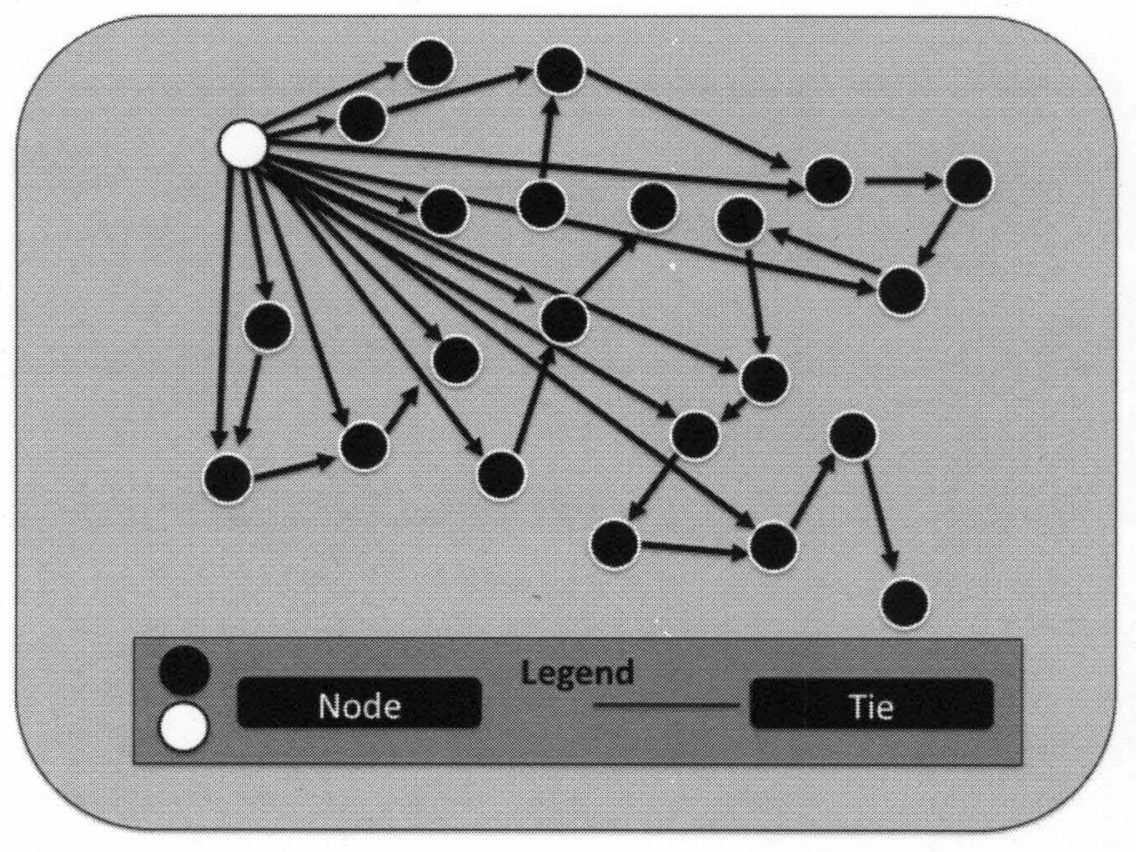

Figure 10b: Node with high closeness centrality

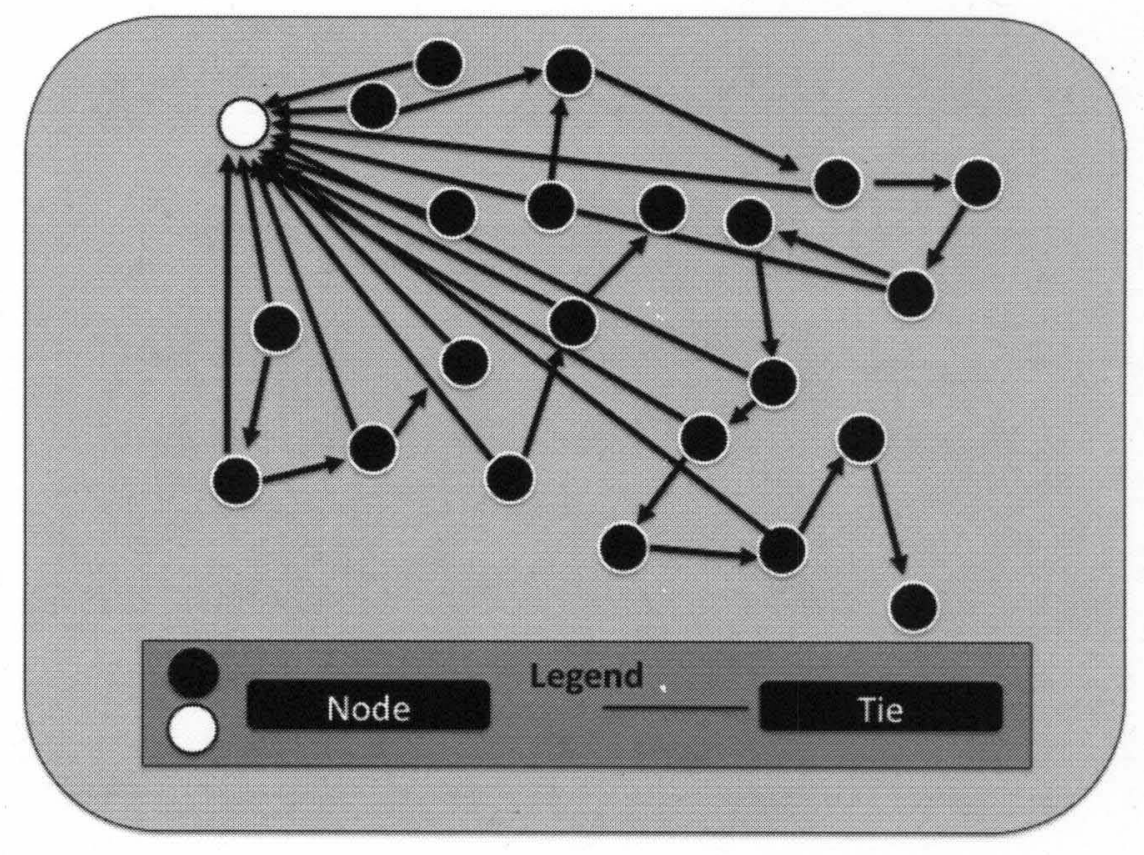

Figure 11a: Node with high in-closeness centrality 


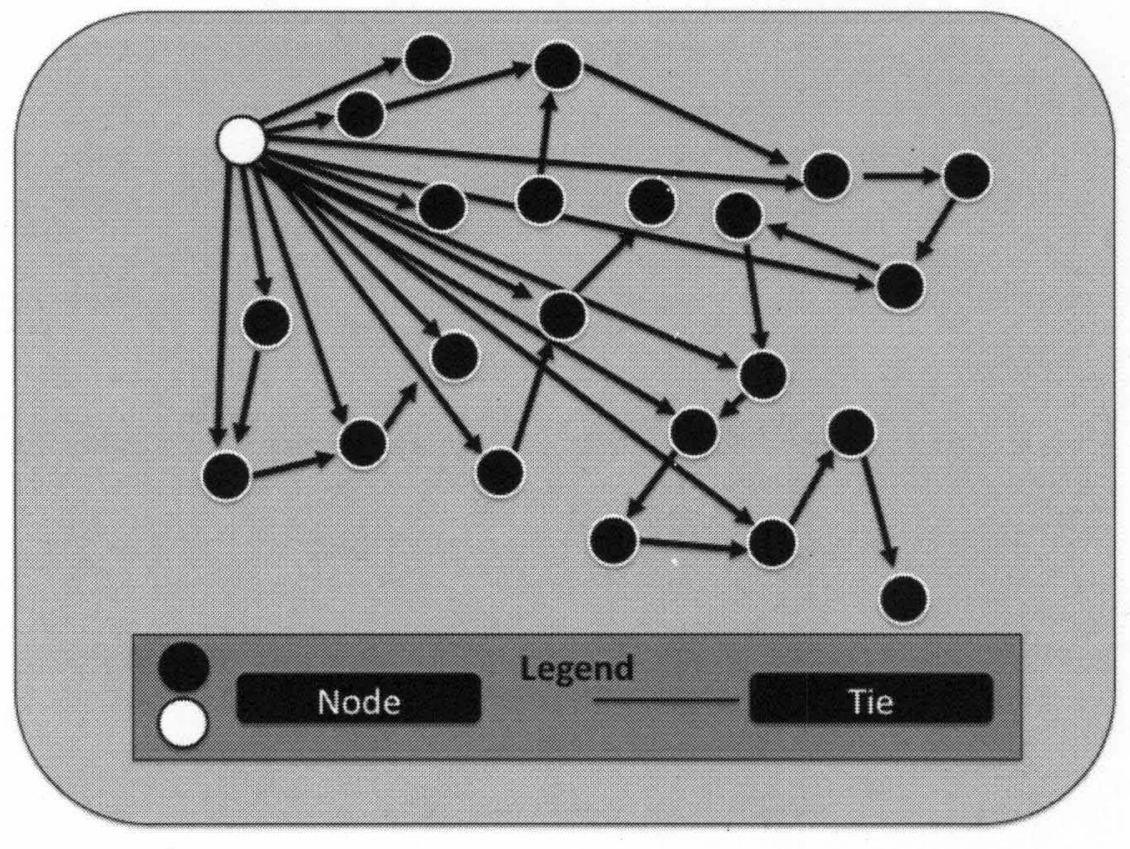

Figure 11b: Node with high out-closeness centrality

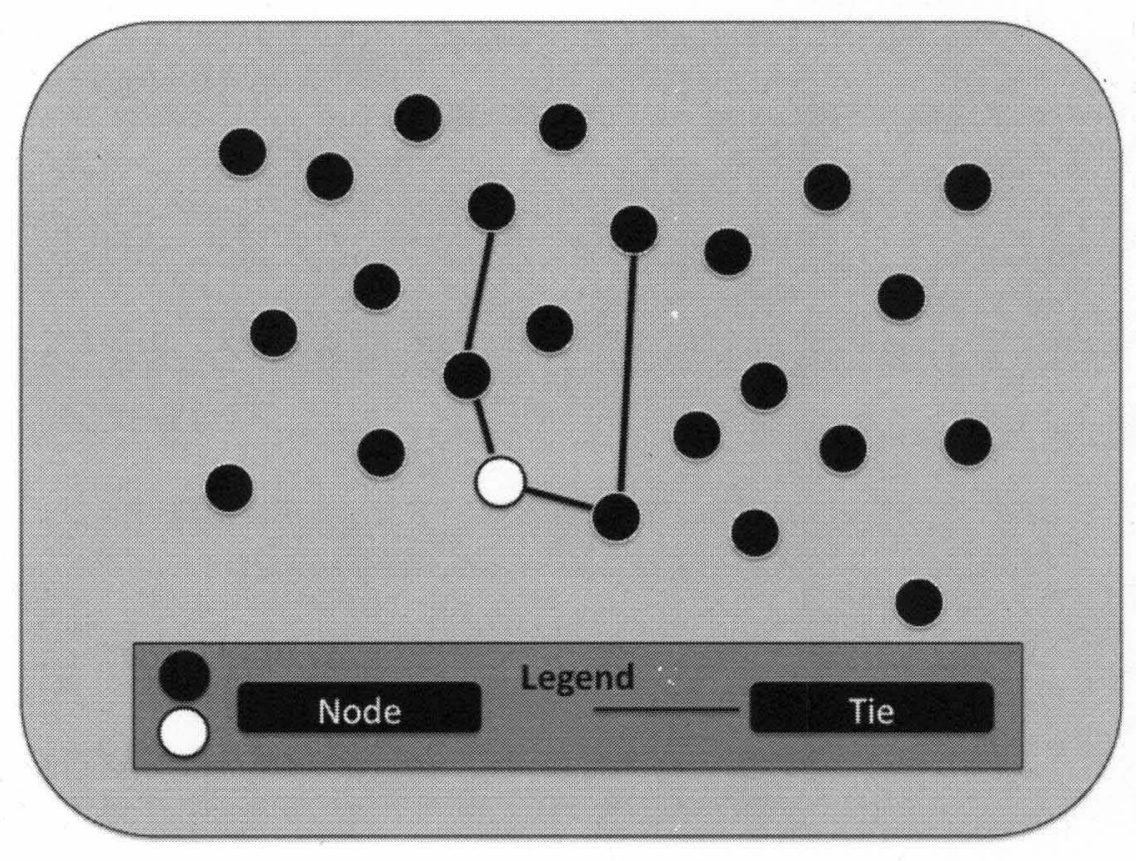

Figure 12a: Node with low eigenvector centrality 


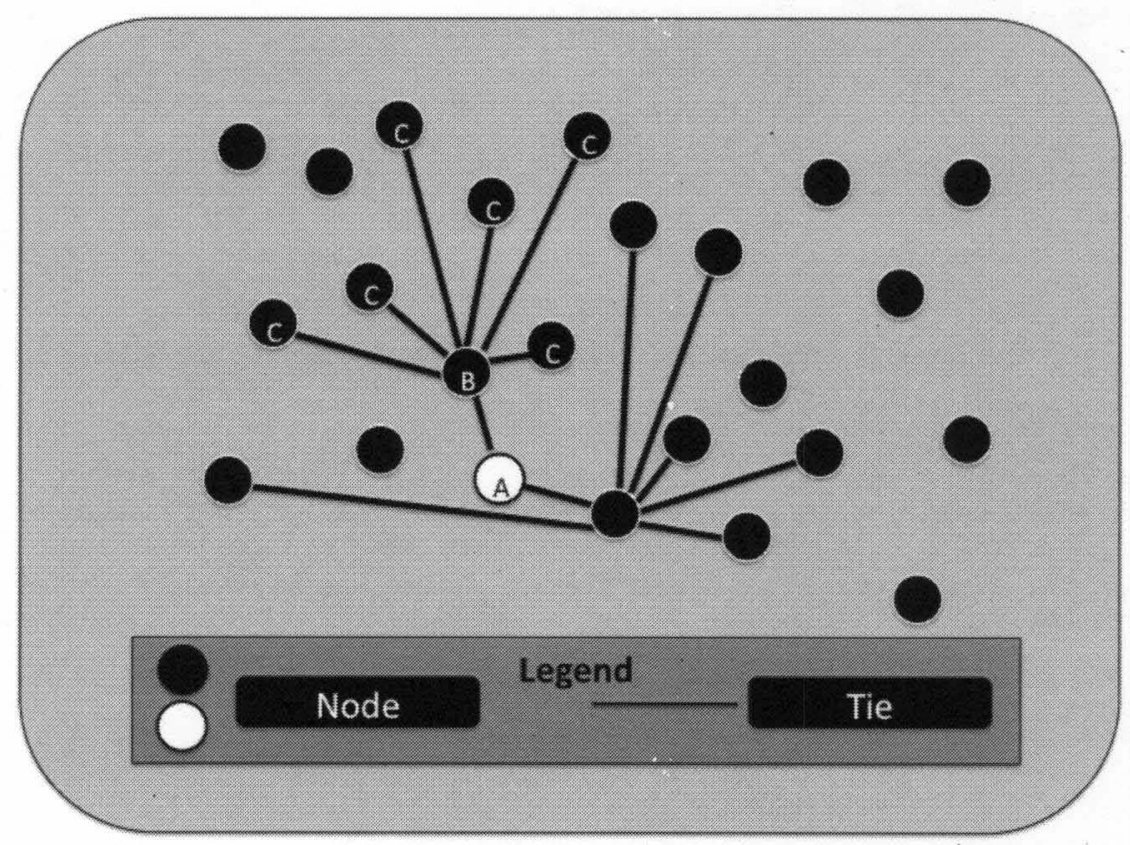

Figure 12b: Node with high eigenvector centrality 


\section{CHAPTER THREE}

\section{Methods}

In order to elicit the knowledge-sharing networks of hospital-based infection preventionists (IP) in Kentucky, an internet-based survey instrument was administered. The University of Louisville Institutional Review Board approved the study prior to data collection to ensure privacy and protection of all data collected and respondents.

Design and Population

A whole network approach was used for this project (Haythornthwaite, 1996; Knoke \& Yang, 2008, p. 16). The whole network approach surveys all potential members of a network and is ideal for eliciting knowledge-sharing networks as opposed to an ego network approach which focuses only on one individual and their respective network connections. As this study did not focus on a single individual, but rather all of the individuals within a specified boundary, the whole network approach was chosen (O'Malley \& Marsden, 2009). As described previously, only hospital-based IPs were surveyed.

Inclusion criteria

To be considered a potential member of the hospital-based IP network and receive the survey instrument, the following criteria must have been met: 
1. Employed in a hospital setting in Kentucky at the time of survey deployment.

2. Job title of infection preventionist or infection prevention and control responsibilities included in the job description.

3. E-mail address available from either the Association for Professionals in Infection Control (APIC) Kentucky website (Association for Professionals in Infection Control Kentucky Chapter, 2010), the Kentucky Hospital Association (KHA) (Kentucky Hospital Association, 2009), or direct contact with the hospital.

All subjects meeting the inclusion criteria were invited to participate through an e-mail including the internet-based survey instrument.

\section{Exclusion criteria}

1. Upon analysis of the data, participants with less than $20 \%$ of daily duties devoted to infection prevention were excluded from further analysis.

Survey Instrument and Procedures

An internet-based network survey eliciting information regarding knowledge-sharing networks within the field of infection prevention was utilized. The instrument was based on a similar instrument designed by Harris and Clements (2007), following recommendations set forth by Vehovar and colleagues (Vehovar, Manfreda, Koren, \& Hlebec, 2008).

The survey instrument included general demographic and work-related questions including: age, gender, race/ethnicity, job title(s), number of years in current position, number of years in infection prevention prior to the current 
position, and percentage of daily time devoted to infection prevention. The survey also included questions regarding the use of various modes for knowledge sharing and acquisition. Network and knowledge sharing-related questions were roster-based. The roster allowed the participant to choose the other hospital-based IPs they shared knowledge with (giving and receiving) from a list of all possible network members (Knoke \& Yang, 2008, p. 23). Finally, ordinally scaled measures of how often knowledge is shared with other IPs: daily, weekly, monthly, quarterly, yearly, or never.

Further questions elicited the number of network members from which the IP asked for knowledge from and provided knowledge to in a typical week with regard to work-related activities as well as information regarding use of electronic means of networking. A copy of the network survey instrument can be found in Appendix A.

Although the survey instrument had not been validated, methods for validation of network survey instruments are not well described. To maximize internal validity of the survey instrument, only minor modifications were made to an instrument previously used to elicit systems of connections between Emergency Preparedness Coordinators (Harris \& Clements, 2007). Furthermore, suggestions on network survey development provided in the literature (Vehovar, et al., 2008) were utilized to influence validity. Finally, the survey instrument was pilot tested in a sample of five IPs to ensure that the questions were understandable and measured what was intended. The pilot test 
included completion of the survey by the IP and a follow-up discussion to clarify any issues.

The internet-based survey was created on http://www.zoomerang.com and e-mailed to all identified hospital-based IPs meeting inclusion criteria of the study. Seven days post introduction of the survey, a follow-up email was sent to all IPs inviting them to complete the survey. Fourteen and twenty-one days post introduction of the survey, IPs who had not yet filled out the survey were telephoned to invite them to complete the survey. The survey was closed thirty days after introduction.

Statistical Analysis

Descriptive analysis of respondents

This survey instrument provided the necessary information to test each of the hypotheses. Demographic information from the survey was compiled into a table along with summary statistics describing the overall network. SAS version 9.2 (SAS Inc, Cary, NC) was used for all descriptive statistics excluding the calculations of those that were social network-specific. Numbers and percentages were calculated for categorical variables and means/medians with standard deviations/interquartile ranges were calculated for continuous variables. To determine if the mean with a standard deviation or a median with the interquartile range should have been presented, the Anderson-Darling statistic was calculated to assess for distribution normality. P-values of $<0.05$ were considered statistically significant to reject the null hypothesis that the data was normally distributed. Normally distributed variables were then presented as 
mean $\pm S D$ and non-normally distributed variables were presented as median \pm interquartile range.

Descriptive analysis of knowledge-sharing networks

Each research question and hypothesis is shown below with a description of the statistical analysis utilized.

R1: What is the structure of knowledge-sharing networks among hospitalbased infection preventionists in Kentucky?

H1: Knowledge-sharing networks among IPs in Kentucky hospitals consist of multiple components.

Statistical Analysis 1: Data from the knowledge-sharing survey of hospital-based IPs in Kentucky was inputted into Microsoft $\circledast$ Excel and imported into UCINET/NETDRAW software for social network analysis (Borgotti, 2009). UCINET is a computer software program created by Dr. Steven Borgotti at the University of Kentucky and is commonly used for social network calculations. The NETDRAW software was also developed by Dr. Borgotti and is used to create sociograms using various algorithms such as the Fruchterman and Reingold spring embedding algorithm described in Chapter 2. Directed sociograms were drawn to visually depict potential knowledge-sharing networks among hospital-based IPs. Nodes represented individual IPs completing the study. Connections between each node represented directional knowledge sharing between the individuals. Directed sociograms incorporated the direction of knowledge sharing, whether it be asking for knowledge or providing knowledge. 
After creation of the sociogram, the visual depiction of connections between nodes indicated the existence of knowledge-sharing networks within this group. Component analysis was used to determine the number of components of the network. The shapes of nodes within each component were modified based on the component to which the node belonged.

R2: How dense are the components and what are the measures of centrality for IPs in knowledge-sharing networks in Kentucky hospitals? H2: Knowledge-sharing networks among IPs in Kentucky hospitals consist of low-density components and nodes with low centrality.

Statistical Analysis 2: Data from the knowledge-sharing survey of hospital-based IPs in Kentucky was inputted into Microsoft $\circledast$ Excel and imported into UCINET/NETDRAW software (Borgotti, 2009) for social network analysis. As described above, sociograms were created in NETDRAW. Network density and four measures of network centrality were calculated using NETDRAW: in- and out-degree centrality, betweenness centrality, and eigenvector centrality. For each sociogram, isolates, or those members who were not connected to anyone else, were removed from analysis to ensure measures of centrality were properly calculated (Knoke \& Yang, 2008, p. 65).

Component analysis was used to determine the number of components of the network. Network density measures were calculated for each component and overall in order to provide a measure of the proportion of connections present versus those that could be present; indicating an overall index of network 
connectedness. Low density networks were considered to be below $50 \%$ (lowest half of density measures).

An examination of differences in network centrality based on demographic characteristics of the population such as gender, age group, race, and hospital size was performed. As all centrality measures consist of continuous data, it was first necessary to determine if they were normally distributed prior to selecting the appropriate statistical tests. The Anderson-Darling statistic was used to assess for distribution normality. P-values of $<0.05$ were be considered statistically significant to reject the null hypothesis that the data are normally distributed. For normally distributed variables, the student's t-test or one-way ANOVA with Tukey's Post-Hoc analysis was used to assess differences in dichotomous and multi-category variables, respectively. $\mathrm{P}$-values of $<0.05$ were considered statistically significant to reject the null hypothesis that the mean centrality measures were the same for each group. For non-normally distributed variables, the Mann-Whitney U-test or the Kruskal-Wallis one way ANOVA were used to assess for differences in dichotomous and multi-category variables, respectively. P-values of $<0.05$ were considered statistically significant to reject the null hypothesis that the median centrality measures were the same for each group. SAS v9.2 was used for all non-social network analyses.

R3: Are there key players in knowledge-sharing networks among infection preventionists in Kentucky hospitals?

H3: Three meaningful key players will be present in knowledge-sharing networks among infection preventionists in Kentucky hospitals. 
Statistical Analysis 3: To identify key players in the network, data from the knowledge-sharing survey of hospital-based IPs in Kentucky was inputted into Microsoft $\circledast$ Excel and imported into Key Player 1 software (Borgotti, 2009) for analysis. The Key Player 1 computer software is included with the UCINET/NETDRAW package and was also developed by Dr. Borgotti. Key players were found using fragmentation and reach algorithms described by Borgotti (2006). The fragmentation option examines the chosen nodes to see if they can maximally disrupt the network. As described by Borgotti (2006), disruption of the network includes not only maximizing the number of components created by removing the node, but also creating equal sized components. The reach algorithm examines the network in terms of how many other nodes can be contacted by the key player node. Each algorithm uses a greedy approach which was shown by Borgotti (2006) to be an appropriate method of node selection. Greedy algorithms work through iterative examination of nodes to arrive at the optimal solution to the problem without re-examination of previous choices (Cormen, 2009). If an optimal choice is not found, a different starting point is chosen and the algorithm continues until the optimal choice is found. Through identifying nodes that, if removed, maximize network fragmentation, determination of nodes that hold important positions within the knowledge-sharing network were identified. Removal of these nodes would disrupt the network in such a way that knowledge could no longer be readily shared through the network. Through identification of nodes that can reach the maximal number of other nodes, key players that can be utilized for points of 
distribution of knowledge can be found. The Key Player 1 software allows for specification of the number of key players the analyst would like to identify. Therefore, beginning with the default value of 3 nodes, consecutive analyses were conducted to identify the fragmentation and reach of various numbers of key players. When the next highest number of key players did not increase the fragmentation or reach of the network by at least $10 \%$, the number of key players was identified. A meaningful key player was defined as a key player within a component with a density of at least $25 \%$.

R4: What is the role of geography in the network connections within knowledge-sharing networks of IPs in Kentucky hospitals?

H4: The knowledge-sharing network of hospital-based infection preventionists in Kentucky will be separated into three major components based on the three APIC regions of Kentucky.

Statistical analysis 4: Data from a knowledge-sharing survey of hospital-based IPs in Kentucky was inputted into Microsoft@ Excel and imported into NETDRAW software (Borgotti, 2009) for social network analysis. Nodes were geocoded using decimal degree measures based on the zip code of employment. The decimal degrees of the location of IP employment were derived from Google® Earth software (Google, 2010). A table consisting of three columns (one for the ID number, one for latitude decimal degree, and one for longitude decimal degree) was created and imported into NETDRAW for the creation of a sociogram. The sociogram was resized and overlaid onto a map of Kentucky with delineations of APIC regions. Network components were identified as a 
group of nodes that were completely connected to one another and not connected to other components (maximally connected subgraph), utilizing the component analysis in NETDRAW (Borgotti, 2009). Shapes of the nodes within each component were modified for ease of visual identification. 


\section{CHAPTER FOUR}

\section{Results}

The results of this study are presented in five sections: a description of the study sample and descriptions of the results of each of the four research questions examined. Only results of the study are presented in this chapter and all discussion and implications are reserved for Chapter 5 .

All completed surveys were analyzed with SAS version 9.2 (SAS Inc., Cary, NC), UCINET, NETDRAW, and KeyPlayer1 (Borgotti, 2009), as previously described. The author of this dissertation performed all statistical analysis. The survey was closed 30 days after deployment.

\section{Description of the Study Sample}

A total of 130 unique infection preventionists (IPs) were identified in Kentucky hospitals. Seventy-five of the IPs responded to the survey for a final response rate of $58 \%$. As depicted in Figure 13, there appeared to be an even distribution of responders and non-responders throughout the state. A total of seven IPs indicated that their efforts toward the practice of infection prevention were less than one day per week and were dropped from subsequent analysis. Therefore, the final sample size for analysis was 68 unique respondents. As it was possible for an IP who completed the survey to select another IP who did not complete the survey, the total number of nodes available for social network 
analysis was higher than the total response rate $(n=110)$. Table 2 describes the overall demographic characteristics of the respondents. The majority of the respondents were in the $26-45$ year age group (37\%), followed by the $56-65$ year age group (32\%). Most of the respondents were female (96\%), white (88\%), had completed a baccalaureate degree (46\%), members of APIC $(96 \%)$, with $43 \%$ belonging to one particular APIC chapter (Bluegrass). Less than half $(40 \%)$ of the respondents were certified in infection control by the Certification Board of Infection Control (CBIC). The majority of respondents had been in their current position for more than 10 years $(31 \%)$, and had had a career in infection prevention for more than 10 years (59\%). Acute care facilities were the highest reported facility type (74\%), and 17 respondents (25\%) reported affiliation with an academic center. Nearly half $(41 \%)$ of respondents reported use of the National Healthcare Safety Network (NHSN) for reporting infection data to the Centers for Disease Control and Prevention.

Eight IPs were identified who had no incoming or outgoing connections. These isolates did not differ from non-isolates on any demographic information with the exception of university affiliation. Isolates were more likely to have a university affiliation than non-isolates $(71 \%$ vs. $23 \%, P=0.01)$.

Table 2: Demographic and employment characteristics of hospital-based infection preventionists in Kentucky

\begin{tabular}{ll}
\hline Variable & n (\%)
\end{tabular}

Age Group 
Variable

\section{Variable}

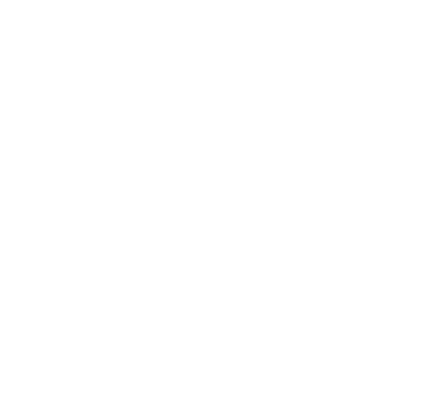

Female Gender

Race/Ethnicity
$18-25 \quad 0(0.0)$

$26-4525(36.8)$

46-55 $21(30.9)$

$56-65 \quad 22(32.4)$

$>65 \quad 0(0.0)$

65 (95.6)

$$
\begin{array}{rc}
\text { Black/African American - Non-Hispanic } & 1(1.5) \\
\text { White/Caucasian - Non-Hispanic } & 60(88.2) \\
\text { Black/African American - Hispanic } & 0(0.0) \\
\text { White/Caucasian - Hispanic } & 7(10.3) \\
\text { Asian } & 0(0.0) \\
\text { Other } & 0(0.0)
\end{array}
$$

Education

\author{
Some College (No Degree) $2(3.0)$ \\ 2 Year College (Including RN) 20 (29.4) \\ 4 Year College 31 (45.6) \\ Some Post-graduate Education 5 (7.4) \\ Master's Degree $9(13.2)$ \\ Doctoral Degree (MD, PhD, etc.) $0(0.0)$ \\ Professional Degree (ARNP, PA, etc.) 1 (1.5)
}


Variable

CIC Certification

APIC Member

APIC Chapter n (\%)

$27(39.7)$

65 (95.6)

$$
\begin{aligned}
\text { Bluegrass } & 29(42.7) \\
\text { Kentuckiana } & 19(27.9) \\
\text { Western Kentucky } & 14(20.6) \\
\text { Do not belong to a chapter } & 3(4.0) \\
\text { Not an APIC Member } & 3(4.0)
\end{aligned}
$$

Regular APIC Meeting Attendance

Time in Current Position

$$
\begin{array}{rr}
\text { Less than } 1 \text { Year } & 7(10.3) \\
1-2 \text { years } & 12(17.7) \\
3-5 \text { years } & 15(22.1) \\
6-10 \text { Years } & 13(19.1) \\
\text { More than } 10 \text { Years } & 21(30.9)
\end{array}
$$

Daily Efforts in Infection Prevention

$$
\begin{array}{rr}
20 \%-50 \% & 21(30.9) \\
\text { More than } 50 \% \text { but less than } 100 \% & 20(29.4) \\
100 \% & 27(39.7)
\end{array}
$$

Length of Career in Infection Prevention

$$
\text { Less than } 1 \text { Year } 1(1.5)
$$


Variable

Variable

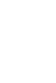


Table 3: Knowledge sharing and seeking behavior of hospital-based infection preventionists in Kentucky

Provide Knowledge to Contacts

Ask for Knowledge from Contacts
Daily $5(7.4)$

Weekly $12(17.7)$

Monthly $23(33.8)$

Quarterly $17(25.0)$

Yearly $11(16.2)$

Table 4: Knowledge sharing behavior of hospital-based infection preventionists in Kentucky with personnel other than hospital-based infection preventionists in Kentucky

\begin{aligned} & \hline Weekly Knowledge Sharing with Non-Kentucky IPs $\mathbf{n}(\%) \\ &$ None $28(41.2) \\ & 1-2$ People $20(29.4) \\ & 3-5$ People $6(8.8) \\ &$\hline\end{aligned}




\title{
Weekly Knowledge Sharing with Non-IPs
}

\author{
None $3(4.4)$ \\ 1-2 People $15(22.1)$ \\ 3-5 People 17 (25.0) \\ 6-10 People $9(13.2)$
}

More than 10 People 24 (35.3)

Table 5 outlines the methods for gaining knowledge among respondents.

The most common methods included governmental or organizational websites $(88 \%)$, reading the scientific literature (79\%), and E-mail communication $(78 \%)$.

Few respondents had mentors (24\%), attended in-person training courses (15\%), or obtained information from the popular press $(5 \%)$.

Table 5: Knowledge sources for hospital-based infection preventionists in Kentucky

\begin{tabular}{rr}
\hline Variable & $\mathbf{n}(\%)^{*}$ \\
\hline Face to Face & $27(40.3)$ \\
E-mail & $52(77.6)$ \\
Virtual Meetings & $15(22.4)$ \\
In-person Training & $10(14.9)$ \\
\hline
\end{tabular}


Web-based Training $30(44.8)$

Reading Literature 53 (79.1)

Mentorship $16(23.9)$

Government/Organizational Websites 59 (88.1)

Popular Press 3 (4.5)

"Number and percent indicating "often" or "always"

\section{Research Question \#1}

What is the structure of knowledge-sharing networks among hospitalbased infection preventionists in Kentucky?

\section{Hypothesis \#1}

Knowledge-sharing networks among IPs in Kentucky hospitals consist of multiple components.

Figure 14 depicts the directed sociogram of the knowledge-sharing network of IPs in Kentucky hospitals. Figure 15 shows the same network indicating the components within the network. Three components were found within the network. One component had 94 nodes (398 ties), the second had 6 nodes (12 ties) and the third had 2 nodes ( 1 tie). Three different node shapes (hourglass, triangle, and square) were used to indicate the three different components. Nodes with the same shape belong to the same component. Hypothesis \#1 is supported by these results. 


\section{Research Question \#2}

How dense are the components and what are the measures of centrality for IPs in knowledge-sharing networks in Kentucky hospitals?

\section{Hypothesis \#2}

Knowledge-sharing networks among IPs in Kentucky hospitals consist of low-density components and nodes with low centrality.

As the number of ties in each component decreased, the density increased. Of the three components identified, the largest component (398 ties) had a density of $2.3 \%$, the next largest component (14 ties) had a density of $47 \%$, and the smallest component ( 1 tie) had a density of $50 \%$.

Centrality measures were calculated and examined for distribution normality using the Anderson-Darling test. All measures were found to be nonnormally distributed $(p>0.05)$ and are therefore presented as medians and ranges. Table 6 depicts these values for each of the centrality measures calculated.

Table 6: Network centrality measures for hospital-based infection preventionists in Kentucky

\begin{aligned} & \hline Centrality Measure Median (Range) \\ & \hline In-degree $2(0-11) \\ &$ Out-degree $0.5(0-5) \\ &$ Betweenness $0.0(0.00-567.17) \\ &$ Eigenvector $0.02(0-0.45) \\ &$\hline\end{aligned}


Figures 16-19 depict histograms of each centrality measure. The median out-degree centrality (4.0) was higher than the median in-degree centrality (1.5). Most of the betweenness centrality measures were low, as were the eigenvector centralities. Table 7 outlines selected demographic information of the IP with the highest centrality measures. One IP had the highest in-degree, betweenness, and eigenvector centrality. This IP was tied with twenty-nine other IPs for the highest out-degree centrality; therefore demographics of IPs with the highest outdegree statistics are not presented in Table 7.

Table 7: Selected demographic information for hospital-based infection preventionists in Kentucky with the highest in-degree, betweenness, and eigenvector centrality measures

\section{Variables}

46-55 Years Old

Post-graduate Education

CIC Certified

APIC Member

Bluegrass APIC Chapter

Practicing infection prevention $>5$ Years

NHSN User

Sharing knowledge with 5-10 non-Kentucky IPs per Week

Sharing knowledge with $>10$ non-IPs per Week 
Centrality measures for each node were examined for statistical differences between each demographic characteristic. Respondents with higher in-degree centrality measures were less likely to be in the $26-45$ year-old age category $(z=2.88, p=0.004)$. These respondents were also more likely to attend local APIC chapter meetings $(z=-1.96, p=0.049)$, have worked in their current position for over 5 years $(z=-2.39, p=0.017)$, and utilize the NHSN $(z=2.90$, $p=0.004$ ). Respondents with higher out-degree centrality measures were more likely to have worked in their current position for over 5 years $(z=-2.31, p=0.021)$ and less likely to be affiliated with a university $(z=-1.98, p=0.047)$. Respondents with higher betweenness centrality measures were more likely to be in the $46-55$ year old age category $(z=-3.77, p<0.001$ versus $26-45$ year old; $z=2.53, p=0.011$ versus 56-65 year old). Respondents with a higher eigenvector centrality measure were found to be more likely to regularly attend local APIC chapter meetings $(z=-2.11, p=0.034)$, have worked in their current position for over 5 years $(z=-2.40, p=0.016)$, and be in the Kentucky Bluegrass APIC chapter $(z=-$ 5.06, $p<0.001$ versus Kentuckiana chapter; $z=-4.11, p<0.001$ versus Western Kentucky chapter).

Hypothesis \#2 is partially supported by these results. The densities of the components were relatively low as were the centrality measures.

\section{Research Question \#3}

Are there key players in knowledge-sharing networks among infection preventionists in Kentucky hospitals? 


\section{Hypothesis \#3}

Three meaningful key players will be present in knowledge-sharing networks among infection preventionists in Kentucky hospitals.

Three key players were found in the fragmentation analysis and three key players were found in the reach analysis. In the fragmentation analysis, the fragmentation index increased less than $10 \%$ ( 0.60 to $0.643,7.2 \%$ increase) when analyzing 3 key players versus 4 . The node with the highest centrality values was not selected as a key player in the fragmentation analysis. In the reach analysis, the percent of nodes reachable increased less than $10 \%(67.3 \%$ to $72.7 \%, 8.0 \%$ increase) when analyzing 3 key players versus 4 . The node with the highest centrality measures was selected as one of the key players in the reach analysis. Figures 20 and 21 depict sociograms with key players highlighted (large, white triangles) for the fragmentation and reach analyses, respectively. The nodes in these sociograms have been geocoded to provide the actual location of nodes with regard to their facility of employment. Figure 22 depicts the sociogram with the fragmentation key players removed. Removal of these three key players increases the number of components to five. Table 8 describes the demographic information of key players in the fragmentation and reach analyses. Key players in both analyses were found in the largest component only, with a density of $2.3 \%$. 
Table 8: Selected demographic information of hospital-based infection prevention key players in Kentucky

\begin{tabular}{|c|c|c|}
\hline Variable & $\begin{array}{l}\text { Fragmentation } \\
\text { n (\%) }\end{array}$ & $\begin{array}{l}\text { Reach } \\
n(\%)\end{array}$ \\
\hline \multicolumn{3}{|l|}{ Age } \\
\hline $25-44$ & $0(0.0)$ & $1(33.3)$ \\
\hline $46-45$ & $1(33.3)$ & $1(33.3)$ \\
\hline $56-65$ & $2(66.7)$ & $1(33.3)$ \\
\hline \multicolumn{3}{|l|}{ Education } \\
\hline 2 Year Degree & $2(66.7)$ & $0(0.0)$ \\
\hline 4 Year Degree & $1(33.3)$ & $2(66.7)$ \\
\hline Some Post-graduate & $0(0.0)$ & $1(33.3)$ \\
\hline CIC Certification & $2(66.7)$ & $3(100)$ \\
\hline APIC Member & $3(100)$ & $3(100)$ \\
\hline \multicolumn{3}{|l|}{ APIC Chapter } \\
\hline Bluegrass & $2(66.7)$ & $1(33.3)$ \\
\hline Kentuckiana & $1(33.3)$ & $1(33.3)$ \\
\hline Western Kentucky & $0(0.0)$ & $1(33.3)$ \\
\hline Length of Time in Current Position $>10$ Years & $3(100)$ & $3(100)$ \\
\hline University Affiliation & $0(0.0)$ & $0(0.0)$ \\
\hline NHSN User & $1(33.3)$ & $3(100)$ \\
\hline
\end{tabular}


Hypothesis \#3 is not supported by these results. Although three key players were found, they were not in a component with a density of at least $25 \%$.

\section{Research Question \#4}

What is the role of geography in the network connections within knowledge-sharing networks of IPs in Kentucky hospitals?

\section{Hypothesis \#4}

The knowledge-sharing networks of hospital-based infection preventionists in Kentucky will be separated into three major components based on the three APIC chapter regions of Kentucky.

Geographic analysis of the nodes in the network indicates that although three components exist, they are not separated into three distinct geographic regions. The network components do not match any of the geographic layouts proposed in Chapters 1 and 2 (physical barriers or medical trade areas). Figure 23 depicts the sociogram separated into three components with geocoded nodes based on the facility of employment. Hypothesis \#4 is not supported by these results. Geographic analysis was also conducted to analyze the geospatial relationships between the knowledge-sharing network and hospital bed size (Figure 24). This analysis indicated that the majority of connections were between small facilities. The smaller components of the network were largely made up of medium-sized facilities. 


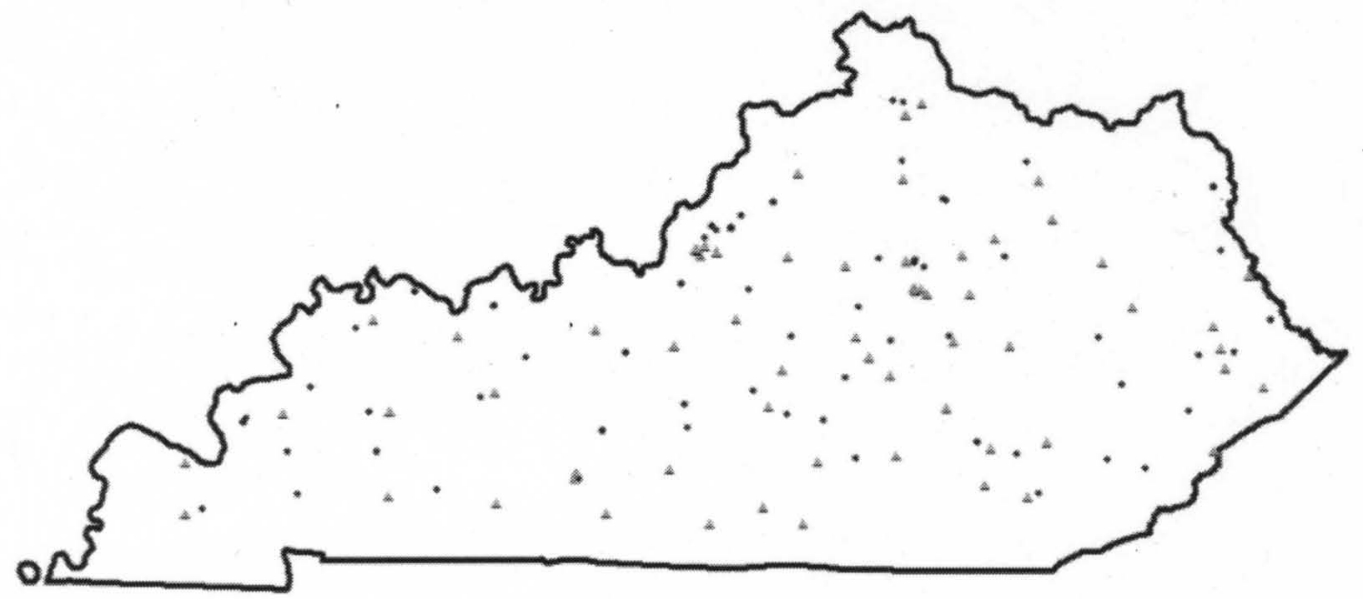

Figure 13: Geocoded location of survey respondents (gray triangles) and nonrespondents (black circles) in the knowledge-sharing network survey of hospitalbased infection preventionists in Kentucky.

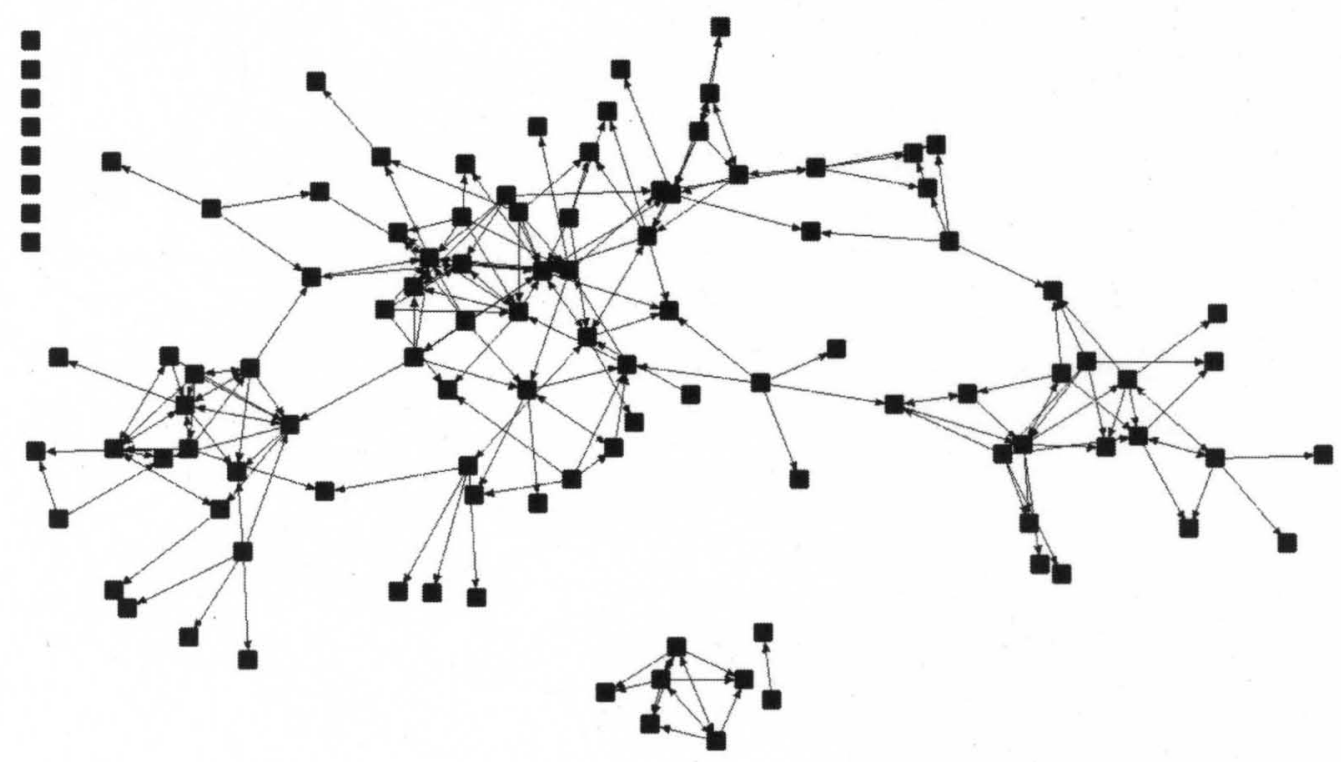

Figure 14: Sociogram of the knowledge-sharing network of hospital-based infection preventionists in Kentucky. 


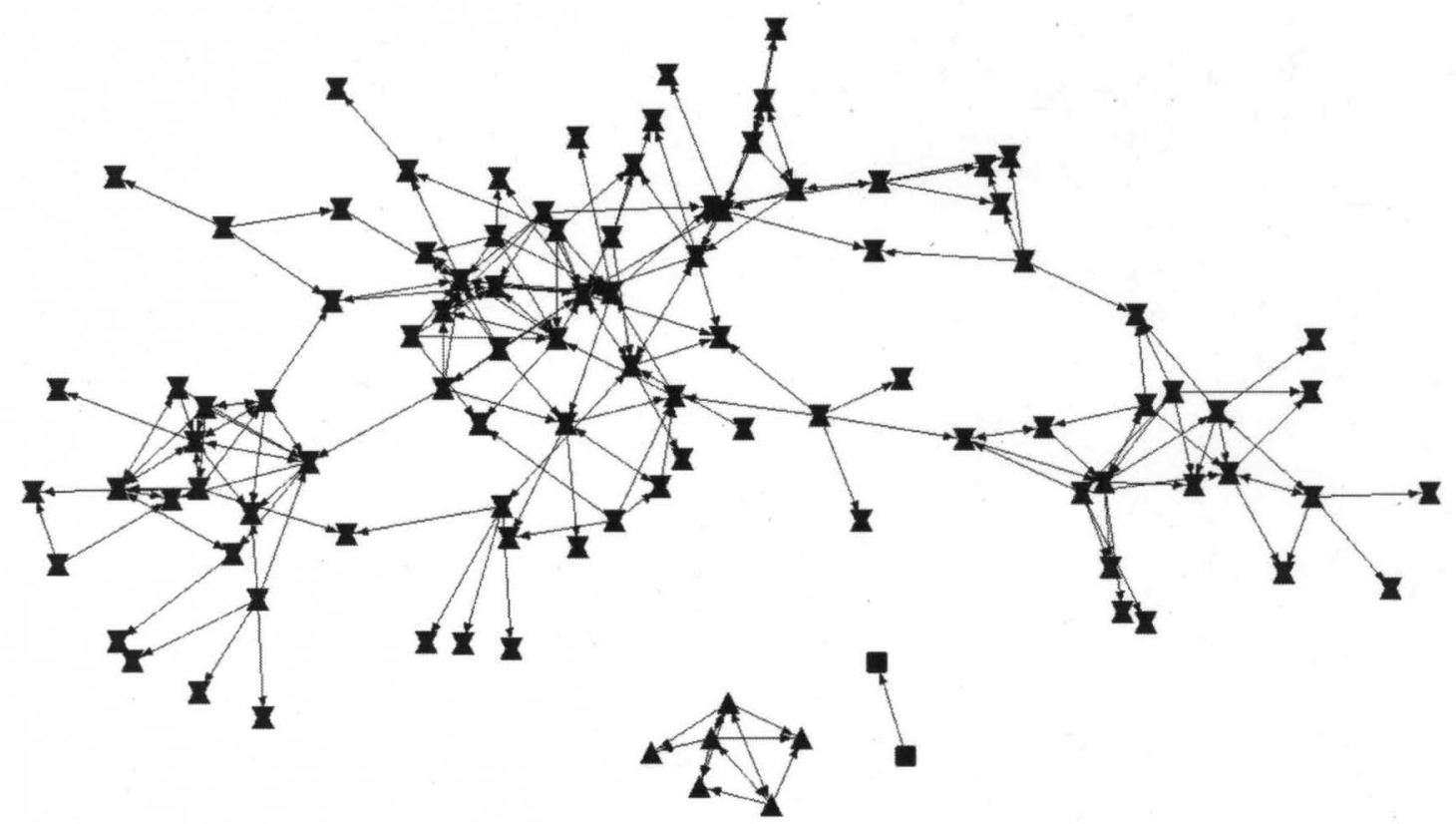

Figure 15: Component analysis of the sociogram of the knowledge-sharing network of hospital-based infection preventionists in Kentucky [components indicated by different shapes].

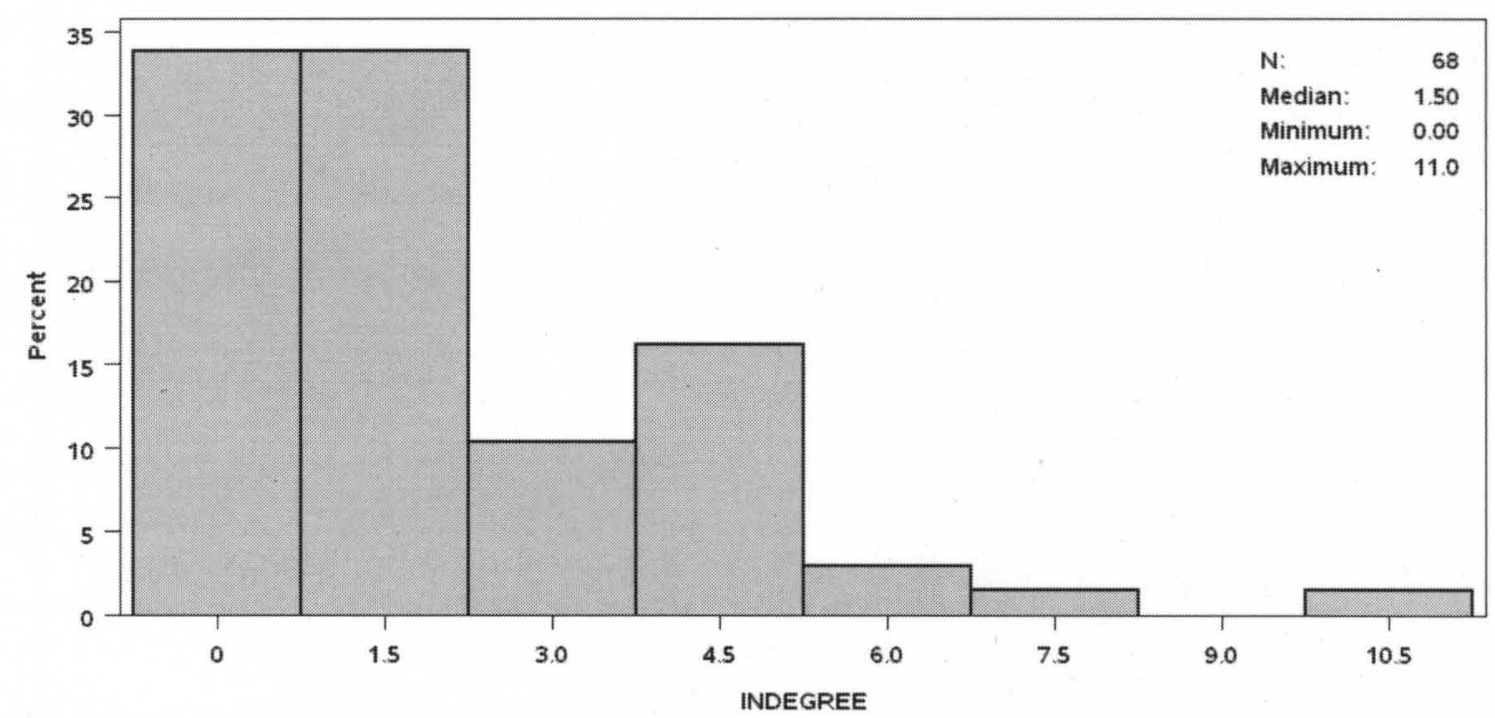

Figure 16: Histogram of the in-degree centrality measures for knowledgesharing network of hospital-based infection preventionists in Kentucky. 


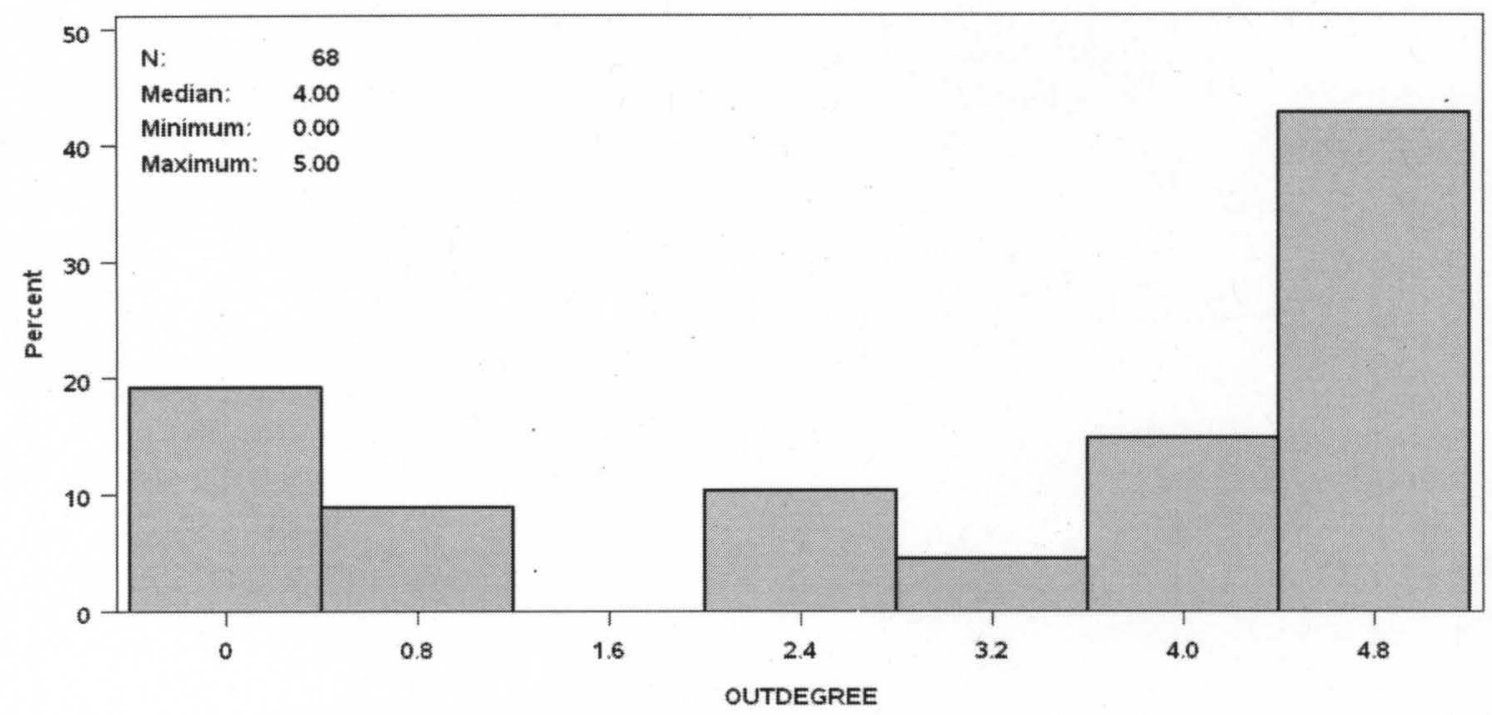

Figure 17: Histogram of the out-degree centrality measures for knowledgesharing network of hospital-based infection preventionists in Kentucky.

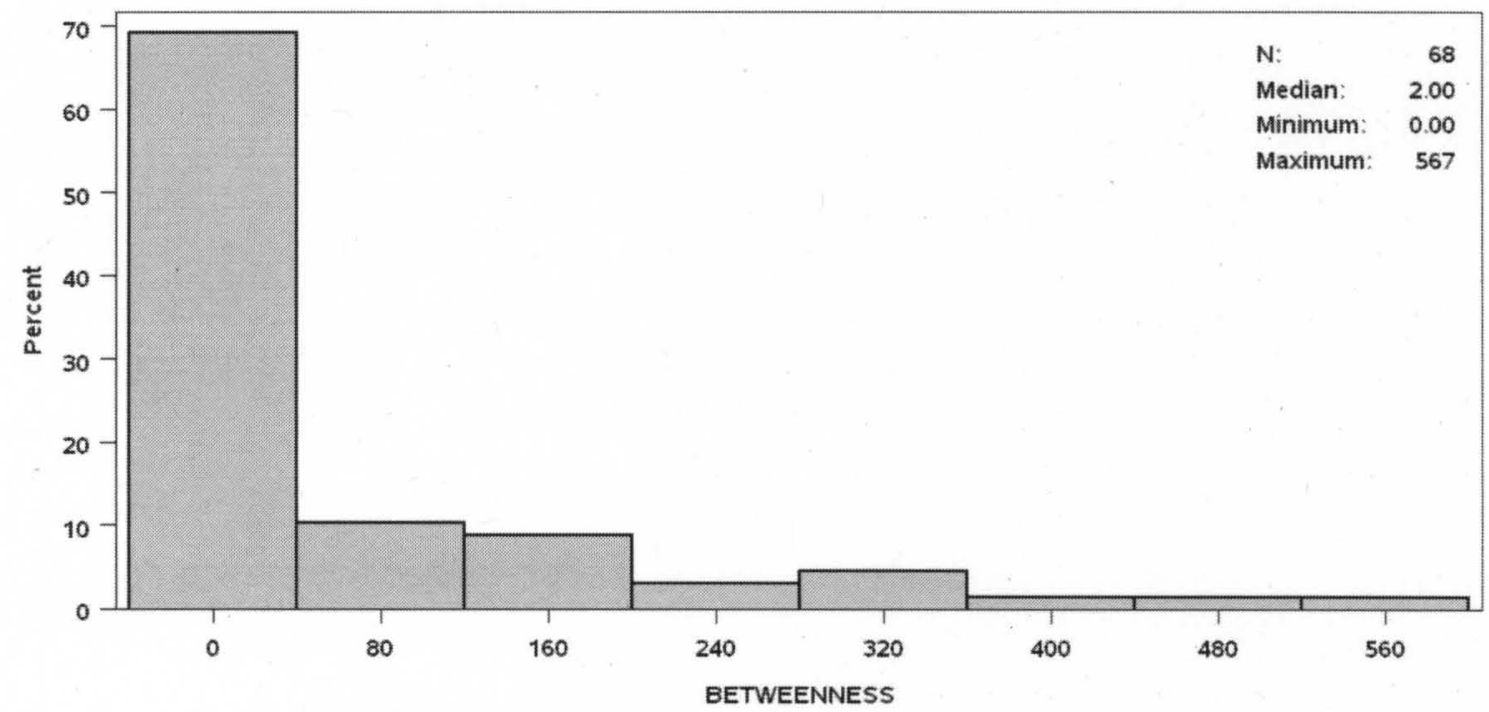

Figure 18: Histogram of the betweenness centrality measures for knowledgesharing network of hospital-based infection preventionists in Kentucky. 


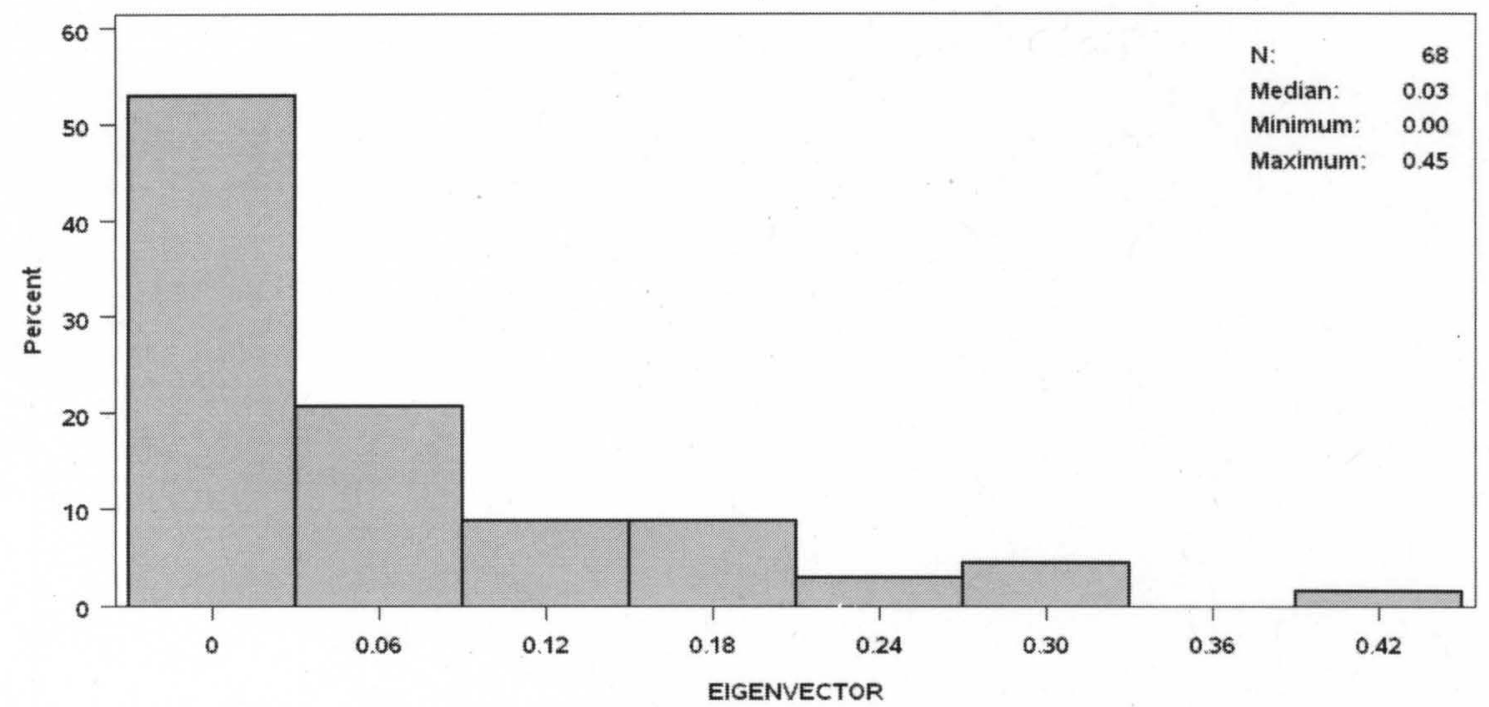

Figure 19: Histogram of the eigenvector centrality measures for knowledgesharing network of hospital-based infection preventionists in Kentucky.

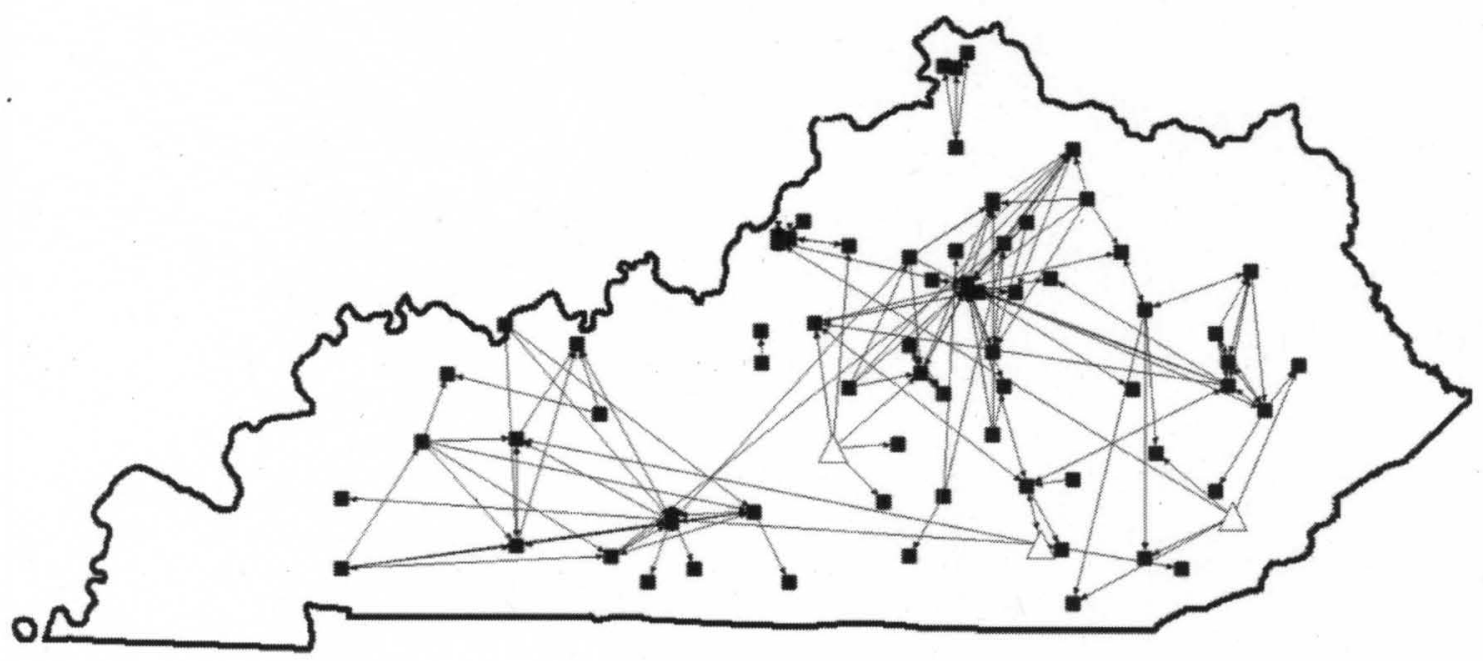

Figure 20: Sociogram of the fragmentation key players for knowledge-sharing network of hospital-based infection preventionists in Kentucky [key players are white triangles]. 


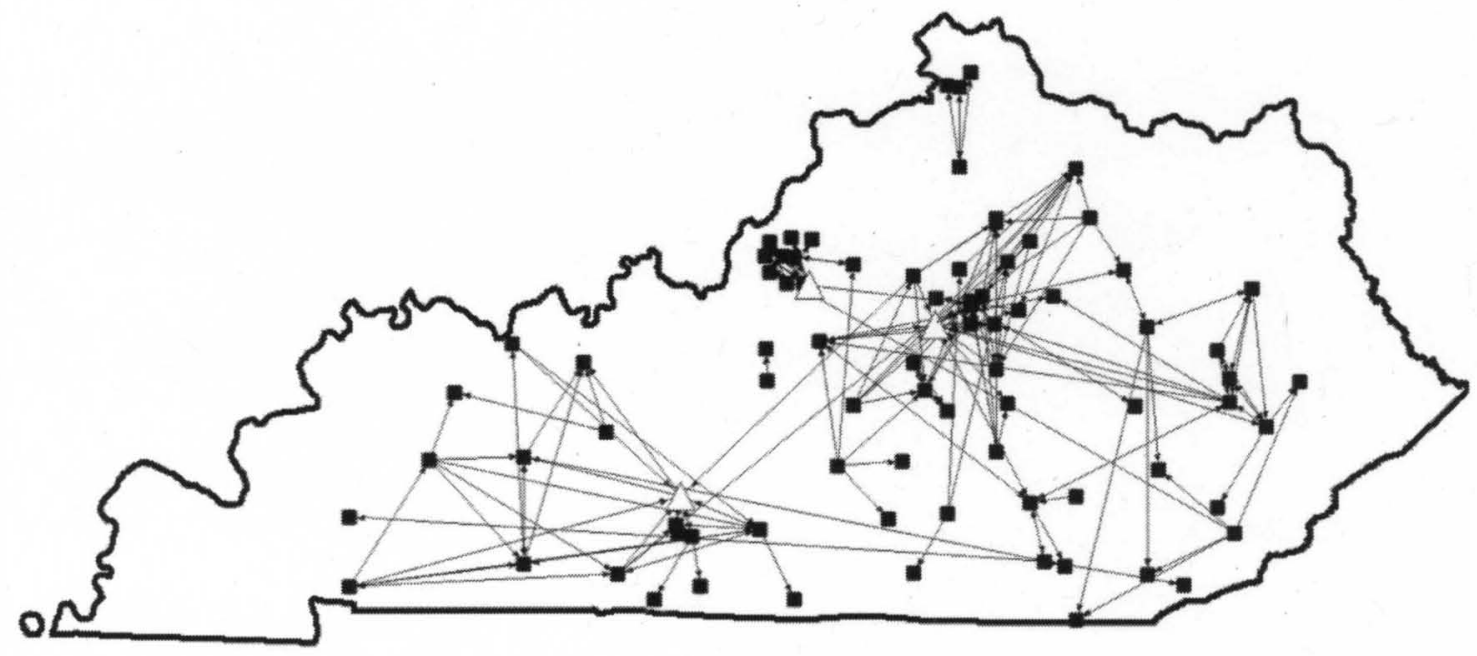

Figure 21: Sociogram of the reach key players for knowledge-sharing network of hospital-based infection preventionists in Kentucky [key players are white triangles].

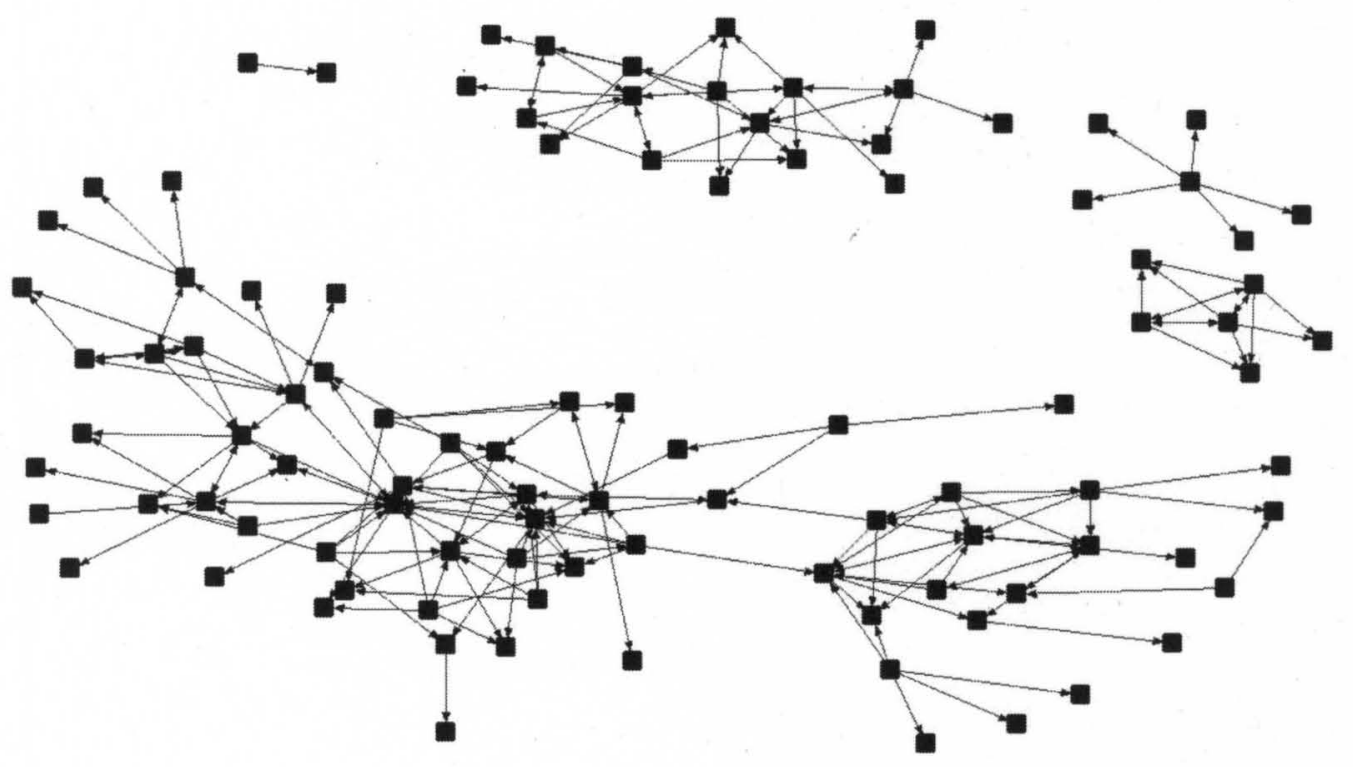

Figure 22: Sociogram of the knowledge-sharing network of hospital-based infection preventionist in Kentucky with three fragmentation key players removed. 


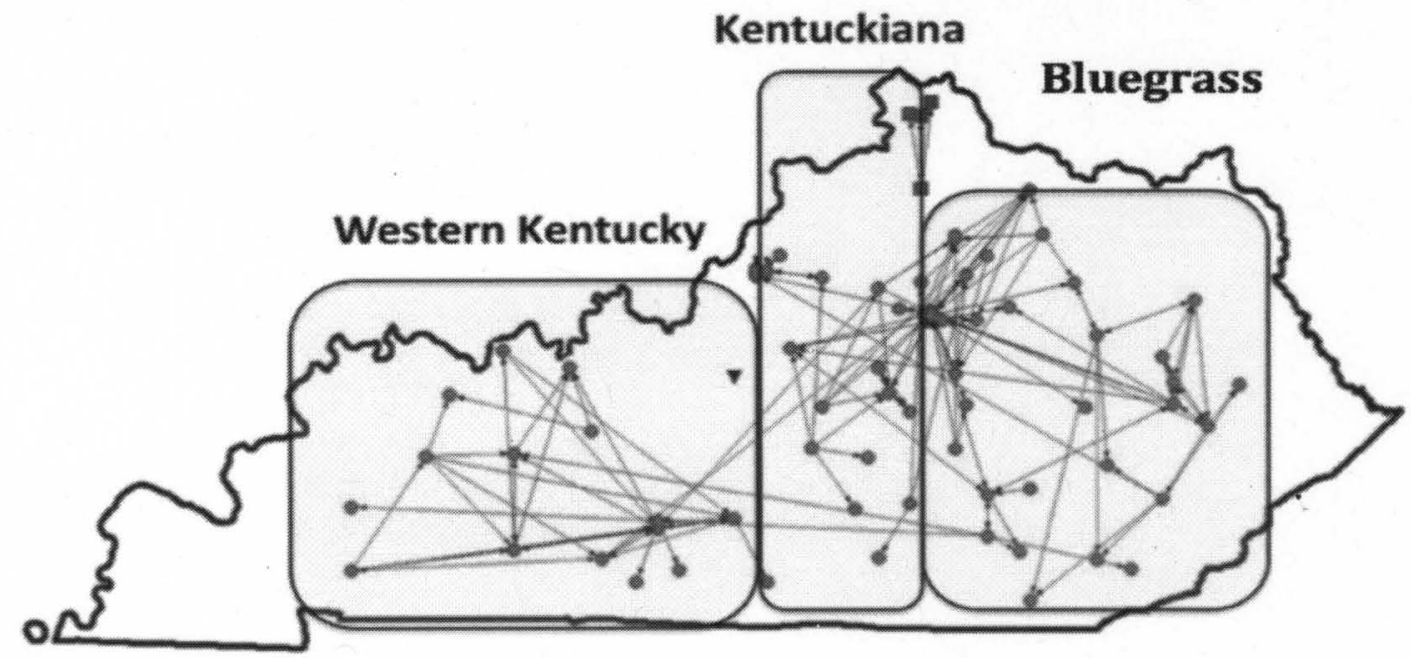

Figure 23: Geocoded component analysis sociogram of the knowledge-sharing network of hospital-based infection preventionists in Kentucky by APIC Chapter [components indicated by different shapes, square, circle, and triangle].

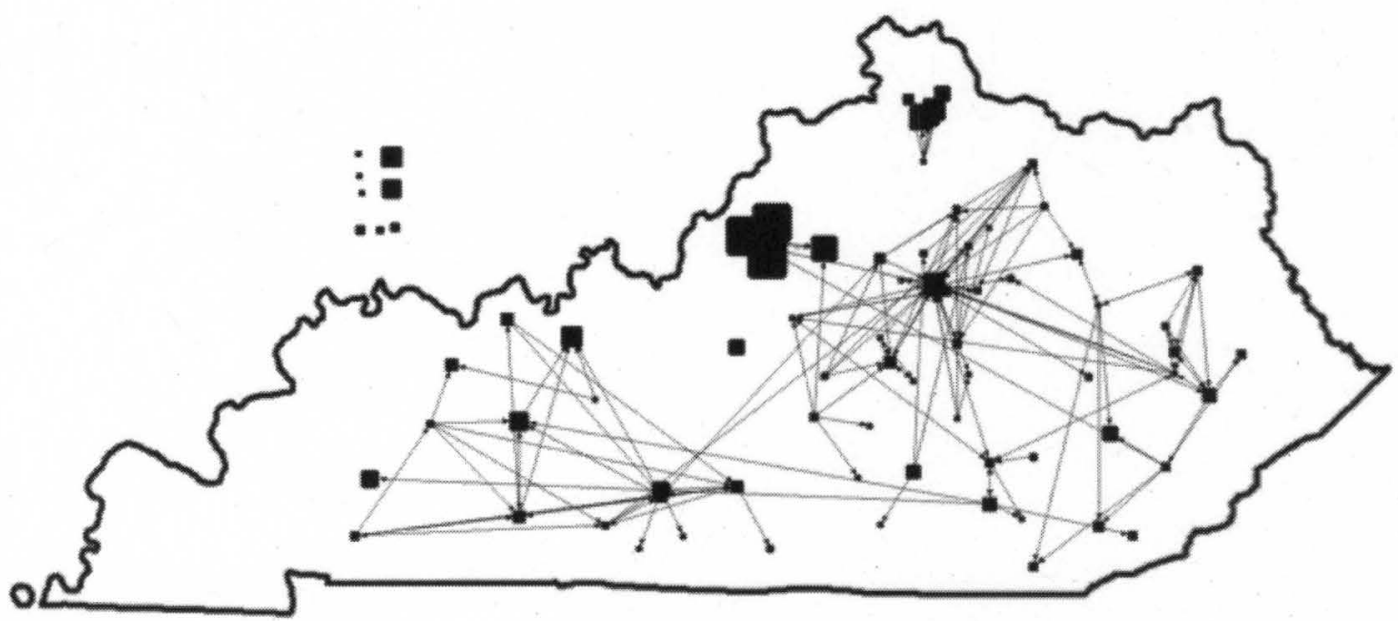

Figure 24: Geocoded network analysis sociogram of hospital bed size of the knowledge-sharing network of hospital-based infection preventionists in Kentucky [Larger nodes indicate higher numbers of licensed beds within the facility]. 
CHAPTER FIVE

Summary, Conclusions, and Future Research

This discussion is arranged according to demographic information and each of the four research questions under study. Each research question will be discussed, followed by conclusions, recommendations, and potential future research projects.

Demographic Information of Respondents

Demographic information of respondents indicates that the infection preventionists (IPs) in Kentucky hospitals are aging. Nearly one third of respondents were in the 56-65 year old age group, indicating that a large proportion of IPs will be eligible for retirement in the near future. As described previously, this loss of workforce can disrupt the ability for IPs to share knowledge. One-third of respondents had a 2-year college degree, which, although less than was described in the SENIC project results, indicates that after 25 years, many IPs remain undereducated for their positions (Haley, et al., 1985). These data support the argument that a large proportion of hospitalbased IPs in the Commonwealth of Kentucky do not have adequate collegiate training in areas such as epidemiology and biostatistics that are necessary for the practice of infection prevention. Nearly $40 \%$ of respondents indicated they were certified in infection control from the CBIC. This is very close to a national, 
1997 survey indicating that $38 \%$ of APIC members were certified (Jackson, Soule, \& Tweeten, 1998). These results indicate that after over a decade, the number of IPs who are certified in their field has not changed to an appreciable extent. The majority of respondents also indicated that they had been in their current positions for over 10 years, indicating a large body of knowledge may be present within these employees. However, over half of the respondents indicated that they did not devote $100 \%$ of their daily efforts to the practice of infection prevention. Although these demographic variables suggest some potential issues with the daily workflow of these professionals, clear communication channels do exist. Most of the respondents indicated that they provide knowledge to or ask for knowledge from other IPs in Kentucky at least monthly. Furthermore, work-related communication exists with IPs outside of Kentucky and with non-IPs. In fact, the majority of respondents indicated that they share work-related knowledge with more than 10 non-IPs in a typical week. This suggests that IPs in Kentucky hospitals may have a much larger knowledgesharing network than indicated by this analysis. Finally, the examination of sources of knowledge for hospital-based IPs in Kentucky revealed that most obtain information from government websites, reading the scientific literature, or e-mail. Although it is expected that IPs obtain information from government websites such as the CDC due to the many guidelines released by this organization, the finding that nearly $80 \%$ of respondents obtain information regularly from the scientific literature is higher than previously reported (Olmsted, et al., 2006). Olmstead and colleagues (2006) found a $75 \%$ reading rate for the 
American Journal of Infection Control however, which is close to the findings presented here. This study did not differentiate between journals, and therefore these data may represent reading of habits for only a few journals. A possible explanation for the findings of high reading rates of scientific journals is the expanded availability of journal articles online. Open access journals as well as dedicated search engines such as Google Scholar ${ }^{\mathrm{TM}}$; make finding evidencebased journal articles much easier and quicker than prior reliance on large medical libraries. Furthermore, reading the literature does not necessarily suggest application of what was read. A lack of training in application of evidence-based literature may limit the IPs ability to utilize the information that was read. As expected, very few IPs had any mentorship and even fewer attended in-person training sessions. This, along with the fact that one-third of the respondents of this survey will be eligible for retirement in the near future, supports the hypothesis that some other mechanism for the sharing of knowledge must be present for knowledge sustainability. The discussion of the four research questions clearly supports that there is at least one other mechanism in place for the sharing of knowledge in this group: the social network.

\section{Research Question \#1}

What is the structure of knowledge-sharing networks among hospitalbased infection preventionists in Kentucky?

Hypothesis \#1 Knowledge-sharing networks among IPs in Kentucky hospitals consist of multiple components. 
Results of the surveys provided to each of the IPs in Kentucky hospitals indicate that there are wide-reaching infection prevention-related knowledgesharing networks present. The hypothesis that three different components existed was supported by the results of the component analysis, however the components that existed were not necessarily meaningful components. There was one major component and two smaller components in this network. The major component consisted of 94 nodes and 398 ties, which represented approximately $97 \%$ of the total ties present in the network. Clearly, this component is the major functioning knowledge-sharing network in this group of professionals. Furthermore, the mid-sized component consisted of only IPS within the same hospital network and the smaller component consisted of only two nodes. Although these data support hypothesis \#1 that multiple components exist in this network, there is one major component that holds the majority of knowledge-sharing episodes. This is an important finding in that it indicates that, in a knowledge-sharing network, not only the number of components but also the size of the components are important factors to examine in the determination of the relative importance of the component. Here, three components exist, however only one appears to have the span that would make it large enough to be a functional and important mechanism of knowledge sharing.

The implications of these findings include that knowledge sharing with regard to work-related information is prevalent, and therefore it is possible to reach a large proportion of IPs in the Commonwealth of Kentucky through this network. This social network may offset the limitation in knowledge sharing from 
a rapidly retiring workforce, limited mentorship, and in-person training attendance.

\section{Research Question \#2}

How dense are the components and what are the measures of centrality for IPs in knowledge-sharing networks in Kentucky hospitals?

\section{Hypothesis \#2}

Knowledge-sharing networks among IPs in Kentucky hospitals consist of low-density components and nodes with low centrality.

Results of the survey indicate that the density of each component decreases with the increasing number of nodes present in the component. This finding is especially intriguing and indicates that it is important to examine the size of the component with regard to the number of nodes when evaluating the density of the component. Here, although the density of the smallest component is relatively high (50\%), indicating that half of the possible connections are present, it consists of only two nodes and is therefore not a relevant component to evaluate. In this directed component, one node shares knowledge with a second node, but the relationship is not reciprocated. Furthermore, the largest component has the smallest density $(2.3 \%)$ indicating that only $2.3 \%$ of the possible connections are present. Although this network is not dense, it clearly spans the entire state of Kentucky and is therefore still an important component in the network. 
Implications of these findings include that even low-density knowledgesharing networks can be important and the overall size of the component may be a more important factor to consider.

Examinations of the centrality statistics of the network showed that, overall, there were few nodes that were central to the network. The in-degree measurement of how often other IPs chose that particular IP as a source of knowledge ranged from $0-11$, with the majority of IPs having an in-degree of zero. This indicates that most of the responding IPs in this knowledge-sharing network were not chosen as a source for knowledge. A possible explanation for these findings is that there may not be efficient sharing of contact information between all IPs in the state. There is currently no statewide meeting of IPs in Kentucky and therefore contact information exchange is limited. Also, as those IPs with higher in-degree and eigenvector statistics were more likely to be APIC members, it is possible that regular meetings of any type may have a significant impact on the ability of IPs to directly share knowledge. Out-degree statistics ranged from $0-5$, though the there was a cap of five due to the fact that the survey instrument limited the choice of respondents to five. Interestingly, nearly $20 \%$ of IPs had an out-degree of zero, suggesting that one-fifth of respondents did not share information with any other IP in Kentucky. This can be very detrimental to the network, as these nodes do not allow their knowledge to infiltrate the network. There were very few gatekeepers of knowledge in the network as indicated by the very low betweenness centrality measures and the nearly $70 \%$ of respondents with a betweenness of zero. This suggests that IPs 
can reach each other more directly without intermediaries. The eigenvector centrality measures were also very low, with over $50 \%$ of respondents with an eigenvector centrality score of zero. This clearly indicates that the IPs' alters, those that they are connected to, are themselves not central. Therefore, there is little mass knowledge available in any particular IP due to the fact that each node does not, in and of itself, have a great deal of knowledge-sharing potential. Finally, the inability to calculate closeness statistics shows that not all network statistics are appropriate for all networks. Here, the closeness statistics were not calculated due to the fragmented nature of the directed network. For example, the closeness statistic can only be calculated in a connected network. Hypothesis \#2 was partially supported by all of these results. Although the network centrality measures were low, there was one component with a high density.

Implications for these data include the importance of centrality statistics for evaluating the relative importance of nodes in the network. In-and out-degree statistics have been previously evaluated in knowledge-sharing networks (Fesenmaier \& Contractor, 2001), and remain important factors in evaluating the nodes in these networks. Betweenness and eigenvector centralities offer further evaluation of the nodes within the networks. Evaluation of knowledge gatekeepers provides data on how often indirect knowledge sharing is occurring. Indirect knowledge sharing may provide accurate information however, secondhand knowledge may carry the risk of being inaccurate, incomplete, or lacking a necessary contextual component. Therefore, a high number of gatekeepers 
would suggest the need to forge more direct connections within the network.

Finally, the use of eigenvector centrality may be a useful tool for node evaluation in knowledge-sharing networks. Nodes with access to more knowledge will have alters who are more central to the network. This introduces the concept of knowledge potential of nodes within a network. Here, this was not the case. Finally, as a number of higher centrality statistics were associated with higher attendance in local APIC chapter meetings, it may be useful to explore the possibility of expanding local chapter meetings to regular statewide meetings. Regular statewide meetings may increase centrality statistics of all IPs through regular exchange of knowledge and contact information.

\section{Research Question \#3}

Are there key players in knowledge-sharing networks among infection preventionists in Kentucky hospitals?

\section{Hypothesis \#3}

Three meaningful key players will be present in knowledge-sharing networks among infection preventionists in Kentucky hospitals.

The concept of the key player in a social network is not new, but the analysis is very new and relatively unstudied (Borgotti, 2006). In this network, three key players exist in both the fragmentation and reach analyses. Importantly, only in the reach algorithm does the IP with the highest centrality scores become a key player. This important finding supports the key player theory as proposed by Borgotti (2006). In this network, the fragmentation algorithm and the reach algorithm did not identify the same IPs as key players. 
The fragmentation algorithm seeks to identify nodes that, if removed, will maximally fragment the network. The reach algorithm selects IPs that can reach the most other IPs the quickest. The IPs identified varied in age and education level, however it is very important to note that two of the three key players $(67 \%)$ identified through the fragmentation algorithm were in the older age group that may be close to retirement age. If these IPs retire and leave the network, it may significantly fragment the network, as is seen in Figure 21 . The fragmented network would limit communication and diffusion of information through the network and could be very deleterious to job performance if these knowledge connections are indeed important for such periormance. All key players in both analyses had been in their current position for more than 10 years suggesting that they have had sufficient time to build their knowledge-sharing networks and become more important in their structure. Interestingly, none of the key players had a university affiliation. This may be due to the majority of hospitals in Kentucky being smaller, rural hospitals that may have little identification or connection to a university setting (Rural Assistance Center, 2010). The IPs in these facilities may choose to share knowledge with IPs who practice in similar work environments, for example a similar rural setting. It is important to understand who the key players are in any particular network in order to ensure they either stay within the network (in the case of fragmentation key players) or in the event that new information needs to be quickly and reliably disseminated through the network (in the case of reach key players). One important factor to consider is the lack of clarity as to whether the importance of the node involves 
the individual or if it involves the employment position of the node. For example, if the IP (the key player) leaves their job, does the influence of the node leave with them or is it retained as part of their position in their hospital. It is still unclear as to whether the key player statistics are a better method of identifying important nodes in a network or if centrality statistics should be used. Borgotti (2006) makes a keen argument for the former, however few studies have tested the utility of these measures.

In this study, the hypothesis indicates that 3 meaningful key players would be present, as determined by being in a component with a high density. Here, the density of the component in which all key players were found was the lowest of the three components. Clearly, these key players are meaningful. If the fragmentation key players were removed, the network could be disrupted to a great extent. Hypothesis \#3 is not supported by these results.

Implications for these findings include a method for identification of the maximum number of key players in a network when it is not known a priori as to how many are present. Furthermore, it is clear that key players can be identified in knowledge-sharing networks by utilizing this software. Depending on the reason for identification of key players, various algorithms can be used. Here, fragmentation and reach were utilized. Each of the two algorithms provided different results, which was expected due to the different rationales for identification. However, the reach key player algorithm identified the IP with the highest centrality statistics as a key player, which indicates some overlap in the statistical measures. The importance of identifying key players in a network 
cannot be stressed enough. Diffusion of Innovations theory indicates that new ideas spread through interpersonal networks effectively (Rogers, 2003; Valente \& Davis, 1999). The diffusion of this information may be best accomplished through opinion leaders, which have had little empirical study. The use of the key players in a network may prove to be the most beneficial method for harnessing these opinion leaders.

\section{Research Question \#4}

What is the role of geography in the network connections within knowledge-sharing networks of IPs in Kentucky hospitals?

\section{Hypothesis \#4}

The knowledge-sharing network of hospital-based infection preventionists in Kentucky will be separated into three major components based on the three APIC chapter regions of Kentucky.

The results of the survey indicate that, although three components do exist in the knowledge-sharing network of hospital-based IPs in Kentucky, they are not separated into the three APIC chapter regions. Furthermore, the network is not separated into any distinct geographic region. Three distinct geographic regions were indicated in Chapter 1 as possible network component areas. Inspection of Figure 22 clearly indicates that the network identified through this analysis does not fit into any of these geographical regions. These results are unexpected, as prior work has demonstrated the importance of geography in the structure of social networks (Rothenberg, et al., 2005; Terrell, 2010; West \& Barron, 2005; Wylie, et al., 2007). In addition, given the topography of Kentucky, 
it was expected that there would be at least some separation (e.g. Appalachian Mountains) of nodes within the network due to the physical barriers of the state. This lack of geographic effects on the knowledge-sharing networks of hospitalbased IPs in Kentucky may be due to the effects of technology and the Internet in knowledge sharing. Since only $40 \%$ of the study population indicated that faceto-face modes were often or always utilized for knowledge sharing, $78 \%$ indicated e-mail, and $22 \%$ indicated virtual meetings, it is apparent that the technology has modified the network to a degree. This wide use of electronic means of communication may be the reason for which geography does not appear to play a role in shaping this network. These data do not support the work of other authors that indicate geography is an important factor in network structure even within networks where electronic communication is common (Cantoni, et al., 2001; Liben-Nowell, et al., 2005). It is possible that, if the survey instrument had asked the respondent to choose the IP to which they share knowledge with face-to-face, geographic effects may be more prevalent.

Furthermore, bed-size analysis indicated that the majority of connections within this network are between hospitals with few beds. Hospitals licensed for larger numbers of beds appeared to communicate only minimally outside of their facilities. A possible reason for this is that the larger facilities may have more resources to provide to the infection preventionist such as a dedicated hospital epidemiologist and infectious diseases specialist physicians. Another potential reason for this is that smaller facilities may have their own unique issues that are different from those of larger facilities. Due to this, smaller facilities would be 
more likely to communicate work-related material with other smaller facilities. This concept is a proposition within social network theory, termed homophily (Kadushin, 2004). The smaller components of the network were made up primarily of medium-sized hospitals that are isolated from the larger component and therefore the knowledge within these facilities cannot be shared with the larger network. This is detrimental to the collective knowledge of the network.

These data do not support hypothesis \#4 as geographic effects are not seen to play a role in shaping these networks. A discrepancy remains in the literature as to how geography can affect a social network.

\section{Limitations}

This study has several limitations. The first limitation is that although this study reports a nearly $60 \%$ response rate with an even distribution of respondents and non-respondents throughout the state, without having $100 \%$ of the sample data, it is possible that important information has been missed. For example, key players or nodes with high centrality statistics may have been missed. Alternatively, the non-responding IPs may have low centrality statistics and therefore be in need of knowledge source connections. Another limitation is the lack of a longitudinal view of the social networks of IPs. By limiting the analysis to a snapshot of the knowledge-sharing network of IPs, it is possible to miss connections that develop over time. Another limitation is the focus on knowledge sharing between hospital-based IPs only. It is possible that IPs share a great deal of knowledge about their practice, but with non-hospital-based IPs such as healthcare epidemiologists, public health practitioners, or other 
healthcare workers. Furthermore, this study limits the connections to an administrative boundary of the state. It is likely that connections are present outside of the state of Kentucky, especially with close locales in cities near state borders. This study also does not account for factors such as administrative policies and budgets that may influence the ability of IPs to discuss matters with each other. Finally, this study does not include information on key factors that may influence knowledge sharing such as trust (Holste \& Fields, 2010), job satisfaction, and the values of the IP (Rangachari, 2009, 2010).

Conclusions

In the Commonwealth of Kentucky, a knowledge-sharing network of hospital-based IPs exists that spans throughout the state. It is important to have a social network for knowledge sharing in order to bypass the difficulties in obtaining information through various other methods such as in-person training or mentorship. Understanding this network and the function of the nodes within is the first step in forging new connections to maximize the connections within the network. Maximizing the connections within the network may serve to improve the knowledge of the professionals within and lead to improved job performance. Improved job performance will provide an avenue for reduced HAls and improved patient outcomes.

The knowledge-sharing network of hospital-based IPs in Kentucky is not optimal, however. Improvement in communication between IPs is needed, as seen by the very low density of the main component of the network. Furthermore a few nodes that hold the network together are present in key positions within the 
network. If these nodes leave the network, fragmentation of the network is possible. Unfortunately for the network, most of the key players in the fragmentation analysis were in the older age bracket, leaving the possibility of retirement for these very important nodes and subsequent disruption of the network.

Geography appears to play little role in these networks, regardless that many face-to-face meetings may only take place within local APIC chapters. Electronic effects may limit the impact of geography on this network but this needs to be explored further. If the Internet were a viable means of communication between IPs, it would be a great potential source for enhancing connections and increasing the network density.

Overall, although knowledge-sharing networks of hospital-based IPs exist within Kentucky, there is ample room for improvement. Enhancing communication within this network would help to offset the difficulty in practicing an extremely important job in an ever-changing healthcare environment.

\section{Recommendations}

Some recommendations can be made based on these analyses, as they are the first of their kind. Of utmost importance is the identification of key players for diffusion of information through the hospital-based IP network, as identified through the reach key player analysis. In the event that an incident of public health importance emerges, it is now known that specific IPs can be identified to supply important information to other IPs in the state. For example, when the pandemic of $2009 \mathrm{H} 1 \mathrm{~N} 1$ influenza A virus began in Louisville, $\mathrm{KY}$, having 
previously identified "go-to" individuals to disseminate information, such as algorithms for patient triage, would have been very beneficial. These IPs that are identified through reach analysis can quickly contact the largest number of other IPs in this network and would therefore be the most important and resourceprudent IPs to harness in these events. Through diffusing important information quickly and reliably through the network, the most IPs can obtain the most relevant information from sources they deem as significant. The rapid diffusion of information through this network may aid in the quick and accurate response to whatever event may be occurring by both healthcare workers and public health staff.

In this network, one IP was identified that had the highest centrality statistics and also was identified as a reach key player. Clearly this IP is very important to the network. It is possible that through providing this IP with more mechanisms of knowledge sharing, such as through officer membership in various organizations or the ability to convey information to the public through the mass media, other IPs may be more likely to take up and utilize information disseminated from this person, as it originated from a source from whom they are used to obtaining information.

Utilization of key players or IPs with high centrality to the network to diffuse information throughout the network fits with the Diffusion of Innovations theory as described by Rogers (2003) as well as Valente and Fosados (2006). Utilization of these opinion leaders, as identified through social network analysis, should impact the recipient of the information in such a way that it is utilized, 
assuming the information was conveyed through the appropriate channels (Valente \& Fosados, 2006). These key players can also be utilized to train other people in the network as it has been described that training may be most efficient when peers are the trainers (Rice, 1993).

This was the first work describing the knowledge-sharing networks of hospital-based IPs. As this was the first work of its kind, a recommendation for future research is also warranted.

\section{Future Research}

Social network research in public health and healthcare is ripe for additional work. Although few studies of social networks in the public health and healthcare environments are currently published, work in other areas can be applied to determine applicability and usefulness. Descriptive studies such as the present work are important first steps in examining the social network structures in any particular environment. However, it is also necessary begin to examine the value other techniques in the prediction of various connections within a social network. Some potential future research questions and descriptions are outlined below.

\section{What is the structure of the infection prevention knowledge-sharing} network in a state with a statewide meeting of IPs and/or nationally?

A local description of the knowledge-sharing network of infection preventionists is presented in this study. It would be interesting to identify of a state with a statewide meeting of IPs is similar to the network identified in Kentucky. From this perspective, a state with a large meeting including all IPs 
should have more connections, as it would be more likely for any particular IP to have the contact information of other IPs in the state. As this study identified that higher centrality statistics were associated with APIC membership and meeting attendance, it is possible that a statewide meeting might also be associated with members becoming more central to the network. It would also be interesting to see if the national structure is similar to that of Kentucky. Many of the demographic characteristics such as age, education level, and certification are similar in this project as with previously published data (Goldrick, 2007; Haley, et al., 1985). This might suggest that other characteristics, and perhaps network characteristics, of these IPs may be the same as well.

\section{What is the role of multivariate modeling techniques for the prediction of ties in social networks of IPs?}

Limited previous work has utilized various regression techniques such as the Network Effects Model to determine the influence of social network structure on outcomes (Zheng, et al., 2010). Similar modeling procedures may be utilized to predict various attributes of the social networks of IPs. For example, utilizing these models to examine the predictability of retwork position on the rates of various HAls (e.g. MRSA) or prevention measures (e.g. hand hygiene compliance) would be extremely useful. If any particular network position or structure (e.g. a high centrality measure or key player position) were to predict low rates of HAls or high rates of hand hygiene in a facility, areas of scrutiny could be: 1) what aspect of that network position affects the outcome (e.g. 
access to more knowledge) and 2) how could the network be best modified to decrease HAls in all facilities.

What types of information are shared within the knowledge-sharing networks of IPs and is this information utilized?

Although this study examined basic knowledge sharing between IPs, it would be interesting to examine the types of information that are shared within the network. For example, it is possible that certain types of information are shared with certain IPs. This would be important to understand, as it would change the centrality measures and key player identification within the network. Some nodes may be central to certain knowledge networks, or key players for specific types of information. Furthermore, it would be noteworthy to recognize if the knowledge that is shared is actually utilized. It is possible that knowledge is shared with certain nodes, but no action is actually taken on the information. In order for knowledge to be relevant, an action must be taken at some point to utilize that piece of information.

What is the role of patient transfers in the knowledge-sharing networks of IPs?

Patient transfers from hospital to hospital or healthcare environment to healthcare environment are prevalent. It would be interesting to investigate the communication patterns between healthcare facilities that "share" patients through regular transfers. It is possible that knowledge sharing is more prevalent between facilities that share patients as they would have regular contact for other 
reasons and, by necessity, have similar patients populations and possibly similar infection prevention issues.

What is the importance of the strength of ties in knowledge-sharing networks of IPs?

In the 1970s, the sociologist Mark Granovetter showed the importance of what he termed "weak ties" (Granovetter, 1973). These ties are the types of ties that are formed through acquaintances, rather than close friends. This work showed that all types of connections within a network are important. Moreover, these weak ties may be more important for various types of information such as bringing in new and innovative information into a network (Granovetter, 1973). The importance of the strength of ties in determining the knowledge-sharing capabilities within a network may be significant in determining how to best influence the flow of knowledge in the future.

\section{What are the long-term changes in the knowledge-sharing network of IPs?}

Examinations of knowledge-sharing networks such as those elicited in this study are important. As Luke and Harris (2007) describe, it is also important to examine changes in networks over time. An examination of the changes in a network after significant events is a possible research plan. For example, does the network change after an outbreak of a disease of public health importance? If communication is prevalent within a facility, it is likely that the network would change as the IP seeks out new sources of information with other facilities that may help their investigation or have had similar issues in the past. Also, a prospective, longitudinal study of the knowledge-sharing networks of IPs would 
be a potential way to investigate this question. For a longitudinal network study, it would be critical to inspect variables that may modify the network over time such as retirement rates, job changes, policy changes, etc. If changes in the network were found, it would be possible to determine: 1) significance of those changes and 2) responsible variables for those changes. This type of network research would examine the very important aspect of the sustainability of ties (Contractor \& Monge, 2002). Furthermore, as very few longitudinal network studies have been published, this would be a significant addition to the literature. It is important to note that this project occurred shortly after the $2009 \mathrm{H} 1 \mathrm{~N} 1$ influenza $A$ virus pandemic. If indeed the network changes due to outbreaks and events of public health importance, the identified network in this research may reflect something that was quite different from a network pre-pandemic.

\section{What is the role of non-IPs in the knowledge-sharing networks of IPs?}

This study identified that many hospital-based IPs in Kentucky share information with non-IPs. An important next step would be to examine a larger knowledge-sharing network, including these non-IPs. As the network elicitation would be difficult with a roster-based name generator such as in this study, it would be possible to include open-ended name elicitation. Respondent-driven sampling techniques could be used to identify nodes to include in the network as they have been shown to be useful in identification of populations that are not known a priori (Heckathorn, 1997).

\section{What are the effects of job satisfaction and employee values in the knowledge-sharing networks of IPs?}


Although knowledge sharing in a professional context should exist between all members of the population for the betterment of their occupation, clearly this is not happening. Potential modifiers of knowledge sharing would be important to identify and examine. Two important potential internal modifiers that could be examined in future studies include job satisfaction and employee values. Both of these variables have the potential to shape the knowledgesharing habits of nodes. For example, if an employee was not satisfied with their job, it is possible that they would be less likely to seek out or share information as they may have little motivation to do so (Gagne, 2009). Furthermore, the value system of the employee may greatly modify the motivation to seek out and share information. Values in social networks have been mentioned in prior work but little assessment in analytical studies has been accomplished (Rangachari, 2009).

What is the role of facility-specific and public policy in the knowledgesharing networks of IPs?

Policy-level modifiers of knowledge sharing may be important drivers of connections between IPs and between IPs and other sources of knowledge within the community. Over time, policies change throughout the healthcare and public health arenas. Single facility, local, state, national, and global policies may affect the ability and motivation of nodes within a network to share knowledge. For example, as the number of states mandating the public reporting of HAls increases, healthcare facilities may lock down the ability of the IP to share certain types of information with others in the attempt to prevent litigation associated with 
HAls (Alston, 2010; Lagu \& Lindenauer, 2010; McKibben, et al., 2005; Muller \& Detsky, 2010).

Do key players or members with high centrality statistics facilitate diffusion of information throughout this network?

It has been described that, in decentralized networks such as the network identified in this study, opinion leaders for diffusion of information do not exist (Valente \& Davis, 1999). In these situations, it may be difficult to find people who can act as leaders for the diffusion process. This study found that key players do exist in a decentralized network and other nodes with high centrality statistics also exist. It is necessary to begin to identify if these nodes who were found to be important in a decentralized network can efficiently act as diffusion leaders.

What methods can be used to forge new ties in a knowledge-sharing network and does forging new ties positively affect HAls or other outcomes?

No studies were identified that specifically investigate methodologies to forge new ties between individuals for knowledge sharing. However, many studies in the electronic social network literature have examined the utilization of discussion boards and online social network (OSN) websites in the forging of ties. OSNs are extremely important, however, in that they provide a means for latent ties (e.g. ties that have not formed but have the potential to form) to form strong or weak ties (Haythornthwaite \& Wellman, 1998). Furthermore, as people connect with others (Haythornthwaite, 1996), an OSN can become quite large as members become linked to their friends' friends and so-on. 
There is debate in the literature as to how useful and sustainable ties are made solely on the Internet, however. For example, Cummings found that email is not as good as face-to-face contact at developing and maintaining ties, and listservs are not as good as small group meetings at developing a sense of community belonging and social support (Cummings, Butler, \& Kraut, 2002). Other researchers have found that this may not be the case, and that concepts salient in face-to-face social networks may not apply to online networks (Brown, Broderick, \& Lee, 2007; Constant, Kiesler, \& Sproull, 1996; Haythornthwaite, 1996). Clearly, the OSN may be one method of forging new connections in this group of practitioners. Development of an OSN specific for IPs may be a possible method of forging these new ties. The wide use of the Internet found in this study suggests that this may be a viable option.

Another possibility for increasing the number of ties is to maintain a statewide meeting of IPs. Higher centrality scores were found in members who attended their local APIC chapter meetings regularly. Attendance of a statewide meeting of IPs may therefore increase the centrality of nodes throughout the state.

As part of forging new ties, it would be possible to begin to empirically measure the utility of centrality statistics versus the key player algorithm for identification of "important" nodes in a network. It would be possible to identify nodes with high centrality measures and those identified as key players and utilize them for points of contact for new tie formation within the network. These members with high centrality statistics or key players may be able to be used for 
training as this may be more effective than utilizing outside people who are not influential in the network. If utilization of a specific measure causes more tie formation, stronger ties, or ties that are sustainable, more evidence-based emphasis could be placed on any of those measures. A limitation of these strictly statistical measures of influence in the network is that these opinion leaders may not want to be opinion leaders (Valente \& Davis, 1999). Because of this, more in-depth interviews may be needed prior to selecting who is indeed influential in the network.

These are only a few proposed research questions. As the area of social network research ages, more methods will become available and more research questions will be important. The data in this project reveals a concise overview of the knowledge-sharing habits of IPs in Kentucky. Because of this, the generalizability of these results is limited. As the issues and policies of each state differ significantly, the goal is not to generalize the results of this study but to maximally impact the social networks to obtain optimal job performance and patient outcomes.

Examination of knowledge sharing in various communities requires a suitable analytic method in order to adequately understand the importance of each person within the community. The use of social network analysis is a unique approach to accomplishing this goal. 


\section{REFERENCES}

5 Million Lives Campaign. (2008a). Getting Started Kit: Prevent Surgical Site Infections How-to Guide. Cambridge, MA.

5 Million Lives Campaign. (2008b). Getting Started Kit: Prevent Ventilatorassociated Pneumonia How-to Guide. Cambridge, MA.

5 Million Lives Campaign. (2008c). Prevent Central Line Infections How-toGuide. Cambridge, MA: Institute for Healthcare Improvement.

Ahmad, N., \& Daghfous, A. (2010). Knowledge sharing through interorganizational knowledge networks. European Business Review, 22(2), 153.

Alston, W. K. (2010). Pitfalls of public reporting. Infect Control Hosp Epidemiol, 31(9), 985-986.

American Thoracic Society. (2005). Guidelines for the management of adults with hospital-acquired, ventilator-associated, and healthcare-associated pneumonia. Am J Respir Crit Care Med, 171(4), 388-416.

Analytic Technologies. (2010). KeyPlayer (Version 2) [Software]. Lexington, KY.

Ancel Meyers, L., Newman, M. E., Martin, M., \& Schrag, S. (2003). Applying network theory to epidemics: control measures for Mycoplasma pneumoniae outbreaks. Emerg Infect Dis, 9(2), 204-210. 
Andre, M., ljaz, K., Tillinghast, J. D., Krebs, V. E., Diem, L. A., Metchock, B., et al. (2007). Transmission network analysis to complement routine tuberculosis contact investigations. Am J Public Health, 97(3), 470-477.

Association for Professionals in Infection Control. (2010). APIC EPI: Education for the prevention of infection. Retrieved June 19, 2010, from http://www.apic.org/AM/Template.cfm?Section=Courses2\&Template=/CM/ HTMLDisplay.cfm\&ContentID=14455

Association for Professionals in Infection Control Kentucky Chapter. (2010). APIC Kentucky: spreading knowledge. Preventing infection. Retrieved June 29, 2010, from www.apic-ky.org

Auerbach, D. M., Darrow, W. W., Jaffe, H. W., \& Curran, J. W. (1984). Cluster of cases of the acquired immune deficiency syndrome. Patients linked by sexual contact. Am J Med, 76(3), 487-492.

Barabasi, A. L., \& Bonabeau, E. (2003). Scale-free networks. Sci Am, 288(5), 6069.

Bialachowski, E. A. (2009). Creating a mentoring culture to connect and empower new ICPs, part one. Can J Infect Control, 24(4), 222-225.

Blankenship, S., \& Ruona, W. (2009). Exploring knowledge sharing in social structures: potential contributions to an overall knowledge management strategy. Advances in Developing Human Resources, 11(3), 290.

Bonacich, P. (1987). Power and centrality: a family of measures. [Article]. American Journal of Sociology, 92(5), 1170-1182. 
Borgatti, S. P. (2006). Identifying sets of key players in a social network. Comput. Math. Organ. Theory, 12(1), 21-34.

Borgotti, S. (2006). Identifying sets of key players in a social network. Comput. Math. Organ. Theory, 12(1), 21-34.

Borgotti, S. (2009). UCINET, NETDRAW and KeyPlayer (Version 6) [Software]. Lexington.

Boucher, H. W., Talbot, G. H., Bradley, J. S., Edwards, J. E., Gilbert, D., Rice, L. B., et al. (2009). Bad bugs, no drugs: no ESKAPE! An update from the Infectious Diseases Society of America. Clin Infect Dis, 48(1), 1-12.

Broadhead, R., Heckathorn, D., Weakliem, D., Anthony, D., Madray, H., Mills, R., et al. (1998). Harnessing peer networks as an instrument for AIDS prevention: results from a peer-driven intervention. Public Health Rep, 113 Suppl 1, 42-57.

Broadhead, W., Kaplan, B., James, S., Wagner, E., Schoenbach, V., Grimson, R., et al. (1983). The epidemiologic evidence for a relationship between social support and health. Am J Epidemiol, 117(5), 521-537.

Brown, J., Broderick, A. J., \& Lee, N. (2007). Word of mouth communication within online communities: Conceptualing the online social network. Journal of Interactive Marketing, 21(3), 2-20.

Burt, R. S. (2000). The network structure of social capital. Research in Organizational Behavior, 22, 345-423.

Cantoni, F., Bello, M., \& Frigerio, C. (2001, June 27-29, 2001). Lowering the barriers to knowledge transfer and dissemination: The Italian cooperative 
banks experience. Paper presented at the The 9th European Conference on Information Systems, Bled, Slovenia.

Carbon, C. (1999). Costs of treating infections caused by methicillin-resistant staphylococci and vancomycin-resistant enterococci. J Antimicrob Chemother, 44 Suppl A, 31-36.

Centers for Disease Control and Prevention. (2008). The National Healthcare Safety Network (NHSN) Manual - Patient Safety Component Protocol. Atlanta: Centers for Disease Control and Prevention.

Centers for Disease Control and Prevention. (2010a). Advisory Committee on Immunization Practices. Retrieved August 14, 2010, from http://www.cdc.gov/vaccines/recs/acip/default.htm

Centers for Disease Control and Prevention. (2010b). Healthcare Infection Control Practices Advisory Committee (HICPAC). Retrieved August 14, 2010, from http://www.cdc.gov/hicpac/about.html

Centers for Disease Control and Prevention. (2010c). Healthcare-associatd infections (HAls). Retrieved June 29, 2010, from http://www.cdc.gov/ncidod/dhqp/healthDis.html

Chan, K., \& Liebowitz, J. (2006). The synergy of social network analysis and knowledge mapping: a case study. International Journal of Management \& Decision Making, 7(1), 19-35.

Choi, K. H., \& Gregorich, S. E. (2009). Social network influences on male and female condom use among women attending family planning clinics in the United States. Sex Transm Dis, 36(12), 757-762. 
Clements, A., Halton, K., Graves, N., Pettitt, A., Morton, A., Looke, D., et al. (2008). Overcrowding and understaffing in modern health-care systems: key determinants in meticillin-resistant Staphylococcus aureus transmission. Lancet Infect Dis, 8(7), 427-434.

Coleman, J. (1988). Social capital in the creation of human capital. American Journal of Sociology, 94, 95-120.

Coleman, J., Katz, E., Menzel, H., \& Columbia University Bureau of Applied Social Research. (1966). Medical innovation; a diffusion study. Indianapolis,: Bobbs-Merrill Co.

Constant, D., Kiesler, S. B., \& Sproull, L. S. (1996). The Kindness of Strangers:

The Usefulness of Electronic Weak Ties for Technical Advice. Organization Science, 7(2), 119-135.

Contractor, N. S., \& Monge, P. R. (2002). Managing knowledge networks. Management Communication Quarterly, 16(2), 249-258.

Cormen, T. H. (2009). Greedy algorithms Introduction to algorithms (3rd ed., pp. 370-384). Cambridge, Mass.: MIT Press.

Costenbader, E., \& Valente, T. W. (2003). The stability of centrality measures when networks are sampled. Social Networks, 25(4), 283-307.

Cummings, J. N., Butler, B., \& Kraut, R. (2002). The quality of online social relationships. Communications of the ACM, 45(7), 103-108.

Curchoe, R., Fabrey, L., \& LeBlanc, M. (2008). The changing role of infection prevention practice as documented by the Certification Board of Infection 
Control and Epidemiology practice analysis survey. Am J Infect Control, 36(4), 241-249.

Curran, J. A., \& Abidi, S. S. (2007). Evaluation of an online discussion forum for emergency practitioners. Health Informatics J, 13(4), 255-266.

Curtis, S. P., \& Edwards, A. (1995). HIV in UK prisons: a review of seroprevalence, transmission and patterns of risk. Int J STD AIDS, 6(6), 387-391.

Drewe, J. A. (2009). Who infects whom? Social networks and tuberculosis transmission in wild meerkats. Proc Biol Sci, 1681, 633-642.

Dube, C., Ribble, C., Kelton, D., \& McNab, B. (2009). A Review of Network Analysis Terminology and its Application to Foot-and-Mouth Disease Modelling and Policy Development. Transbound Emerg Dis, 56(3), 73-85.

Durland, M. M., \& Fredericks, K. A. (2005). An introduction to social network analysis. New Directions for Evaluation, 2005(107), 5-13.

Eames, K. T., \& Keeling, M. J. (2002). Modeling dynamic and network heterogeneities in the spread of sexually transmitted diseases. Proc Natl Acad Sci U S A, 99(20), 13330-13335.

Edmond, M., \& Eickhoff, T. C. (2008). Who is steering the ship? External influences on infection control programs. Clin Infect Dis, 46(11), 17461750.

Ellison, N. B., Steinfield, C., \& Lampe, C. (2007). The benefits of Facebook "friends": Social capital and college students' use of online social network sites. Journal of Computer-Mediated Communication, 12(4), --. 
Ennett, S. T., \& Bauman, K. E. (1993). Peer group structure and adolescent cigarette smoking: a social network analysis. J Health Soc Behav, 34(3), 226-236.

Fattore, G., Frosini, F., Salvatore, D., \& Tozzi, V. (2009). Social network analysis in primary care: The impact of interactions on prescribing behaviour. Health Policy.

Feeley, T., Hwang, J., \& Barnett, G. (2008). Predicting Employee Turnover from Friendship Networks. Journal of Applied Communication Research, 36(1), 56.

Fesenmaier, J., \& Contractor, N. (2001). The evolution of knowledge networks: an example for rural development. Journal of the Community Development Society, 32(1), 160-175.

Freeman, L. C. (1979). Centrality in Social Networks Conceptual Clarification. Social Networks, 1(3), 215-239.

Friedman, S. R., \& Aral, S. (2001). Social networks, risk-potential networks, health, and disease. J Urban Health, 78(3), 411-418.

Friedman, S. R., Jose, B., Deren, S., Des Jarlais, D. C., \& Neaigus, A. (1995). Risk factors for human immunodeficiency virus seroconversion among out-of-treatment drug injectors in high and low seroprevalence cities. The National AIDS Research Consortium. Am J Epidemiol, 142(8), 864-874.

Friedman, S. R., Neaigus, A., Jose, B., Curtis, R., Goldstein, M., Ildefonso, G., et al. (1997). Sociometric risk networks and risk for HIV infection. Am J Public Health, 87(8), 1289-1296. 
Fruchterman, T., \& Reingold, E. (1991). Graph drawing by force-directed placement. Software: Practice and Experience, 21(11), 1129-1164.

Gagne, M. (2009). A model of knowledge-sharing motivation. Human Resource Management, 48(4), 571-589.

Gamage, B., Pugh, S., Litt, M., \& Bryce, E. (2009). A survey of infection prevention and control resources in acute care facilities across British Columbia. Can J Infect Control, 24(4), 213-218.

Gamage, B., Varia, M., Litt, M., Pugh, S., \& Bryce, E. (2008). Finding the gaps: an assessment of infection control surveillance needs in British Columbia acute care facilities. Am J Infect Control, 36(10), 706-710.

Goldbeck, J., \& Mutton, P. (2006). Spring-embedded graphs for semantic visualization. In V. Geroimenko \& C. Chen (Eds.), Visualizing the Semantic Web : XML-based Internet and information visualization (2nd ed., pp. 172-182). London: Springer.

Goldrick, B. A. (2005). The practice of infection control and applied epidemiology: a historical perspective. Am J Infect Control, 33(9), 493-500.

Goldrick, B. A. (2006). Assessment of infection surveillance and control programs in nursing homes. Am J Infect Control, 34(7), 467.

Goldrick, B. A. (2007). The Certification Board of Infection Control and Epidemiology white paper: the value of certification for infection control professionals. Am J Infect Control, 35(3), 150-156.

Google. (2010). Google Earth (Version 5) [Software]. Mountain View, CA. 
Granovetter, M. S. (1973). The Strength of Weak Ties. The American Journal of Sociology, 78(6), 1360-1380.

Haley, R. W., Morgan, W. M., Culver, D. H., White, J. W., Emori, T. G., Mosser, J., et al. (1985). Update from the SENIC project. Hospital infection control: recent progress and opportunities under prospective payment. Am J Infect Control, 13(3), 97-108.

Hammer, D., Phillips, B., \& Schmidt, T. L. (2010). The intended-and unintendedconsequences of healthcare reform. Healthc Financ Manage, 64(10), 5055.

Hanchette, C., Biddle, D., Austin, R., \& Esterhay, R. Medical tade area analysis and mapping project. Louisville, KY: University of Louisville.

Harris, J. K. (2008). Consent and Confidentiality: Exploring Ethical Issues in Public Health Social Network Research.

Harris, J. K., \& Clements, B. (2007). Using social network analysis to understand Missouri's system of public health emergency planners. Public Health Reports, 122(4), 488-498.

Haythornthwaite, C. (1996). Social network analysis. an approach and technique for the study of information exchange. Library \& Information Science Research, 18(4), 323-342.

Haythornthwaite, C., \& Wellman, B. (1998). Work, friendship, and media use for information exchange in a networked organization. Journal of the American Society for Information Science, 49(12), 1101-1114. 
Heckathorn, D. D. (1997). Respondent-driven sampling: a new approach to the study of hidden populations. Social Problems, 44(2), 174-199.

Herwaldt, L. A., Appelgate, D., Kuntz, J., Chen, Y., \& Pottinger, J. M. (2007). Infection control resources in lowa. Am J Infect Control, 35(10), 662-665. Holste, J. S., \& Fields, D. (2010). Trust and tacit knowledge sharing and use. Journal of Knowledge Management, 14(1), 128-140.

Huang, S. S., Datta, R., \& Platt, R. (2006). Risk of acquiring antibiotic-resistant bacteria from prior room occupants. Arch Intern Med, 166(18), 1945-1951.

Huang, S. S., \& Platt, R. (2003). Risk of methicillin-resistant Staphylococcus aureus infection after previous infection or colonization. Clin Infect Dis, 36(3), 281-285.

Huang, S. S., Yokoe, D. S., Hinrichsen, V. L., Spurchise, L. S., Datta, R., Miroshnik, I., et al. (2006). Impact of routine intensive care unit surveillance cultures and resultant barrier precautions on hospital-wide methicillin-resistant Staphylococcus aureus bacteremia. Clin Infect Dis, 43(8), 971-978.

Ibrahim, E. H., Tracy, L., Hill, C., Fraser, V. J., \& Kollef, M. H. (2001). The occurrence of ventilator-associated pneumonia in a community hospital: risk factors and clinical outcomes. Chest, 120(2), 555-561.

Jack, S. L. (2005). The Role, Use and Activation of Strong and Weak network Ties: A Qualitative Analysis. The Journal of Management Studies, 42(6), 1233. 
Jackson, M. M., Soule, B. M., \& Tweeten, S. S. (1998). APIC strategic planning member survey, 1997. Association for Professionals in Infection Control and Epidemiology, Inc. Am J Infect Control, 26(2), 113-125.

Januel, J. M., Harbarth, S., Allard, R., Voirin, N., Lepape, A., Allaouchiche, B., et al. (2010). Estimating attributable mortality due to nosocomial infections acquired in intensive care units. Infect Control Hosp Epidemiol, 31(4), 388394.

Jolly, A. M., Muth, S. Q., Wylie, J. L., \& Potterat, J. J. (2001). Sexual networks and sexually transmitted infections: a tale of two cities. J Urban Health, 78(3), 433-445.

Kadushin, C. (2004). Introduction to Social Network Theory Basic Network Concepts: Unpublished.

Kentucky Hospital Association. (2009, March 24, 2009). Kentucky Hospital Association: Find a hospital. Retrieved February 18, 2010, from http://info.kyha.com/KHADBS/Hospitals.asp

Kentucky Secretary of State. (2010). Kentucky geography and regions.

Retrieved June 30, 2010, from http://www.sos.ky.gov/kids/all/geographyandregions/

Klevens, R. M., Edwards, J. R., Richards, C. L., Horan, T. C., Gaynes, R. P., Pollock, D. A., et al. (2007). Estimating health care-associated infections and deaths in U.S. hospitals, 2002. Public Health Rep, 122(2), 160-166. Knoke, D., \& Yang, S. (2008). Social network analysis (2nd ed.). Los Angeles,: Sage Publications. 
Ladin, K., Hanto, D. W., O'Malley, A. J., \& Marsden, P. V. (2009). Understanding disparities in transplantation: Do social networks provide the missing clue. The American Journal of Transplantation, 10(3), 472-476.

Lagu, T., \& Lindenauer, P. K. (2010). Putting the public back in public reporting of health care quality. JAMA, 304(15), 1711-1712.

Liben-Nowell, D., Novak, J., Kumar, R., Raghavan, P., \& Tomkins, A. (2005).

Geographic routing in social networks. Proc Natl Acad Sci U S A, 102(33), $11623-11628$.

Lo, E., Nicolle, L., Classen, D., Arias, K. M., Podgorny, K., Anderson, D. J., et al. (2008). Strategies to prevent catheter-associated urinary tract infections in acute care hospitals. Infect Control Hosp Epidemiol, 29 Suppl 1, S41-50.

Luke, D. A., \& Harris, J. K. (2007). Network Analysis in Public Health: History, Methods, and Applications. Annual Review of Public Health, 28(1), 69-93. Marschall, J., Mermel, L. A., Classen, D., Arias, K. M., Podgorny, K., Anderson, D. J., et al. (2008). Strategies to prevent central line-associated bloodstream infections in acute care hospitals. Infect Control Hosp Epidemiol, 29 Suppl 1, S22-30.

McKibben, L., Horan, T., Tokars, J. I., Fowler, G., Cardo, D. M., Pearson, M. L., et al. (2005). Guidance on public reporting of healthcare-associated infections: recommendations of the Healthcare Infection Control Practices Advisory Committee. Am J Infect Control, 33(4), 217-226.

McNeish, J., \& Mann, I. (2010). Knowledge sharing and trust in organizations. The ICFAI Journal of Knowledge Management, 8(1/2), 18. 
Milgram, S. (1967). The small-world problem. Psychology Today, 1(1), 60-67.

Montoya, I. D. (1998). Social network ties, self-efficacy, and condom use among women who use crack cocaine: a pilot study. Subst Use Misuse, 33(10), 2049-2073.

Moreno, J. L., \& Jennings, H. H. (1934). Who shall survive? A new approach to the problem of human interrelations (Vol. 58). Washington, D.C.,: Nervous and mental disease publishing co.

Morris, M. (1997): Sexual networks and HIV. AIDS, 11 Suppl A, S209-216.

Morris, M., \& Kretzschmar, M. (1997). Concurrent partnerships and the spread of HIV. AIDS, 11(5), 641-648.

Morris, M., Kurth, A. E., Hamilton, D. T., Moody, J., \& Wakefield, S. (2009). Concurrent partnerships and HIV prevalence disparities by race: linking science and public health practice. Am J Public Health, 99(6), 1023-1031.

Morris, M., Zavisca, J., \& Dean, L. (1995). Social and sexual networks: their role in the spread of HIVIAIDS among young gay men. AIDS Educ Prev, 7(5 Suppl), 24-35.

Muller, M. P., \& Detsky, A. S. (2010). Public reporting of hospital hand hygiene compliance--helpful or harmful? JAMA, 304(10), 1116-1117.

Murphy, D., Carrico, R., \& Warye, K. (2008). Building the infection prevention system of tomorrow: proceedings of the 2007 APIC Futures Summit. Am J Infect Control, 36(4), 232-240.

Neely, A. N. (2000). A survey of gram-negative bacteria survival on hospital fabrics and plastics. J Burn Care Rehabil, 21(6), 523-527. 
Netstate.com. (2009, September 24, 2009). Kentucky: the geography of Kentucky. Retrieved June 29, 2010, from http://www.netstate.com/states/geography/ky_geography.htm

O'Malley, A. J., \& Marsden, P. V. (2009). The Analysis of Social Networks. (13873741 (Electronic)).

Oh, H. S., Chung, H. W., Kim, J. S., \& Cho, S. I. (2006). National survey of the status of infection surveillance and control programs in acute care hospitals with more than 300 beds in the Republic of Korea. Am J Infect Control, 34(4), 223-233.

Olmsted, R. N., Kowalski, C. P., Krein, S. L., \& Saint, S. (2006). Reading habits of infection control coordinators in the United States: peer-reviewed or non-peer-reviewed evidence? Am J Infect Control, 34(10), 616-620.

Owens, C. D., \& Stoessel, K. (2008). Surgical site infections: epidemiology, microbiology and prevention. $J$ Hosp Infect, 70 Supp/ 2, 3-10.

Plickert, G., Côté, R. R., \& Wellman, B. (2007). It's not who you know, it's how you know them: Who exchanges what with whom? Social Networks, 29(3), 405-429.

Potterat, J. J., Muth, S. Q., Rothenberg, R. B., Zimmerman-Rogers, H., Green, D. L., Taylor, J. E., et al. (2002). Sexual network structure as an indicator of epidemic phase. Sex Transm Infect, 78 Suppl 1, i152-158.

Potterat, J. J., Phillips-Plummer, L., Muth, S. Q., Rothenberg, R. B., Woodhouse, D. E., Maldonado-Long, T. S., et al. (2002). Risk network structure in the 
early epidemic phase of HIV transmission in Colorado Springs. Sex Transm Infect, 78 Suppl 1, i159-163.

Rangachari, P. (2009). Knowledge sharing networks in professional complex systems. Journal of Knowledge Management, 13(3), 132.

Rangachari, P. (2010). Knowledge Sharing and Organizational Learning in the Context of Hospital Infection Prevention. Quality Management in Health Care, 19(1), 34

Reagans, R., \& Zuckerman, E. W. (2001). Networks, diversity, and productivity: The social capital of corporate R\&D teams. Organization Science, 12(4), 502.

Reo, N., Morbius, M. M., \& Rosenblat, T. (2007). Social Networks and Vaccination Decisions.

Rice, R. E. (1993). Using network concepts to clarify sources and mechanisms of social influence. In J. Richards \& B. G. (Eds.), Progress in Communication Sciences (Vol. 12, pp. 43-62). Norwood, NJ: ABLEX.

Robicsek, A., Beaumont, J. L., Paule, S. M., Hacek, D. M., Thomson, R. B., Jr., Kaul, K. L., et al. (2008). Universal survaillance for methicillin-resistant Staphylococcus aureus in 3 affiliated hospitals. Ann Intern Med, 148(6), 409-418.

Rogers, E. M. (2003). Diffusion of innovations (5th ed.). New York: Free Press.

Roszak, D. B., \& Colwell, R. R. (1987). Survival strategies of bacteria in the natural environment. Microbiol Rev, 51(3), 365-379. 
Rothenberg, R., Baldwin, J., Trotter, R., \& Muth, S. (2001). The risk environment for HIV transmission: results from the Atlanta and Flagstaff network studies. J Urban Health, 78(3), 419-432.

Rothenberg, R., Muth, S. Q., Malone, S., Potterat, J. J., \& Woodhouse, D. E. (2005). Social and geographic distance in HIV risk. Sex Transm Dis, 32(8), 506-512.

Rothenberg, R., Potterat, J., Woodhouse, D., Muth, S., Darrow, W., \& Klovdahl, A. (1998). Social network dynamics and HIV transmission. AIDS, 12(12), $1529-1536$.

Rural Assistance Center. (2010, March 4, 2010). Kentucky. Retrieved March 10, 2010, from http://www.raconline.org/states/kentucky.php

Ryan, B., \& Gross, N. (1943). The diffusion of hybrid seed corn in two lowa communities. Rural Sociology, 8(1), 15-24.

Sabidussi, G. (1966). The centrality index of a graph. [10.1007/BF02289527]. Psychometrika, 31(4), 581-603.

Sales, A. E., Estabrooks, C. A., \& Valente, T. W. (2010). The impact of social networks on knowledge transfer in long-term care facilities: protocol for a study. Implement Sci, 5(1), 49.

Sarma, J. B., \& Ahmed, G. U. (2010). Infection control with limited resources: why and how to make it possible? Indian J Med Microbiol, 28(1), 11-16.

Scheckler, W. E., \& Peterson, P. J. (1986). Infections and infection control among residents of eight rural Wisconsin nursing homes. Arch Intern Med, 146(10), 1981-1984. 
Seeman, T. E., \& Berkman, L. F. (1988). Structural characteristics of social networks and their relationship with social support in the elderly: who provides support. Soc Sci Med, 26(7), 737-749.

Sekimoto, M., Imanaka, Y., Kobayashi, H., Okubo, T., Kizu, J., Kobuse, H., et al. (2009). Factors affecting performance of hospital infection control in Japan. Am J Infect Control, 37(2), 136-142.

Stone, P. W., Dick, A., Pogorzelska, M., Horan, T. C., Furuya, E. Y., \& Larson, E. (2009). Staffing and structure of infection prevention and control programs. Am J Infect Control, 37(5), 351-357.

Stone, P. W., Glied, S. A., McNair, P. D., Matthes, N., Cohen, B., Landers, T. F., et al. (2010). CMS changes in reimbursement for HAls: setting a research agenda. Med Care, 48(5), 433-439.

Stricof, R. F., Schabses, K. A., \& Tserenpuntsag, B. (2008). Infection control resources in New York State hospitals, 2007. (1527-3296 (Electronic)).

Tablan, O. C., Anderson, L. J., Besser, R., Bridges, C., \& Hajjeh, R. (2004). Guidelines for preventing health-care--associated pneumonia, 2003: recommendations of CDC and the Healthcare Infection Control Practices Advisory Committee. MMWR Recomm Rep, 53(RR-3), 1-36.

Terrell, J. E. (2010). Social network analysis of the genetic structure of Pacific islanders. Ann Hum Genet, 74(3), 211-232.

The Joint Commission. (2010). Benefits of Joint Commission accreditation.

Retrieved July 11, 2010, from http://www.jointcommission.org/HTBAC/benefits_accreditation.htm 
The Kentucky Telehealth Network. (2010). Kentucky telehealth board. Retrieved October 16, 2010, from http://www.kthnschedule.com/

United States Department of Labor. (2010). Occupational Safety and Health Standards, Toxic and Hazardous Substances, Bloodborne Pathogens (Vol. 1910). Washington, DC.

United States Environmental Protection Agency. (2009). Selected EPAregistered Disinfectants. Retrieved August 14, 2010, from http://www.epa.gov/oppad001/chemregindex.htm

Valente, T. W., \& Davis, R. L. (1999). Accelerating the diffusion of innovations using opinion leaders. Annals of the American Academy of Political and Social Science, 566, 55-67.

Valente, T. W., \& Foreman, R. K. (1998). Integration and radiality: measuring the extent of an individual's connectedness and reachability in a network. Social Networks, 20(1), 89-105.

Valente, T. W., \& Fosados, R. (2006). Diffusion of innovations and network segmentation: the part played by people in promoting health. Sex Transm Dis, 33(7 Suppl), S23-31.

Valente, T. W., \& Rogers, E. M. (1995). The origins and development of the diffusion of innovations paradigm as an example of scientific growth. Sci Commun, 16(3), 242-273.

Valente, T. W., Unger, J. B., \& Johnson, C. A. (2005). Do popular students smoke? The association between popularity and smoking among middle school students. Journal of Adolescent Health, 37(4), 323-329. 
Valente, T. W., \& Vlahov, D. (2001). Selective risk taking among needle exchange participants: implications for supplemental interventions. Am J Public Health, 91(3), 406-411.

Vehovar, V., Manfreda, K. L., Koren, G., \& Hlebec, V. (2008). Measuring egocentered social networks on the web: Questionnaire design issues. Social Networks, 30(3), 213-222.

Wellman, B., \& Wortley, S. (1990). Different strokes from different folks: Community ties and social support. American Journal of Sociology, 96(3), 558.

West, E., \& Barron, D. N. (2005). Social and geographical boundaries around senior nurse and physician leaders: an application of social network analysis. Can J Nurs Res, 37(3), 132-148.

Williams, M. L., Trotter II, R. T., Zhuo, Z., Siegal, H. A., Robbles, R. R., \& Jones, A. (1995). An investigation of the HIV risk behaviors of drug use networks. Connections, 18(1), 58-72.

Wohlfeiler, D. (2000). Structural and environmental HIV prevention for gay and bisexual men. AIDS, 14 Suppl 1, S52-56.

Wright, S. B., Ostrowsky, B., Fishman, N., Deloney, V. M., Mermel, L., \& Perl, T. M. (2010). Expanding roles of healthcare epidemiology and infection control in spite of limited resources and compensation. Infect Control Hosp Epidemiol, 31(2), 127-132. 
Wylie, J. L., Shah, L., \& Jolly, A. (2007). Incorporating geographic settings into a social network analysis of injection drug use and bloodborne pathogen prevalence. Health Place, 13(3), 617-628.

Yang, S., \& Farn, C. (2009). Social capital, behavioural control, and tacit knowledge sharing - A multi-informant design. International Journal of Information Management, 29(3), 210.

Zheng, K., Padman, R., Krackhardt, D., Johnson, M. P., \& Diamond, H. S. (2010). Social networks and physician adoption of electronic health records: insights from an empirical study. J Am Med Inform Assoc, 17(3), 328-336. 
Appendix A: Survey Instrument 


\section{Kentucky Infection Prevention Knowledge Sharing Social Networks}

Created: October 23 2010, 3:08 PM

Last Modified: November 28 2010, 9:20 AM

Design Theme: Basic Green

Language: English

Button Options: Labels

Disable Browser "Back" Button: False

\section{Kentucky Infection Prevention Knowledge Sharing Social Networks}

Page 1 - Image

The University of Louisville School of Public Health and Information Sciences and School of Medicine is inviting you to participate in a survey of infection preventionists throughout Kentucky as part of the Severe Influenza Pneumonia Surveillance (SIPS) Project. The purpose of the survey is to learn more about the networks that allow infection preventionists (IPs) to share knowledge among each other. This information will be used to help all IPs better understand how knowledge is spread throughout your professional network. It may also assist you in indentifying resources for infection prevention information.

Your participation in this survey is voluntary. The results of this study may be included in unpublished reports, published in scientific research journals, or presented at professional conferences. Any and all identifying information will be coded to ensure that none of your personal information is ever shared with others.

There are four sections and 36 questions in this survey. The survey should take you approximately 10-15 minutes to complete. If you have any questions, please contact Tim Wiemken, SIPS Clinical Coordinator, at tim.wiemken@louisville.edu / 502-852-1144 or Ruth Carrico at ruth.carrico@louisville.edu / 502-852-3992.

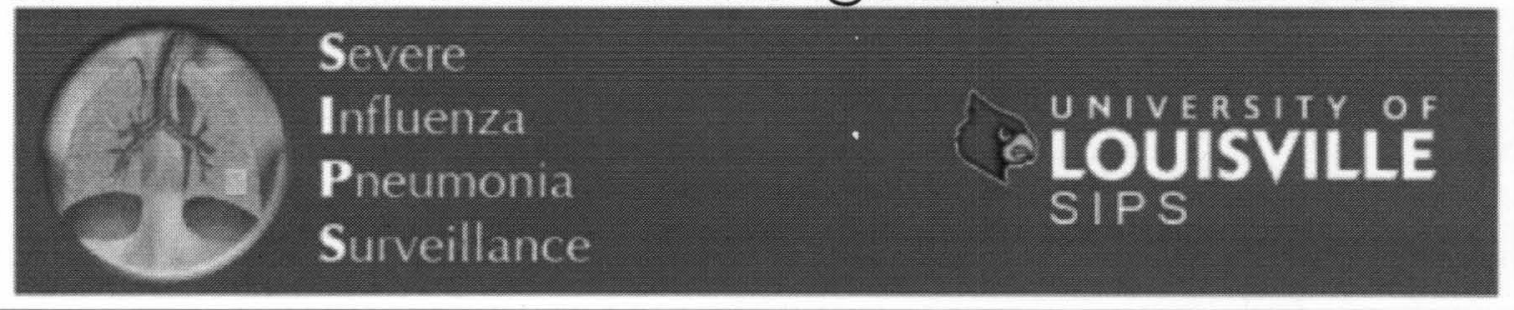


Page 1 - Heading

DEMOGRAPHIC INFORMATION

[8 ITEMS]

Page 1 - Question 1 - Choice - One Answer (Bullets)

Please select your age group:
O $18-25$
O 26-45
O $46-55$
O $56-65$
O Over 65

Page 1 - Question 2 - Choice - One Answer (Bullets)

Please select your gender:

O Male

Female

Transgender

Page 1 - Question 3 - Choice - One Answer (Bullets)

Please select your race/ethnicity:

O Black/African American - Non-Hispanic

White/Caucasian - Non-Hispanic

O Black/African American - Hispanic

O White/Caucasian - Hispanic

O Asian

Other, please specify

Page 1 - Question 4 - Choice - One Answer (Bullets)

Please select your highest level of education:

O Some College (no degree)

O 2 Year College Degree

O 4 Year (Bachelor's or Equivalent) College Degree

O Some Post-graduate Education

O Master's Degree

$\bigcirc$ Professional Degree (Nurse Practitioner, Physicians Assistant) 
Doctoral Degree (PhD, MD, etc.)

Other, please specify

Page 1 - Question 5 - Choice - One Answer (Bullets)

Are you certified in Infection Control and Epidemiology $(\mathrm{CIC})$ through the Certification Board on Infection Control and Epidemiology (CBIC)?

O Yes

O No

I don't know what this is

Page 1 - Question 6 - Choice - One Answer (Bullets)

Are you a member of the Association for Professionals in Infection Control (APIC)?

O Yes

O No

O I do not know about APIC

Page 1 - Question 7 - Choice - One Answer (Bullets)

To which local APIC Chapter do you belong?

O Bluegrass

O Kentuckiana

O Western Kentucky

$O$ I am not an APIC member

O I do not belong to an APIC Chapter

$O$ I do not know about APIC

Page 1 - Question 8 - Choice - One Answer (Bullets)

Do you regularly attend your local APIC Chapter meetings?

O Yes

O No

I am not an APIC member

$O$ I do not know about APIC 
Page 2 - Heading

\section{EMPLOYMENT INFORMATION}

[7 ITEMS]

Page 2 - Question 9 - Open Ended - One Line

What is your current job title?

[Example: Infection Control Coordinator, Infection Prevention Director, Infection

Control Practitioner, etc. - please be as specific as possible]

Page 2 - Question 10 - Choice - One Answer (Bullets)

How long have you been in your current position?

Less than 1 year

O 1-2 years

o 3-5 years

6-10 years

More than 10 years

Page 2 - Question 11 - Choice - One Answer (Bullets)

What percentage of your daily efforts are dedicated to the practice of infection prevention?

None

Less than 20\% [One Day Per Week]

O $20 \%-50 \%$

More than $50 \%$ but less than $100 \%$

o $100 \%$ [Five or More Days Per Week]

Page 2 - Question 12 - Choice - One Answer (Bullets)

How long has your career (including jobs prior to your current) included a focus on infection prevention?

Less than 1 year

O 1-2 years

o 3-5 years

O 6-10 years

O More than 10 years 
Page 2 - Question 13 - Choice - One Answer (Bullets)

How is your facility classified?

O Critical Access Hospital

O Acute Care Facility

Long-Term Acute Care Facility

O Other

Page 2 - Question 14 - Choice - One Answer (Bullets)

Is your facility affiliated with an academic institution such as the University of Louisville or the University of Kentucky?

O Yes

O No

O I am not sure

Page 2 - Question 15 - Choice - One Answer (Bullets)

Does your facility report infection data to the National Healthcare Safety Network (NHSN)?

O Yes

O No

O I do not know what NHSN is.

Page 3 - Heading

\section{COMMUNICATION}

[17 ITEMS]

The following questions are about who you share knowledge with regarding infection prevention-related activities.

Please only include names of other infection preventionists in Kentucky. For your assistance, we have included a list of all of the infection preventionists in Kentucky from which you can choose.

Page 3 - Question 16 - Rating Scale - Matrix

How often do you obtain infection prevention-related information from each of these sources?

\begin{tabular}{|l|l|l|l|l|l|}
\hline & Never & Rarely & Sometimes & Often & $\begin{array}{l}\text { All of } \\
\text { the time }\end{array}$ \\
\hline Face-to-face communication & & & & & \\
\hline Email communication & & & & & \\
\hline
\end{tabular}




\begin{tabular}{|l|l|l|l|l|l|}
\hline $\begin{array}{l}\text { Virtual meetings (Skype, } \\
\text { Kentucky TeleHealth Network, } \\
\text { etc.) }\end{array}$ & & & & & \\
\hline In-person training sessions & & & & & \\
\hline Web-based training sessions & & & & & \\
\hline $\begin{array}{l}\text { Reading scientific literature } \\
\text { [American Journal of Infection } \\
\text { Control, Infection Control and } \\
\text { Hospital Epidemiology Journal, } \\
\text { etc.] }\end{array}$ & & & & & \\
\hline Mentorship & & & & & \\
\hline $\begin{array}{l}\text { Governmental or Organizational } \\
\text { Websites [www.cdc.gov, } \\
\text { www.who.org, www.apic.org, } \\
\text { etc.] }\end{array}$ & & & & & \\
\hline $\begin{array}{l}\text { Popular Press (CNN, FOX } \\
\text { News, etc.) }\end{array}$ & & & & & \\
\hline
\end{tabular}

Page 3 - Heading

The next five questions are regarding the other infection preventionists to whom you provide infection prevention-related knowledge. If you gave infectionprevention-related information to another infection preventionist in Kentucky, this would constitute providing knowledge.

Page 3 - Question 17 - Choice - One Answer (Drop Down)

Over the past six months, who were the top five (5) infection preventionists in Kentucky to whom you provided infection prevention-related knowledge (e.g. via meetings, phone calls, email, fax, letters, etc.)?

If you do not provide knowledge to anyone or their name is not listed, please select 'none'. If the Infection Preventionist you would like to choose is not listed, you will be able to write in names after these five questions.

Select your first choice here:

O None

O Name Roster -- Hospital

Page 3 - Question 18 - Choice - One Answer (Drop Down)

Select your second choice here:

O None

O Name Roster -- Hospital 
Page 3 - Question 19 - Choice - One Answer (Drop Down)

Select your third choice here:

O None

O Name Roster -- Hospital

Page 3 - Question 20 - Choice - One Answer (Drop Down)

Select your fourth choice here:

O None

O Name Roster -- Hospital

Page 3 - Question 21 - Choice - One Answer (Drop Down)

Select your fifth and final choice here:

O None

O Name Roster -- Hospital

Page 3 - Question 22 - Open Ended - Comments Box

If the Infection Preventionist(s) you would like to choose was/were not listed in the drop-down menus, please write their names and facilities here. Please only include those that practice Infection Prevention in Kentucky Hospitals.

Page 3 - Question 23 - Choice - One Answer (Bullets)

On average, approximately how often do you provide your knowledge to those individuals you selected in the previous five questions?

O Daily

Weekly

O Monthly

Q Quarterly

O Yearly 
Page 3 - Heading

The second five questions are regarding the infection preventionists from whom you ask for infection prevention-related knowledge. If you asked another infection preventionist in Kentucky for infection-prevention-related information, this would constitute asking for knowledge.

Page 3 - Question 24 - Choice - One Answer (Drop Down)

Over the past six months, who were the top five (5) infection preventionists in Kentucky from whom you asked for infection prevention-related knowledge (e.g. via meetings, phone calls, email, fax, letters, etc.)?

If you do not ask for knowledge from anyone or their name is not listed, please select 'none'. If the Infection Preventionist you would like to choose is not listed, you will be able to write in names after these five questions.

Select your first choice here:

None

O Name Roster -- Hospital

Page 3 - Question 25 - Choice - One Answer (Drop Down)

Select your second choice here:

O None

O Name Roster -- Hospital

Page 3 - Question 26 - Choice - One Answer (Drop Down)

Select your third choice here:

O None

O Name Roster -- Hospital

Page 3 - Question 27 - Choice - One Answer (Drop Down)

Select your fourth choice here:

O None

O Name Roster -- Hospital

Page 3 - Question 28 - Choice - One Answer (Drop Down)

Select your fifth and final choice here: 
O None

O Name Roster -- Hospital

Page 3 - Question 29 - Open Ended - Comments Box

If the Infection Preventionist(s) you would like to choose was/were not listed in the drop-down menus, please write their names and facilities here. Please only include those that practice Infection Prevention in Kentucky Hospitals.

Page 3 - Question 30 - Choice - One Answer (Bullets)

On average, approximately how often do you ask for knowledge from the individuals you selected in the previous five questions?
Daily
O Weekly
O Monthly
Q Quarterly
O Yearly

Page 3 - Heading

The next questions are regarding how many people you share knowledge with that are not infection preventionists in Kentucky.

Page 3 - Question 31 - Choice - One Answer (Bullets)

In a typical week, approximately how many infection preventionists outside of Kentucky do you call, email, meet with, or other wise share knowledge with regarding infection prevention?

O Nobody

1-2 people

2-4 people

5-10 people

- More than 10 people 
Page 3 - Question 32 - Choice - One Answer (Bullets)

In a typical week, approximately how many people other than infection preventionists do you call, email, meet with, or other wise share knowledge with regarding infection prevention? These people may be physicians, nurses, health department personnel, etc.

- Nobody

1-2 people

O 2-4 people

5-10 people

O More than 10 people

Page 4 - Heading

\section{PERSONAL INFORMATION}

\section{[4 ITEMS]}

The personal information included in this section will not be shared with anyone. This information will only be used to link your responses with those infection preventionists you chose in each of the prior questions. Once this is completed, your name will be permanently deleted. Only de-identified information will be analyzed and nobody will be able to identify you or your answers. The information you provide will help to build a visual knowledge network and without it, the development of the network will not be possible.

Page 4 - Question 33 - Choice - One Answer (Drop Down)

Please select your name. If your name is not in this list, please select "not listed".

Not Listed

O Name Roster

Page 4 - Question 34 - Open Ended - Comments Box If your name was not listed above, please include it here. 
Page 4 - Question 35 - Name and Address (General)

Please provide your email address if you wish to be emailed the results of this survey when analysis is complete.

Email Address

Page 4 - Question 36 - Name and Address (General)

Please complete the following information about the hospital for which you currently work.

¿ Hospital Name

Address 1

* Address 2

City/Town

× State/Province

× Zip/Postal Code

Thank You Page

Thank you for taking the time to complete this survey! If you included your e-mail address, you will be emailed results when the analysis is complete. 


\section{CURRICULUM VITAE}

NAME: $\quad$ Timothy Lee Wiemken

ADDRESS: 2017 Sherwood Ave

Louisville, KY 40205

PHONE: $\quad$ 502-263-8786

EMAIL: tim.wiemken@gmail.com

DOB: $\quad$ December 11, 1979

SPOUSE: Cassandra Jane Wiemken

CHILDREN: None

Education

2007-Present University of Louisville, Doctor of Philosophy, Public Health Sciences - Health Promotion and Behavioral Sciences Doctoral Candidacy, March 2010.

Dissertation Title: Knowledge-sharing networks of hospitalbased infection preventionists in Kentucky.

2004-2006

Saint Louis University, Master of Public Health, Epidemiology

2001-2003 Southern Illinois University, Bachelor of Arts, Microbiology

1998-2001 Sauk Valley College, Associate in Science, Biology

Employment

2008 -Present Database Analyst, University of Louisville Division of Infectious Diseases

2008 - Present Clinical Research Associate, Veterans Affairs Hospital, Louisville, KY 
2008 - Present Data Specialist, Kindred Hospital, Louisville, KY

2007-2008 Biological Safety Specialist, University of Louisville

2006-2007 Infection Preventionist, University of Louisville Healthcare

2004-2006 Program Evaluation Specialist, Saint Louis University Heartland Centers for Public Health and Community Capacity Development

2006 Research Assistant, Missouri Syphilis Elimination Project

2005 Epidemiologist Intern, Communicable Disease Control Services, Saint Louis County Department of Health

$2004 \quad$ Microbiologist, Abbott Laboratories

2002-2003 Research Assistant - Molecular Mutagenesis, Southern Illinois University, Carbondale

2001-2003 Natural Science Technician - Southern Illinois University Carbondale

1998-2003 Funeral Director Assistant, McDonald Funeral Home

\section{Ongoing Research Support}

1. Period: 2009-present

Title: "Severe Influenza Pneumonia Surveillance (SIPS) Network"

Goal: To develop and implement a comprehensive surveillance plan for pandemic influenza based on clinical and laboratory-based surveillance.

Sponsor: United States Department of Homeland Security/Department of Hometown Security.

Role: Clinical Coordinator

2. Period: 2010-present

Title: "Effectiveness of Empiric Antiviral Treatment for Hospitalized Community Acquired Pneumonia during the Influenza Season".

Sponsor: United States Department of Health and Human Services, Centers for Disease Control and Prevention.

Role: Subinvestigator 


\section{Scientific Reviewer for:}

1. Annals of Internal Medicine (top $30 \%$ of reviewers for 2009)

2. Chest

3. Journal of Public Health and Epidemiology

\section{Books and Book Chapters}

1. Wiemken T. APIC Text of Infection Control and Epidemiology: Chapter 6, Statistical Process Control. Carrico R (editor). Association for Professionals in Infection Control (APIC). 2009.

2. Carrico R, Wiemken T. Guide to the Elimination of Clostridium difficile in healthcare facilities. Association for Professionals in Infection Control (APIC). 2008.

\section{Peer Reviewed Manuscripts}

1. Haque NZ, Cahuayme Zuniga L, Peyrani $P$, Reyes $K$, Lamerato L, Moore $\mathrm{CL}$, Patel S, Allen M, Peterson E, Wiemken T, Cano E, Mangino JE, Kett $\mathrm{DH}$, Ramirez JA, Zervos MJ; the Improving Medicine through Pathway Assessment of Critical Therapy of Hospital-Acquired Pneumonia (IMPACT-HAP) Investigators. Relationship of Vancomycin MIC to Mortality in Patients with Methicillin-Resistant Staphylococcus aureus HospitalAcquired, Ventilator-Associated and Healthcare-Associated Pneumonia. Chest. 2010 Dec;138(6):1356-6.

2. Bordon J, Wiemken T, Peyrani P, Paz ML, Gnoni M, Cabral P, Venero MD, Ramirez J, CAPO Study Group. Decrease in long-term survival for hospitalized patients with community-acquired pneumonia. Chest. August 2010 138(2): 279-283.

a. Editorial: Hurley, JC. Bob Hope, Pneumonia, and the Counterfactual. Chest, August 2010 138(2): 248-249.

3. Riquelme R, Riquelme M, Rioseco ML, Inzunza C, Gomez Y, Contreras C, Riquelme J, Peyrani P, Wiemken T, Ramirez J. Characteristics of hospitalized patients with 2009 H1N1 influenza in Chile. Eur Resp J. 2010 Feb 25. [Epub ahead of print] 
2. Griffin A, Peyrani P, Wiemken T, Arnold F. Macrolides verusus Quinolones for Treatment of Legionella Pneumonia. Int J Tuberc Lung Dis. 2010 Apr; 14(4):495-9.

3. Beavers S, Blossom D, Wiemken T, Goss L, Kawaoka K, Wong A, Srinivasan A. Comparison of Risk Factors for Recovery of Acinetobacter During Outbreaks at Two Kentucky Hospitals, 2006. Public Health Rep. 2009 Nov-Dec; 124(6): 868-74.

4. Mirsaeidi $M$, Peyrani $P$, Ramirez $J$ and the IMPACT-HAP Investigators. Predicting Mortality in Patients with Ventilator-associated Pneumonia: The APACHE II Score Versus the New IBMP-10 Score. Clin Infect Dis. 2009 Jul 1; 49(1): $72-7$.

\section{Non-Peer Reviewed Manuscripts and Reports}

1. Griffin A, Peyrani $P$, Wiemken $T$, Arnold $F$. Elderly Patients with Legionella Pneumonia. Kentucky Medical Journal. 2010, February, 108(2): 54-59.

2. Umoren I, Nakamatsu $R$, Sciortino $C$, Sarver J, Blake $S$, Peyrani $P$, Wiemken ' $T$, Woods $C$, Ramirez $J$. An Investigation of an Outbreak: Methicillin-resistant Staphylococcus aureus Colonization in an Intensive Care Cardiac Unit. Kentucky Medical Journal. 2009,107:443-449.

3. Wright, K, Edgar M, Wiemken T, Scharff D. Kansas Local Public Health Department Needs Assessment, May, 2006.

4. Wiemken T. Risk Factors for STD Infection among Men Who Have Sex with Men in a Saint Louis, MO Area Bathhouse. December, 2005.

5. Blaskiewicz, Robert, Chrusciel, Tim, Wiemken, Timothy, Deshpande, Anjali. The Risk of Small for Gestational Age Infant in Twin vs. Singleton Births and Effect Modification. Obstet Gynecol. 2006 April;107 (4 Suppl):62S

6. Wiemken T. Saint Louis County, MO Sexually Transmitted Disease Epidemiologic Profile, 2005.

7. Wiemken T. Saint Louis County, MO Pertussis Epidemiologic Profile, 2005.

8. Wiemken T. Saint Louis County, MO Tuberculosis Epidemiologic Profile, 2005. 
9. Wiemken T. Saint Louis County, MO Perinatal Hepatitis B Epidemiologic Profile, 2005.

10. Wiemken T. Saint Louis County, MO Infertility Prevention Project Chlamydia Report, 2005.

11. Wiemken T. Environmental Public Health Leadership Institute Speaker Evaluation. 2005.

12. Edgar $M$, Wiemken T. First Annual Maternal and Child Health Conference, 2005.

13. Edgar M, Wiemken T. Jimmy's Getting Better: A Lead Awareness Program. 2005.

14. Wiemken T. Transmissible Spongiform Encephalopathies. 2005.

15. Wright K, Edgar M, Wiemken T. Missouri Local Public Health Department Needs Assessment, 2004.

16. Wright K, Edgar M, Wiemken T. Kansas State Public Health Department Needs Assessment, 2004.

17. Wright K, Edgar M, Wiemken T. Missouri State Public Health Department Needs Assessment, 2004

18. Wright $\mathrm{K}$, Edgar $\mathrm{M}$, Wiemken $\mathrm{T}$. A Retrospective Evaluation of the Missouri Public Health Leadership Institute Cycles 1-8, 2004.

19. Edgar M, Wiemken T. State Emergency Operations Center/Disaster Situation Room Crisis Leadership 3 Day Training Executive Summary and Evaluation Report, 2004.

20. Ewertowski K, Edgar, M, Wiemken T. Project Ready Emergency Preparedness Needs Assessment and Public Health Ready Certification Procedure for Independence, Missouri, 2004.

\section{Abstracts, Posters and Oral Conference Presentations}

1. Pasquale $T$, Salstrom $S$, Jabrocki B, Wiemken $T$, Peyrani $P$, Haque $N$, Zervos M, Ramirez J, Scerpella E, Ford K, File T. Molecular Evaluation of MRSA in Patients with Nosocomial Pneumonia: Early Onset Versus Late Onset. Infectious Diseases Society of America $48^{\text {th }}$ Annual Meeting, Vancouver BC, Canada. October 21-October 24, 2010 [Abstract \# 463]. 
2. Pallam H, McCurley K, Harting J, Clay J, Hall M, Muldoon S, Wiemken T, Peyrani P, Ramirez J. Correlation of Antibiotic Exposure with Development of Extreme Drug Resistant Acinetobacter baumannii. American Public Health Association 138th Annual Conference, November 4-10, 2010. Oral Presentation, [Poster 225520].

3. Pallam H, McCurley K, Harting J, Clay J, Hall M, Muldoon S, Wiemken T, Peyrani P, Ramirez J. Evaluating the Role of the Environment in an Outbreak Investigation of Acinetobacter baumannii: Application of Social Network Analysis. American Public Health Association 138th Annual Conference, November 4-10, 2010, Oral Presentation, [Poster 225261].

4. Kapoor R, Wiemken T, Davidson A, Peyrani P, Nakamatsu R, Huang A, Barve S, Ramirez J. Impact of Heavy Alcohol Use on HIV Disease Progression in the Era of HAART. Infectious Diseases Society of America $47^{\text {th }}$ Annual Meeting, Philadelphia, PA. October 29-November 1, 2009 [Abstract \# 348].

5. Scerpella EG, Welch VL, Peyrani $P$, Haque NZ, Ford KD, Mangino JE, Kett DH, Zervos MJ, Ramirez JA, the IMPACT-HAP Study Group. Outcome of Intensive Care Unit (ICU) Patients with Hospital-Acquired Pneumonia (HAP) Is Not Related to Causative Organism: Results from the IMPACT HAP Study. Infectious Diseases Society of America $47^{\text {th }}$ Annual Meeting, Philadelphia, PA. October 29-November 1, 2009 [Abstract \# 378].

6. Gnoni M, Cabral P, Wiemken T, Peyrani P, Snyder J, Patel A, Ramirez. Incidence and Etiology of Early (E) and Late (L) Onset VentilatorAssociated Pneumonia (VAP) in a University Hospital. Infectious Diseases Society of America $47^{\text {th }}$ Annual Meeting, Philadelphia, PA. October 29November 1, 2009 [Abstract \# 380].

7. Allen $M$, Mirsaeidi $M$, Cabral $P$, Gnoni M, Peyrani $P$, Mangino J, Zervos $M$, Kett D, Ford K, Scerpella E, Ramirez J, the IMPACT-HAP Study Group. Clinical Outcomes of Patients with HAPNAP Due to PVL(+) vs. PVL(-) MRSA: Results from the IMPACT-HAP Study. Infectious Diseases Society of America $47^{\text {th }}$ Annual Meeting, Philadelphia, PA. October 29-November 1, 2009 [Abstract \# 381].

8. Gnoni M, Wiemken T, Peyrani P, Cabral P, Uriarte S, Ramirez J. Mortality in Patients with Ventilator-Associated Pneumonia and Severe Sepsis Is Determined by the Number of Organ Failures. Infectious Diseases Society of America $47^{\text {th }}$ Annual Meeting, Philadelphia, PA. October 29-November 1, 2009 [Abstract \# 391]. 
9. Kett DH, Cano E, Quartin AA, Castelblanco AS, Ramirez JA, Mangino JE, Zervos MJ, Peyrani P, Ford KD, Scerpella EG, and the IMPACT-HAP Study Group. Management of Health Care Associated Pneumonia (HCAP): Economic Assessment of Compliance to the American Thoracic Society (ATS) and the Infectious Diseases Society of America (IDSA) Guidelines. Infectious Diseases Society of America $47^{\text {th }}$ Annual Meeting, Philadelphia, PA: October 29-November 1, 2009 [Abstract \# 392].

10. Wiemken T, Peyrani P, Sarver J, Lattus J, Coates L, Blake S, Nakamatsu R, Sciortino C. Active Surveillance for MRSA in Hospitalized Patients: Impact on Colonization and Bacteremia. Infectious Diseases Society of America $47^{\text {th }}$ Annual Meeting, Philadelphia, PA. October 29-November 1, 2009 [Abstract \# 486].

11. Wiemken T, Cabral P, Peyrani $P$, Arnold F, Bryant K, Nakamatsu R, Summersgill J, Sciortino C, Snyder J, Ramirez J. Severe Influenza Pneumonia Surveillance (SIPS) Project: A Tool for the Detection of Human and Non-Human Strains of Influenza A in Kentucky. Infectious Diseases Society of America $47^{\text {th }}$ Annual Meeting, Philadelphia, PA. October 29-November 1, 2009 [Abstract \# 522].

12. Allen M, Peyrani $P$, Roberts $C$, Seligson D, Chen A, Zervos M, Ramirez J. Clinical Outcomes of Patients with Osteomyelitis Due to CommunityAssociated MRSA Versus Hospital-Associated MRSA: Results from the BAJIO Study Group. Infectious Diseases Society of America $47^{\text {th }}$ Annual Meeting, Philadelphia, PA. October 29-November 1, 2009 [Abstract \# 942].

13. Peyrani $P$, Wiemken $T$, Ramirez $J$, the CAPO Investigators. Worldwide Perspective of the Quality of Care Delivered to Hospitalized Patients with Community-Acquired Pneumonia: Results from the CAPO International Cohort Study. Infectious Diseases Society of America $47^{\text {th }}$ Annual Meeting, Philadelphia, PA. October 29-November 1, 2009 [Abstract \# 944].

14. Burdette S, Peyrani P, Wiemken T, Ramirez J, the CAPO Investigators. Mortality in Community-Acquired Pneumonia for Patients with No Diabetes vs. Controlled Diabetes and Uncontrolled Diabetes: Results from the CAPO International Cohort Study. Infectious Diseases Society of America $47^{\text {th }}$ Annual Meeting. Philadelphia, PA. October 29-November 1, 2009 [Abstract \# 945].

15. Bordon J, Wiemken T, Peyrani P, Ramirez J. Significant Decrease in Long-Term Survival for Hospitalized Patients with Community-Acquired 
Pneumonia. Infectious Diseases Society of America $47^{\text {th }}$ Annual Meeting, Philadelphia, PA. October 29-November 1, 2009 [Abstract \# 948].

16. Malinis $M$, Myers $J$, Bordon $J$, Peyrani $P$, Kapoor R, Nakamatsu R, Lopardo G, Torres A, Feldman C, Allen M, Arnold F, Ramirez J, the CAPO Investigators. Clinical Outcomes of HIV-Infected Patients Hospitalized with Community-Acquired Pneumonia: Results from CAPO International Cohort Study. Infectious Diseases Society of America $47^{\text {th }}$ Annual Meeting, Philadelphia, PA. October 29-November 1, 2009 [Abstract \# 953].

17. Peyrani $P$, Mirsaeidi $M$, Ramirez $J$, the CAPO Investigators. Female Gender Is Associated with Poor Outcomes in Patients Hospitalized with Community-Acquired Pneumonia: Results from the CAPO International Cohort Study. Infectious Diseases Society of America $47^{\text {th }}$ Annual Meeting, Philadelphia, PA. October 29-November 1, 2009 [Abstract \# 956].

18. Nakamatsu R, Mirsaeidi M, Peyrani $P$, Arnold $F$, Ramirez J, the CAPO Investigators. Pleural Effusion Predicts Poor Outcomes in Hospitalized Patients with Community-Acquired Pneumonia: Results from the CAPO International Cohort Study. Infectious Diseases Society of America 47th Annual Meeting, Philadelphia, PA. October 29-November 1, 2009 [Abstract \# 959].

19. Kapoor R, Wiemken T, Peyrani P, Allen M, Ramirez J, Arnold F, the CAPO Investigators. Clinical Outcomes of Patients with CommunityAcquired Pneumonia Caused by Community-Acquired MRSA vs. MSSA. Infectious Diseases Society of America 47th Annual Meeting, Philadelphia, PA. October 29-November 1, 2009 [Abstract \# 961].

20. Newman, D, Smith S, Peyrani P, Wiemken T, Nakamatsu R, Lattus J, Ramirez J. Physician Acceptance of Switch Therapy and De-Escalation of Therapy Recommendations by the Antimicrobial Stewardship Program. Infectious Diseases Society of America 47th Annual Meeting, Philadelphia, PA. October 29-November 1, 2009 [Abstract \# 965].

21. Ramirez J. Dukart G, Cooper CA, Wiemken T, Gardiner D, Babinchak T. Switch Therapy in Hospitalized Patients with Community-acquired Pneumonia (CAP): Tigecycline versus Levofloxacin. Infectious Diseases Society of America $47^{\text {th }}$ Annual Meeting, Philadelphia, PA. October 29November 1, 2009 [Abstract \# 966].

22. Griffin A, Arnold F, Peyrani $P$, Wiemken $T$, Ramirez $J$, the CAPO Investigators. Macrolides Versus Quinolones for Legionella Pneumonia 
Acquired in the Community: Results from the CAPO International Cohort Study. Infectious Diseases Society of America 47th Annual Meeting, Philadelphia, PA. October 29-November 1, 2009 [Abstract \# 969].

23. Peyrani $P$, Wiemken $T$, Zervos $M$, Ford $K$, Scerpella $E$, Ramirez J, the IMPACT-HAP Study Group. Clinical Outcomes for Patients with MRSA HAP Treated with Vancomycin Versus Linezolid: Results from the IMPACT-HAP Study. Infectious Diseases Society of America 47th Annual Meeting, Philadelphia, PA. October 29-November 1, 2009 [Abstract \# 1250].

24. Arnold F, Lajoie As, Brock G, Peyrani P, Rello J, Menendez R, Lopardo G, Torres $A$, Rossi $P$, Ramirez $J$, the CAPO Investigators. Improving Outcomes in Elderly Patients with Community-Acquired Pneumonia by Adhering to National Guidelines: Results from the CAPO International Cohort Study. Infectious Diseases Society of America 47th Annual Meeting, Philadelphia, PA. October 29-November 1, 2009 [Abstract \# 1325].

25. Smith $S$, Newman D, Mirsaeidi M, Peyrani P, Wiemken $T$, Ramirez $J$, the CAPO Investigators. Early Antibiotic Administration Does Not Decrease Mortality in Hospitalized Patients with Community-Acquired-Pneumonia: Results from the CAPO International Cohort Study. Infectious Diseases Society of America 47th Annual Meeting, Philadelphia, PA. October 29November 1, 2009 [Abstract \# 1326].

26. Bordon J, Wiemken T, Paz ML, Memon S, Venero MC, Cabral P, Gnoni $M$, Peyrani $\mathbf{P}$, RamirezJ. Significant Decrease in Long-term Survival for Hospitalized Patients with Community-Acquired Pneumonia (CAP): Results from the Community-Acquired Pneumonia Organization (CAPO) International Cohort Study. European Respiratory Society 2009 Vienna, Austria, September 12-16, 2009. [Abstract \# 1784, Oral Presentation].

27. Peyrani $P$, Wiemken $T$, Cabral $P$, Gnoni M, Paz ML, Venero MC, Ramirez J. APACHE II Score and Prediction of ventilator-Associated Pneumonia (VAP). European Respiratory Society 2009 Vienna, Austria, September 12-16, 2009. [Abstract \# 2373].

28. Cabral $P$, Gnoni $M$, Wiemken $T$, Karanjeet $R$, Goss L, Nolting $P$, Marini $S$, Peyrani P, Ramirez J. Type of Acute Respiratory Failure and Development of Ventilator-Associated Pneumonia (VAP). European Respiratory Society 2009 Vienna, Austria, September 12-16, 2009. [Abstract \# 2392]. 
29. Gnoni M, Cabral P, Wiemken T, Paz ML, Venero MC, Peyrani P, Ramirez $\mathrm{J}$. Incidence and Etiology of Early (E) and Late (L) onset VentilatorAssociated Pneumonia (VAP) in a University Hospital. European Respiratory Society 2009 Vienna, Austria, September 12-16, 2009. [Abstract \# 2393].

30. Gnoni M, Wiemken T, Peyrani $P$, Cabral $P$, Ramirez J. Mortality in Patients with Ventilator-Associated Pneumonia (VAP) and Severe Sepsis is Determine by the Number of Organ Failures. European Respiratory Society 2009 Vienna, Austria, September 12-16, 2009. [Abstract \# 2394].

31. Forster D, Panchabhai T, Vasquez A, Landes S, Knight J, Espinosa-Ginic M, Cabral P, Wiemken T, Peyrani P, Ramirez J. Risk Factors for the Development of Cardiovascular Events in Patients Hospitalized with Community-Acquired Pneumonia: Results from the CAPO International Cohort Study. Research Louisville 2009 and the CAPO Investigators.

32. Espinosa-Ginic M, Forster D, Panchabhai T, Vasquez A, Landes S, Knight $\mathrm{J}$, Cabral P, Wiemken T, Peyrani $\mathrm{P}$, Ramirez $\mathrm{J}$ and the CAPO Investigators.. Obese Hospitalized Patients with CAP are at Lower Risk for Clinical Failure and Death: Results from the CAPO International Cohort Study. Research Louisville 2009.

33. Olivarez G, Cabral P Vasquez A, Panchabhai T, Forster D, Knight J, Espinoza-Ginic M, Peyrani P, Wiemken T, Ramirez $J$ and the CAPO Investigators.. Antibiotic Resistance Bacteria in Hospitalized Patients with Community-acquired Pneumonia: Infection or Colonization? Research Louisville 2009.

34. Panchabhai T, Vasquez A, Forster D, Knight J, Espinosa-Ginic M, Landes $\mathrm{S}$, Gonzalo O, Wiemken T, Peyrani P, Ramirez J. Impact of Prior Antibiotic Use on Clinical Outcomes of Patients Hospitalized with Community-acquired Pneumonia: Results of the CAPO International Cohort Study. Research Louisville 2009.

35. Vasquez A, Forster D, Panchabhai T, Espinosa-Ginic M, Landes S, Knight $\mathrm{J}$, Cabral $\mathrm{P}$, Wiemken $\mathrm{T}$, Peyrani $\mathrm{P}$, Ramirez $\mathrm{J}$ and the CAPO Investigators. Effect of Adjunctive Corticosteroid Therapy on Clinical Outcomes of Patients Admitted with CAP: Results from the CAPO International Cohort Study. Research Louisville 2009.

36. Knight J, Vasquez A, Wiemken $T$, Stockton $S$, Sedlak J, Peyrani $P$, Ramirez J. Fatal Pneumonia Due to Novel Influenza A Virus Associated with Methicillin-resistant Staphylococcus aureus: A Case Report from the 
Severe Influenza Pneumonia Surveillance Kentucky Project. Research Louisville 2009.

37. Wiemken, Timothy, Carrico, Ruth, Carrico, Jonathan. Social Networking Among Infection Preventionists: Use of a Shared Knowledge Website. The Association for Professionals in Infection Control 36th Annual Meeting. Ft. Lauderdale, FL, June, 2009.

38. Wiemken T, Carrico R, Carrico J. Social Networking Among Infection Preventionists: Use of a Shared Knowledge Website. The Society for Healthcare Epidemiology of America $19^{\text {th }}$ Annual Meeting. San Deigo, CA, March 21, 2009. Poster \#426

39. Sarver J, Umoren I, Peyrani P, Wiemken T, Sciortino C, Blake S, Nakamatsu R, Ramirez J. Investigation of a Methicillin-resistant Staphylococcus aureus Nasal Colonization Outbreak in an Intensive Care Unit. Veterans Health Administration National MRSA Prevention Forum. San Jose, CA, February, 2009.

40. Ezike U, Kapoor R, Gnoni M, Wiemken T, Davidson A, Peyrani $P$, Nakamatsu R, Arnold F. Increased Age is Associated with Better Outcomes in HIV Infected Patients. Poster Presentation: Research Louisville. October, 2008.

41. Kapoor R, Amjadi A, Wiemken T, Davidson A, Peyrani P, Huang A, Ramirez J. Impact of Heavy Alcohol Use on the Clinical Course of HIV Disease. Poster Presentation: Research Louisville. October, 2008.

42. Amjadi A, Umoren I, Wiemken $T$, Davidson A, Peyrani $P$, Allen $M$, Nakamatsu R. Effects of Community Acquired Pneumonia on HIV Progression in the Highly Active Antiretroviral Therapy Era. Poster Presentation: Research Louisville. October, 2008.

43. Umoren I, Ezike U, Wiemken T, Davidson A, Peyrani P, Huang A, Arnold $F$, Allen $M$. Outcomes in Patients Co-infected with Human Immunodeficiency Virus and Hepatitis $\mathrm{C}$ in the HAART Era. Poster Presentation: Research Louisville. October, 2008.

44. Griffin A, Peyrani P, Wiemken T, Arnold F, and the CAPO Investigators. Clinical Outcomes of Elderly Patients Hospitalized with Legionella Pneumonia: Results from the CAPO International Cohort Study. Poster Presentation: Research Louisville. October, 2008.

45. Gnoni M, Vasquez R, Wiemken T, Peyrani $P$, Nakamatsu R, Ramirez J. Mortality in Patients with Ventilator-associated Pneumonia and Severe 
Sepsis is Determined by the Number of Organ Failures. Poster Presentation: Research Louisville. October, 2008.

46. Mirsaeidi M, Peyrani P, Portillo J, Allen M, Arteta F, Porras J, Roig J, Rodríguez E, Rodriguez M, Ramirez J, The CAPO Investigators. Female gender is associated with poor clinical outcomes in hospitalized patients with community-acquired pneumonia: results from the CAPO international cohort study. ERS 2008 Berlin, Germany, October 4-8, 2008. [Session 216, \# 1855]

47. Peyrani P, Rello J, Menendez R, Rossi P, Torres A, Blasi F, Cosentini R, Luna C, Feldman C, Ramirez J, The CAPO Investigators. A worldwide perspective of the level of compliance with guidelines in hospitalized patients with community-acquired pneumonia: results from the CAPO cohort international study. ERS 2008 Berlin, Germany, October 4-8, 2008. [Session 216, \# 1857]

48. Mirsaeidi M, Peyrani P, Aliberti S, Filardo G, Blasi F, Lode H, Luna JM, Parada MT, Ramirez J, The CAPO Investigators. Thrombocytosis predicts poor outcomes in patients with community-acquired pneumonia: results from the CAPO international cohort study. ERS 2008 Berlin, Germany, October 4-8, 2008. [Session 237, \# 2207]

49. Mirsaeidi M, Peyrani P, Diaz Fuenzalida A, Gonzalez J, Marzoratti L, Toala I, Rivero L, Ramirez J, The CAPO Investigators. Penicillin-resistant streptococcus pneumoniae is a rare etiology of community-acquired pneumonia requiring hospitalization: results from the CAPO international cohort study. ERS 2008 Berlin, Germany, October 4-8, 2008. [Session 238, \# 2240]

50. Mirsaeidi M, Portillo J, Anaya E, Peyrani P, Guardiola J, Arnold F, Nakamatsu R, Victorio C, Aiello G, Perez Mirabal M, Ramirez J, The CAPO Investigators. Pleural effusion predicts poor outcomes in hospitalized patients with community-acquired pneumonia: results from the CAPO international cohort study. ERS 2008 Berlin, Germany, October 4-8, 2008. [Session 239, \# 2255]

51. Peyrani P, Mangino J, Zervos M, Kett D, Ford K, Scerpella E, Ramirez J, The IMPACT-HAP Investigators. Performance indicators to evaluate the management of patients with ventilator-associated pneumonia: results from the IMPACT-HAP study group. ERS 2008 Berlin, Germany, October 4-8, 2008. [Session 242, \# 2306]

52. Peyrani $P$, Wiemken $T$, Mirsaeidi $M$, Gnoni $M$, Ramirez $J$, and the IMPACT-HAP Study Group. Variability of Hospital Cost for Patients with 
Ventilator-Associated Pneumonia: Results from the IMPACT-HAP Study. $48^{\text {th }}$ Annual Interscience Conference on Antimicrobial Agents and Chemotherapy (ICAAC) $/ 46^{\text {th }}$ Annual Conference of the Infectious Diseases Society of America (IDSA), Washington, D.C., October 2008.

53. Mirseidi M, Peyrani P, Wiemken T, Gnoni M, Ramirez J, and the IMPACTHAP Study Group. Making the Microbiological Diagnosis in Patients with Healthcare-Associated Pneumonia, Hospital-Acquired Pneumonia, and Ventilator-Associated Pneumonia: Role of Bacteremia. Results from the IMPACT-HAP Study Group. $48^{\text {th }}$ Annual Interscience Conference on Antimicrobial Agents and Chemotherapy (ICAAC) $/ 46^{\text {th }}$ Annual Conference of the Infectious Diseases Society of America (IDSA), Washington, D.C., October 2008.

54. Mirsaeidi M, Peyrani P, Kapoor R, Amjadi A, Ezike U, Umoren I, Allen MB, Ramirez J, and the IMPACT-HAP Study Group. Predicting Mortality in Patients with Ventilator-Associated Pneumonia: The APACHE II score versus the new IBMP-10 score. Results from the IMPACT-HAP Study Group. 48 ${ }^{\text {th }}$ Annual Interscience Conference on Antimicrobial Agents and Chemotherapy (ICAAC) $/ 46^{\text {th }}$ Annual Conference of the Infectious Diseases Society of America (IDSA), Washington, D.C., October 2008.

55. Mirsaidi M, Peyrani P, Aliberti S, Filardo G, Blasi F, Lode $H$, Luna JM, Parada MT, Ramirez $J$ and CAPO Invstigators. Thrombocytosis Predicts Poor Outcomes in Patients with Community-Acquired Pneumonia: Results from the CAPO Cohort Study. 48 ${ }^{\text {th }}$ Annual Interscience Conference on Antimicrobial Agents and Chemotherapy (ICAAC) $/ 46^{\text {th }}$ Annual Conference of the Infectious Diseases Society of America (IDSA), Washington, D.C., October 2008.

56.Zanewicz LK, Wiemken T, King W. Assessment of Current Classroombased IACUC Mandated Animal Training and a Possible Transition to Web-based Training. First Biennial Conference on RCR-EIT, Responsible Conduct of Research Education, Instruction and Training. St. Louis, MO, April 2008.

57. Arnold F, Wiemken T, Peyrani $P$, Nakamatsu R, Lett $P$, Ramirez J. Potential Treatment for Nosocomial Respiratory Strains of Extreme Drug Resistant Acinetobacter baumanii. $6^{\text {th }}$ Annual European Respiratory Society (ERS) Lung Science Conference, Stockholm, Sweeden. September, 2007. Poster \# P2418.

58. Beavers S, Blossom D, Wiemken T, Goss L, Kawaoka K, Wong A, Srinivasan A. Risk Factors for Hospital-Acquired Acinetobacter Infection 
in Two Kentucky Hospitals. $47^{\text {th }}$ Annual Interscience Conference on Antimicrobial Agents and Chemotherapy (ICAAC), September 2007.

59. Wiemken T, Goss L, Arnold F, Ramirez J. The Association of Antibiotics with Nosocomial Acquisition of Multi-Drug Resistant Acinetobacter Infections. Research Louisville, 2006.

60. Goss L, Wiemken T, Arnold F, Ramirez J. Acinetobacter baumannii in an Acute Care Facility: Outbreak or New Norm? Research Louisville, 2006.

61. Tumosa N, Wiemken T. Core Competencies for Geriatric Leadership in the VA. Presented at Veterans Health Administration, Veterans Affairs Educators Integrated Network (VEIN), 2005.

62. Blaskiewicz R, Chrusciel T, Wiemken T. Increased Risk of Small for Gestational Age in Twin vs. Singleton Births and Effect Modification by Preeclampsia. American College of Obstetrics and Gynecology (ACOG) Conference. 2005.

\section{Teaching and Invited Lectures}

1. Analyzing Clinical Data: Confounding. University of Louisville Process of Clinical Research Course, Louisville, KY. November, 2010.

2. Analyzing Clinical Data: Using Microsoft Excel Part 2. University of Louisville Process of Clinical Research Course, Louisville, KY. November, 2010.

3. Analyzing Clinical Data: Using Microsoft Excel Part 1. University of Louisville Process of Clinical Research Course, Louisville, KY. November, 2010.

4. Epi202. Association for Professionals in Infection Control. San Francisco, CA. August 25-26, 2010.

5. Pandemic Viruses. Infusion Nurses Society Annual Meeting and Industrial Exhibition. Ft. Lauderdale, FL. May 16, 2010.

6. Health Promotion and Healthcare-associated Infections. Course \# PHPB721. Surveillance and Statistical Process Control. University of Louisville School of Public Health and Information Sciences. March 2010.

7. Health Decision and Risk Analysis. Course \#PHPB 604. Social Networks and Social Network Analysis. March 2010. 
8. Healthy Lifestyles. Course \# 310 . Sexually Transmitted Diseases. University of Louisville. March 2010.

9. Healthy Lifestyles. Course \# 310. Sexually Transmitted Diseases. University of Louisville. October 2009.

10. Health Decision and Risk Analysis. Course \#PHPB 604. Social Networks and Social Network Analysis. March 2009.

7. Analyzing Clinical Data: Confounding. University of Louisville Process of Clinical Research Course, Louisville, KY. November, 2009.

8. Analyzing Clinical Data: Using Microsoft Excel Part 2. University of Louisville Process of Clinical Research Course, Louisville, KY. November, 2008.

9. Analyzing Clinical Data: Using Microsoft Excel Part 1. University of Louisville Process of Clinical Research Course, Louisville, KY. November, 2008.

10. Basic Statistics. University of Louisville. October 2009.

11. Statistical Process Control. University of Louisville. September, 2009.

12. Basic Statistics. University of Louisville. September, 2009.

13. Analyzing Clinical Data: Study Results. University of Louisville Process of Clinical Research Course, Louisville, KY. November, 2008.

14. Analyzing Clinical Data: Confounding. University of Louisville Process of Clinical Research Course, Louisville, KY. November, 2008.

15. Analyzing Clinical Data: Time-to-event. University of Louisville Process of Clinical Research Course, Louisville, KY. November, 2008.

16. Analyzing Clinical Data: Medical Tests. University of Louisville Process of Clinical Research Course, Louisville, KY. November, 2008.

17. Disease Transmission. Medical Reserve Corps, Louisville, KY. November, 2008.

18. Survival Analysis. University of Louisville, Louisville, KY. September, 2008. 
19. Statistical Process Control in Healthcare. University of Louisville, Louisville, KY. July, 2008.

20. Infection Control Assessment. Kentucky Association for Professionals in Infection Control, Louisville, KY. June, 2008.

21. Disease Transmission. Medical Reserve Corps, Louisville, KY. April, 2008.

22. Biological Safety: A Workforce Needs Assessment. University of Louisville, Louisville, KY. December, 2007.

23. Infection Control in Healthcare Construction. Kentucky Society for Healthcare Engineers (KSHE), Lexington, KY, May 2007.

24. Statistical Process Control with Minitab. University of Louisville Hospital, Louisville, KY. February, 2007.

25. Overview of Control Charts and Statistical Process Control. University of Louisville Hospital, Louisville, KY. January, 2007.

26. Basic Epidemiology and Biostatistics. University of Louisville Hospital, Louisville, KY. September, 2006.

27. Outbreak Investigation. University of Louisville Hospital, Louisville, KY. September, 2006.

28. Risk Factors for STD Infection among Men Who Have Sex with Men in a Saint Louis, MO Area Bathhouse. Saint Louis University, St. Louis, MO. December, 2005.

29. Burke R, Chrusciel T, Krahl K, Wiemken T. Environmental Health. Saint Louis University, St. Louis, MO. October, 2005.

30. Chrusciel T, Wiemken T. Increased Risk of Small for Gestational Age in Twin vs. Singleton Births and Effect Modification by Preeclampsia. Saint Louis University, St. Louis, MO. June, 2005.

31. Flomo D, Hoffsuemer J, Wiemken T. Combating Childhood Type-II Diabetes and Obesity. Saint Louis University, St. Louis, MO. April, 2005.

32. Brown K, Finn D, Graves M, Kothari A, Mackinnon-Patterson B, Wiemken T. Nutrition in Adolescents: An Intervention Using Constructs from the Social Cognitive Theory. Saint Louis University, St. Louis, MO. November, 2004. 
33. Long-Circulating Bacteriophage as Antimicrobial Agents. Southern Illinois University, Carbondale, IL. April 2003.

\section{Statistical Packages}

1. SAS

2. SPSS

3. ESRI ArcGIS

4. MedCalc

5. Epi-Info

6. Minitab

\section{Certifications}

1. Certified in Infection Control and Epidemiology $(\mathrm{CIC})$ - Certification Board on Infection Control and Epidemiology (CBIC) - Expiration December 2012.

\section{Awards and Non-Degree Coursework}

1. First Place Poster:

Espinosa-Ginic M, Forster D, Panchabhai T, Vasquez A, Landes S, Knight J, Cabral P, Wiemken T, Peyrani P, Ramirez J. Obese Hospitalized Patients with CAP are at Lower Risk for Clinical Failure and Death: Results from the CAPO International Cohort Study. Research Louisville 2009.

2. LINKS: Social Network Analysis. Lexington, KY. June 2-5, 2009.

3. SEIPS Short Course on Human Factors Engineering \& Patient Safety. Madison, WI. August 18-22, 2008.

4. American Biological Safety Association Courses, Nashville, TN, October 2007.

a. Virology and Virus Based Gene Vectors

b. Animal Biosafety Level-3

c. Biosafety Level-3 Principles and Practices

d. Risk Assessment

5. First Place Poster:

Goss L, Wiemken T, Arnold F, Carrico R. Acinetobacter baumannii in an Acute Care Facility: Outbreak or New Norm? Research Louisville 2006. 
6. Leadership in Healthcare, Full-scale Disaster Training in the Hospital, Anniston, AL, 2006.

7. National Incident Management System (NIMS) ICS-700, 2005

8. Selected to appear on the Saint Louis University School of Public Health Epidemiology Webpage, 2005-2006.

9. Biography selected to appear in the National Dean's List Publication, 2004.

10. Venipuncture and Phlebotomy, 2003

11. Southern Illinois University College of Science, Department of Microbiology Student Leadership Award, 2003

\section{Professional Organizations}

1. Association for Professionals in Infection Control and Epidemiology (APIC) National Chapter- 2006-Present. Member \#102725

2. Association for Professionals in Infection Control and Epidemiology (APIC) Kentuckiana Chapter - 2006-Present

3. American Association for the Advancement of Science - 2008- Present

4. American Biological Safety Association (ABSA) National Chapter - 2007 2008

5. Midwest Area Biosafety Network (MABioN) - 2007- 2008

6. Council for State and Territorial Epidemiologists - 2005-2007

7. Phi Kappa Phi - 2002-2005

8. American Society for Microbiology - 2001-2003, 2007-2008

9. Phi Theta Kappa -2000-2001 